JENNY JAKOBSSON

THE PROCESS OF RECOVERY

AFTER COLORECTAL CANCER

SURGERY

Patients' experiences and factors of influence

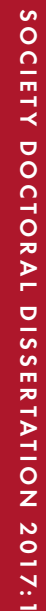



THE PROCESS OF RECOVERY AFTER COLORECTAL CANCER SURGERY 
Malmö University, Faculty of Health and Society Department of Caring Science Doctoral Dissertation 2017:1

(C) Jenny Jakobsson 2017

ISBN 978-9I-7IO4-756-4 (print)

ISBN 978-9I-7IO4-757-I (pdf)

ISSN $1653-5383$

Holmbergs, Malmö 2017 


\section{JENNY JAKOBSSON THE PROCESS OF RECOVERY AFTER COLORECTAL CANCER SURGERY}

Patients' experiences and factors of influence 
This publication is also available at:

http://dspace.mah.se/handle/2043/21587 
Imagine if recovery was as easy as pushing a button! Unfortunately, it's not... 



\section{CONTENTS}

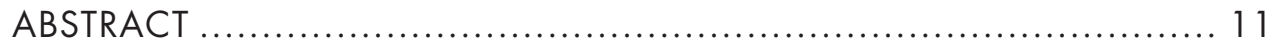

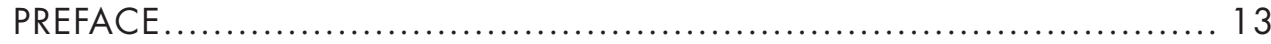

LIST OF PUBLICATIONS ............................................. 14

ABBREVIATIONS .......................................................... 15

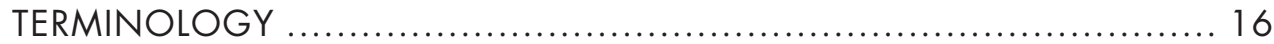

INTRODUCTION ................................................... 17

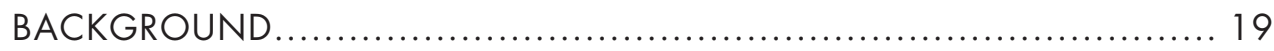

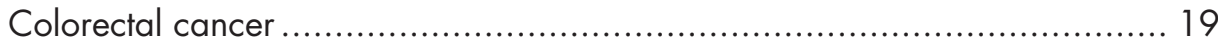

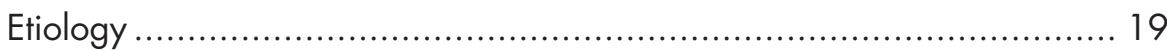

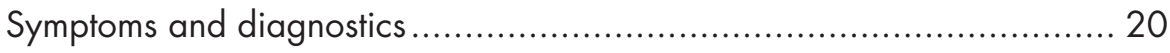

Patients' experiences of the period from diagnosis to surgery ................. 21

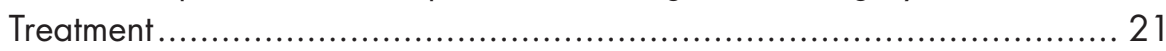

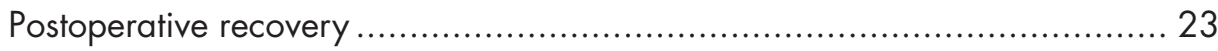

Stress as a consequence of surgery ................................................. 23

Factors with an impact on postoperative recovery ............................... 25

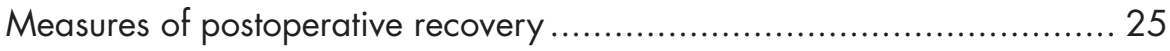

Patients' experiences of postoperative recovery .................................... 27

Implications of person-centred and empowering nursing .......................... 28

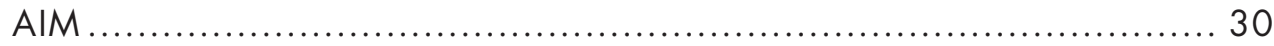

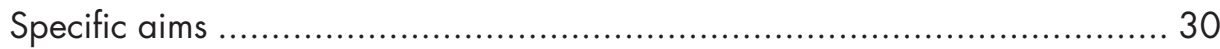

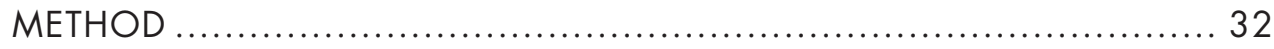

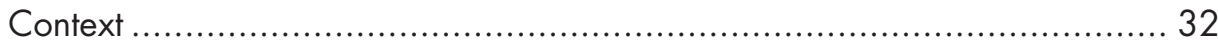

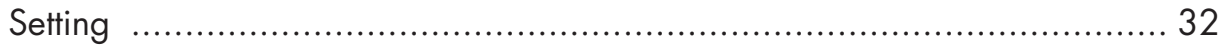




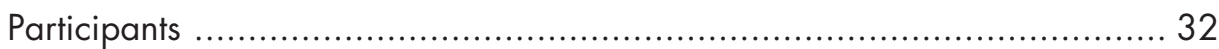

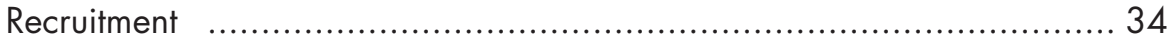

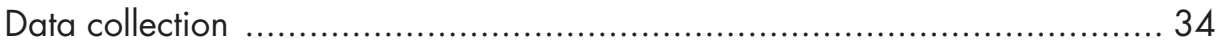

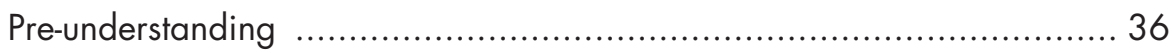

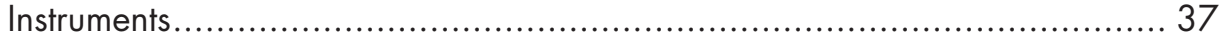

The EuroQol 5-Dimensions 3-levels (EQ-5D-3L) ................................... 37

The State-Trait Anxiety Inventory (STAI) ........................................... 38

The Postoperative Recovery Profile (PRP) ............................................ 38

Patient characteristics and factors related to surgery ................................ 40

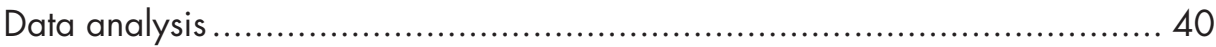

Variables concerning patient characteristics and factors

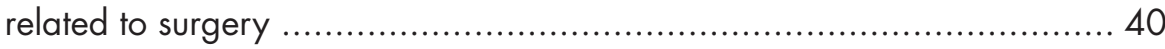

Postoperative recovery and patterns of changes ............................... 41

Calculating and comparing health and anxiety .................................. 42

The lived experience of recovery ................................................. 42

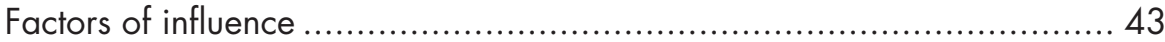

ETHICAL CONSIDERATIONS ............................................ 44

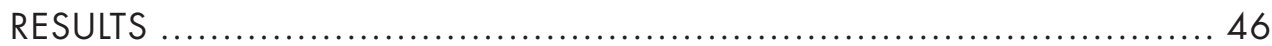

Patient demographics and preoperative levels of health and anxiety ........... 47

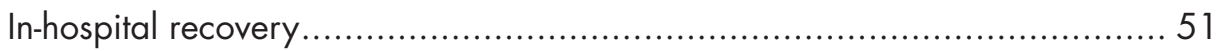

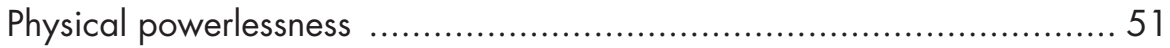

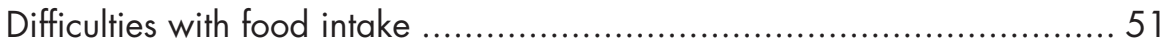

Bowel function ....................................................................... 52

The recovery period between discharge from hospital

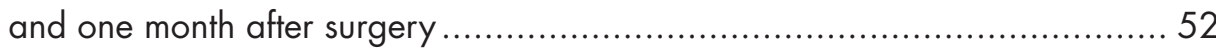

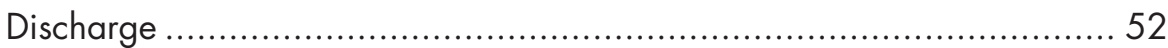

Physical powerlessness, dependence, and social impairments .............. 54

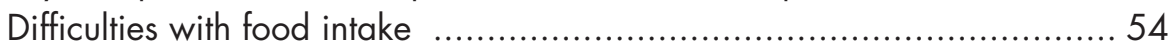

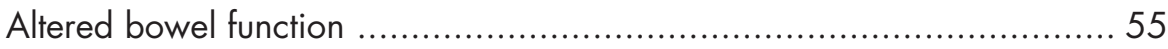

Health and state anxiety one month after surgery............................... 55

Factors associated with recovery one month after surgery ..................... 56

The recovery period between one month and six months after surgery ......... 58

Health and state anxiety six months after surgery .............................. 58

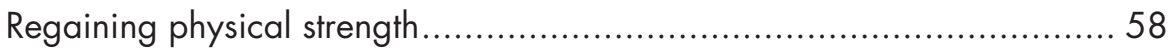

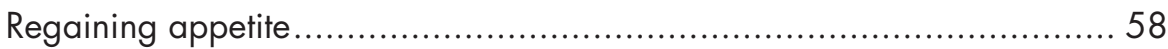

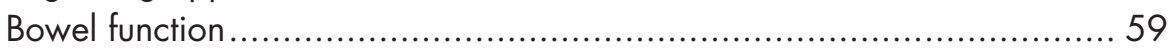

Factors associated with recovery six months after surgery ..................... 59 
METHODOLOGICAL CONSIDERATIONS ................................6 62

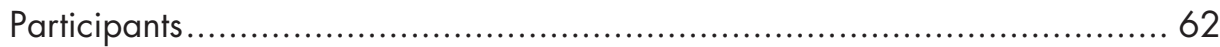

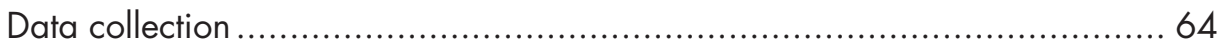

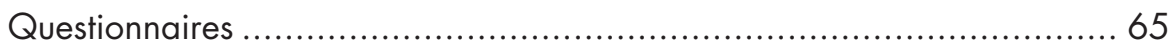

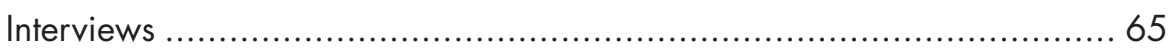

Patient characteristics and factors related to surgery...........................6 66

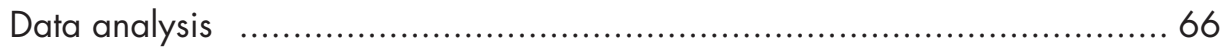

DISCUSSION OF RESULT ............................................... 68

CONCLUSIONS ........................................................... 73

CLINICAL IMPLICATIONS AND FUTURE RESEARCH ..................... 75

POPULÄRVETENSKAPLIG SAMMANFATTNING ......................... 77

ACKNOWLEDGEMENTS ................................................ 82

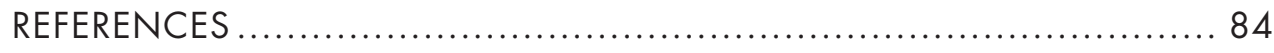

APPENDICES .............................................................. 93

ORIGINAL PAPERS I- IV ................................................ 101 



\section{ABSTRACT}

The aim of this thesis was to describe and compare how patients recovering from different forms of colorectal cancer surgery experience their postoperative recovery, general health, and anxiety, up to six months after surgery. In addition, the aim was to describe the influence of patient- and surgery-related factors on patient-reported recovery.

Data was collected through questionnaires containing instruments measuring general health, trait and state anxiety, and recovery. Recruitment was made consecutively. In total, 176 patients chose to participate and received the questionnaires before surgery, on the day of discharge, and one and six months after surgery. In addition, information concerning patient characteristics and factors related to surgery was retrieved from the patients' medical journals. Data was also collected through in-depth interviews one and six months after surgery with ten purposefully included patients.

Postoperative recovery after colorectal cancer surgery was described as a progressive process. Experiences of physical powerlessness, difficulties with food intake, altered bowel function, and dependence on others, were prominent and changed from being intense in the beginning of the process to gradually disappearing as time went by.

On the day of discharge, no patient was considered fully recovered or almost fully recovered. Thereafter, it could be seen that patients after colonic resection improved regarding the majority of symptoms connected to recovery already during the first month after surgery, while patients after abdominoperineal resection deteriorated somewhat. Patients after rectal resection recovered better during the first month than those after abdominoperineal resection but not as well as patients after 
colonic resection. Health was shown to be generally good preoperatively. One month after surgery, patients recovering from abdominoperineal resection and rectal resection had a temporary reduction in health, while patients after a colonic resection had improved. Six months after surgery, health had improved to better than preoperative values without any differences between groups of patients. Regarding anxiety, both as a trait and as a state, this was shown to be low, without any differences between groups.

Once at home from hospital, the patients experienced a continued difficulty with food intake, and the physical powerlessness made them initially dependent on relatives or friends in order to manage everyday life. The bowel function, as well as the practical management of a possible stoma, caused feelings of insecurity and concern. During the period from one month to six months after surgery, improvements were seen in symptoms connected to recovery for all patients and especially after abdominoperineal resection. However, it was also clear that patients after a rectal resection had not recovered to the same extent as those after an abdominoperineal or colonic resection.

Some factors related to patient characteristics and surgery were shown to be associated with the odds for a good recovery one and six months after surgery. Those factors were age, grade of ASA, EQ VAS, EQ index, BMI, duration of surgery, APR procedure, presence of stoma, LoS, and postoperative treatment. In addition, the dimensional levels of recovery could to a great extent predict recovery in corresponding dimensions.

The result of this thesis showed a diverse pattern of recovery. Nevertheless, there were also some similarities. This illustrates the complexity of postoperative recovery. In order to avoid unnecessary concerns, it is important for health care professionals to provide the patients with appropriate information and support throughout the whole recovery period and to design individual follow-up strategies. 


\section{PREFACE}

To me, surgical nursing is a challenge. As a surgical nurse, you have to have practical skills as well as a comprehensive medical knowledge, and you always have to be a step ahead. Most of all, you have to be able to combine those qualities with an approach that casts the person under care as the main character.

About ten years ago, I became part of a group assembled with the purpose of writing a standardised care plan. At that time, standardised care plans were popular, aiming at ensuring that all patients received the same high-quality care. Our clinic was about to implement a new fast-track strategy of care, later known as Enhanced Recovery After Surgery, ERAS, for patients undergoing colorectal surgery. This was regarded as an opportunity to combine one structured care plan with another one and thus our work began. Not much literature was available and it seemed as if all the relevant literature concentrated on outcomes such as cost savings or a shortened length of stay. A question arose in my mind: how do these patients experience their recovery after surgery? All interventions within the strategy seemed to focus on the period before surgery, during surgery, and during the hospital stay. Consequently, the strategy appeared to "end" when the patients left hospital. Years later, when the chance to apply for a $\mathrm{PhD}$ education turned up, I got the opportunity to search for an answer to my question. 


\section{LIST OF PUBLICATIONS}

The thesis is based on results from the following papers referred to in the text by Roman numbers. The published papers have been reprinted with permission from the publishers.

I. Jakobsson J, Idvall E, Wann-Hansson C. Patient-reported recovery after enhanced colorectal cancer surgery: a longitudinal six-month follow-up study. International Journal of Colorectal Diseases, 2014, 29(8): 989-98. doi: 10.1007/s00384-014-1939-2

II. Jakobsson J, Idvall E, Wann-Hansson C. General health and state anxiety in patients recovering from colorectal cancer surgery. Journal of Advanced Nursing, 2016, 72(2): 328-38. doi: 10.1111/jan.12841

III. Jakobsson J, Idvall E, Wann-Hansson C. The lived experience of recovering during the first six months after colorectal cancer surgery. Resubmitted 160818

IV. Jakobsson J, Idvall E, Kumlien C. Patient characteristics and surgery-related factors associated with patient-reported recovery at one and six months after colorectal surgery. Resubmitted 161018

Contributions to the papers listed above: The first author $(\mathrm{JJ})$ planned the studies, collected and analysed the data, and wrote the paper with support from the co-authors. 


\section{ABBREVIATIONS}

ASA The American Society of Anesthesiologists' physical status classification

APR Abdominoperineal resection

BMI Body Mass Index

CN Contact nurse

CRC Colorectal cancer

CT Computer tomography

ERAS Enhanced Recovery After Surgery

EQ-5D-3L The EuroQol 5-Dimensional 3-Levels

FAP Familial adenomatous polyposis

GSR Global Score of Recovery

HRQoL Health-related quality of life

HNPCC Hereditary non-polyposis colorectal cancer

LoS Length of Stay

MRI Magnetic resonance imaging

OR Odds Ratio

PA Percentage agreement

PCC Person-centred care

PRP The Postoperative Recovery Profile

QoL Quality of life

RN Registred nurse

RP Relative position

RV Relative rank variance

SD Standard deviation

SPSS Statistical Package for the Social Sciences

STAI The State-Trait Anxiety Inventory

TTO Time trade-off valuation technique

WHO World Health Organization 


\section{TERMINOLOGY}

ASA is a grading system used for grading the patients' physical status prior to anaesthesia and surgery. An ASA grade 1 refers to a normal healthy person, grade 2 indicates that the patient has a mild systemic disease, and grade 3 indicates severe systemic diseases. There are 6 grades of ASA, and in grade 6 the patient is declared brain-dead and surgery is performed with the purpose of organ donation (1).

BMI is a commonly used index for classification of underweight, overweight, and obesity in adults. It is calculated by dividing the body weight $(\mathrm{kg})$ by the squared height $\left(\mathrm{m}^{2}\right)$. A normal BMI ranges between 18,5 and 25, according to the World Health Organization, WHO (2).

A contact nurse, $\mathrm{CN}$, is a registred nurse that is working as a contact person for a specific group of patients, in this thesis patients with colorectal diseases. According to the Swedish National Board of Health and Welfare, every patient with breast, prostate, or colorectal cancer, should be assigned a contact nurse (3). 


\section{INTRODUCTION}

A cancer diagnosis can induce emotional reactions, such as shock, disbelief, fear, and uncertainty about the future (4-6). In addition, a diagnosis of colorectal cancer (CRC) is commonly accompanied with unpleasant symptoms, such as changed bowel behaviour, rectal bleeding, abdominal pain, weight loss, and fatigue $(7,8)$. Today, surgery has developed to become highly technological. A prerequisite for advanced technological interventions to be practicable is the coincidental development of other specialities, such as anaesthesia and intensive care, and the cooperation with those specialities in connection to surgery. Another prerequisite is without doubt the improved surgical care before, during, and after surgery. Those improvements, preceded by an accessible, rapid detection of the cancer, have made surgical treatment of CRC successful, and it is now possible to provide surgical treatment also for older patients (9) and patients with high comorbidity (10).

For a registred nurse, $\mathrm{RN}$, caring for patients undergoing or recovering from CRC surgery, there are limited possibilities to influence the decision-making about the cancer treatment. What can be influenced is how the patient will be able to deal with the postoperative situation he or she has to face. Before and during hospitalisation, the $\mathrm{RN}$ plays a prominent role in the multiprofessional team caring for the patient. A patient who is recovering after CRC surgery is most likely experiencing postoperative symptoms, as well as psychological distress, that affect his or her life to a varying degree. Surgical nursing care involves information, education, motivation, and facilitation, in order to empower the patients to manage the different challenges that arise during their recovery. 
Despite the growing number of CRC patients worldwide, the majority of whom undergo surgical treatment, knowledge about the entire postoperative recovery as described by patients themselves is sparse. Since the length of hospital stay after surgery is decreasing, as a result of the improvements within perioperative care, patients have to manage the main part of their postoperative recovery outside of hospital. This poses a challenge for both the $\mathrm{RN}$ and the whole multiprofessional team who need to prepare the patients not only for surgery but also for the postoperative period, when the patients are supposed to manage without direct support from the health care. Consequently, there is a need to gain a comprehensive knowledge of the postoperative recovery period as experienced by the patients.

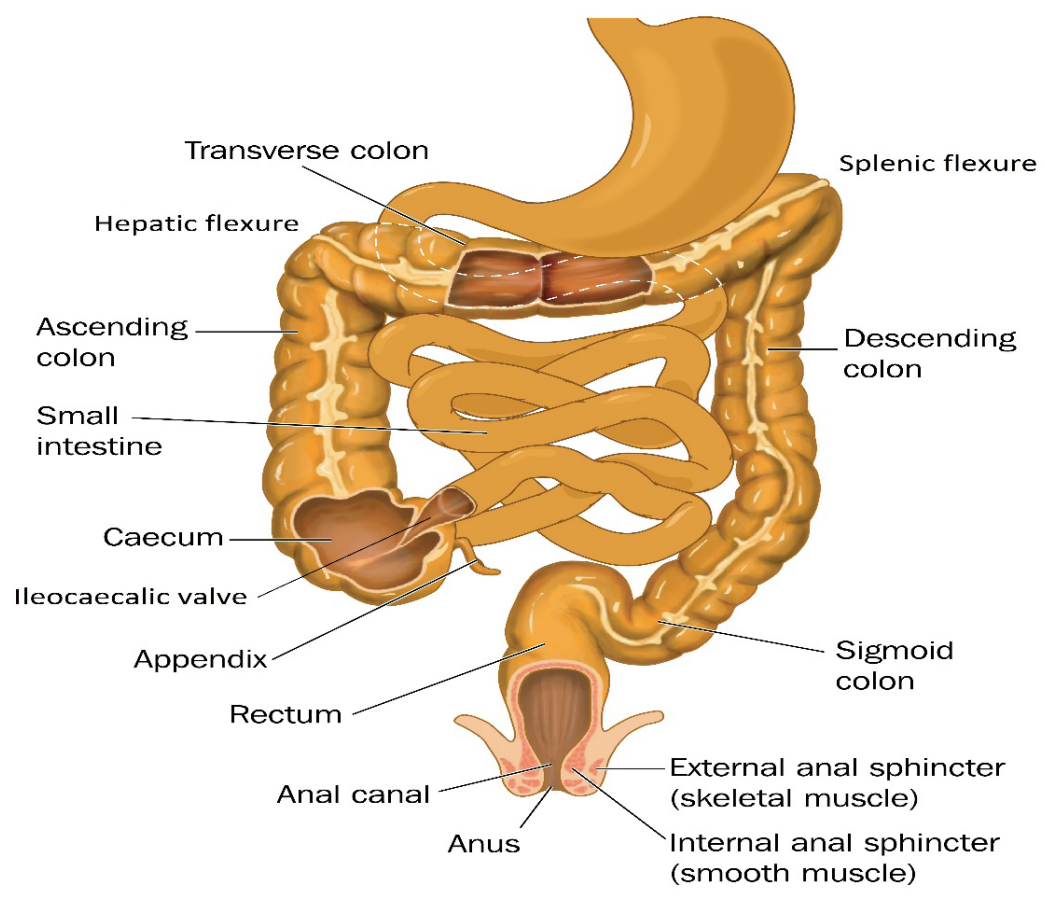

Figure 1. Anatomic structures of the colon and rectum 


\section{BACKGROUND}

\section{Colorectal cancer}

Colorectal cancer is a heterogeneous cancer sited in the colon or rectum. The symptoms differ depending on the location of the tumour. Essentially, different parts of the intestine are surgically removed, which causes diverse changes, both functionally and visually, that affect the patients in various degrees.

Colonic cancer refers to a cancer located in the area from the ileocaecal valve to fifteen centimetres above the anal verge (Figure 1). The right side of the colon includes the appendix, the caecum, the ascending colon, the hepatic flexure, and the first part of the transverse colon. The left side includes the last part of the transverse colon, the splenic flexure, the descending colon, and the sigmoid colon. Colonic cancer is more common than rectal cancer (11), which refers to cancer in the rectum, that is, the remaining fifteen centimetres above the anal verge.

\section{Etiology}

Most cases of CRC develop in an existing adenomatous polyp. The probability for an adenomatous polyp to be malignant increases with the size of the polyp (12). The development of the malignancy is regarded as a slow process (13). Therefore, higher age is a factor that increases the risk of the disease. In Sweden, $29 \%$ of patients with colonic cancer and $23 \%$ of patients with rectal cancer are older than 80 years at diagnosis (11). Further, CRC is slightly more common for men than for women (14).

Worldwide, approximately 1.4 million men and women are diagnosed with CRC every year (15). It is the third most common cancer after lung and breast cancer, and the fourth most common cause of cancer mortality in the world. However, if detected at an early stage, it is also one of the most curable malignancies (12). 
In Sweden, just over 6,000 persons are diagnosed with the disease annually (16), which makes it the third most common cancer after prostate and breast cancer (14). The Swedish incidence has been relatively stable during the period from 2010 to 2014, and the five-year relative survival is now reported to be $64 \%$ for men and $67 \%$ for women $(11,16)$. This means that the number of persons living with or living after a diagnosis of CRC is increasing.

Colorectal cancer has been mentioned as a multifactorial disease, since no specific cause is described (17). It has been suggested that about 2-4\% of all CRC affects persons with one of the two hereditary diseases familial adenomatous polyposis (FAP) and Lynch syndrome (earlier referred to as hereditary nonpolyposis colorectal cancer, HNPCC) (11). In addition, there is a strong association to inflammatory bowel diseases as well as to a history of adenomatous polyps (12). The incidence of sporadic, that is, non-hereditary, CRC has been shown to vary considerably worldwide (18). Industrialised countries, such as Australia, New Zealand, and countries in northern Europe and Northern America, have the highest incidence. Almost 55\% of all cases occur in those regions (15). However, the incidence in countries that are economically developing is increasing (18). The greatest increases are observed in Western Asia and Eastern Europe. The most likely explanation for this is that, parallel to the economic development, those countries are about to adopt the "Western" lifestyle. This lifestyle includes inactivity, a diet with a high consumption of fat and of red and processed meat, a low intake of vegetables and fibres, as well as an excess intake of alcohol (18-21). In addition, smoking has been shown to be associated with CRC and a reduced survival in patients with non-metastatic CRC (22).

\section{Symptoms and diagnostics}

Symptoms are related to the location of the tumour. If the tumour is located within the right side of the colon, symptoms do not manifest until the tumour has grown large in size $(7,8)$. This depends on to the fact that the right colon has a large diameter and the intestinal content is fluid and can pass the tumour. Therefore, the tumour does not cause obstruction as a primary symptom. More frequently, the patient suffers from subtle symptoms, such as anaemia with fatigue and weakness, abdominal pain, or a palpable lump in the right side of the abdomen. Left-sided tumours cause symptoms at an earlier stage because of the smaller diameter of the left side of the colon, together with a more solid intestinal content. Symptoms such as changed bowel habits, often with constipation, rectal bleeding, mucus in the stool, or obstruction, are typical. Rectal bleeding is the most significant 
symptom of rectal cancer together with changes in bowel habits and a sensation of incomplete bowel emptying $(7,8)$.

A well-founded suspicion of CRC should induce a diagnostic procedure (23) including a thorough anamnesis and physical examination, a colonoscopy with biopsy of the tumour, or, for rectal cancers, a proctoscopy with local evaluation of the tumour. Further, a computer tomography (CT) or magnetic resonance imaging (MRI) should be performed in order to collect sufficient information about the extent of the tumour. The most appropriate treatment is decided in a multidisciplinary conference (ibid.).

\section{Patients' experiences of the period from diagnosis to surgery}

A cancer diagnosis may give rise to fear, but it has also been described as an event that removes the frustrating and worrying uncertainty of a suspected cancer. At the same time, concerns about survival arise $(4,6)$. The time between diagnosis and surgery has been described as filled with anxiety (4). The symptoms and the medical procedures cause a disruption of the self and the body (24) and the body is experienced as "handed over" to health care professionals $(4,24)$. Trust appears to be an important issue when there is an absence of control of one's own body and future - trust in the body's capacity to overcome surgery and trust in the competence of the health care professionals. Studies have indicated that a trustful relationship is established when the health care professionals listen to the patients, treat them as unique individuals, and respond to questions and thoughts in a reliable manner $(4,6,25)$.

\section{Treatment}

Surgery is the first choice of treatment $(7,11)$. The type of surgery depends on the location of the tumour, as visualised in Table 1 . The part of the bowel affected by the tumour is removed together with its mesentery and lymphatic drainage. For rectal cancers, surgery can be preceded by neoadjuvant radiation therapy in order to shrink the tumour before surgery and thereby lower the risk of local recurrence (11). To prevent postoperative leakage from a distal, rectal anastomosis, a temporary stoma, loop ileostomy, is created during surgery (8). This type of stoma can be reversed after three to four months. A permanent stoma, colostomy, is created if no distal segment of the bowel is left after surgery. Patients undergoing abdominoperineal resection (APR) always receive a colostomy. 
Table 1. Type of surgical intervention with regard to location of tumour (12), and the division into colonic resection, rectal resection, and APR in the thesis

\begin{tabular}{|c|c|c|}
\hline Location of tumour & Type of surgical intervention & In thesis \\
\hline $\begin{array}{l}\text { Caecum } \\
\text { Ascending colon } \\
\text { Hepatic flexure } \\
\text { Right part of transverse colon }\end{array}$ & $\begin{array}{l}\text { Right hemicolectomy } \\
\text { (including } 5-10 \mathrm{~cm} \text { of distal ileum, } \\
\text { ascending colon, hepatic flexure, } \\
\text { and right part of transverse colon) }\end{array}$ & $\curvearrowright$ \\
\hline $\begin{array}{l}\text { Left part of transverse colon } \\
\text { Splenic flexure } \\
\text { Descending colon }\end{array}$ & $\begin{array}{l}\text { Left hemicolectomy } \\
\text { (including splenic flexure and } \\
\text { descending colon) }\end{array}$ & 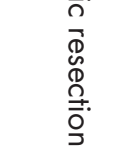 \\
\hline Sigmoid colon & Sigmoid resection & \\
\hline Rectosigmoid orifice & High anterior resection & \\
\hline $\begin{array}{l}\text { Upper third of rectum } \\
\text { (12-16 cm above the anal verge) }\end{array}$ & High anterior resection & 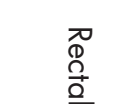 \\
\hline $\begin{array}{l}\text { Middle third of rectum } \\
\text { (8-12 cm above the anal verge) }\end{array}$ & $\begin{array}{l}\text { Low anterior resection (LAR) or a } \\
\text { total mesorectal resection (TME) } \\
\text { together with a temporary loop } \\
\text { ileostomy }\end{array}$ & 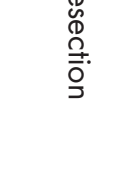 \\
\hline $\begin{array}{l}\text { Lower third of rectum }(8 \mathrm{~cm} \text { down } \\
\text { to anal verge) }\end{array}$ & $\begin{array}{l}\text { Abdominoperineal resection } \\
\text { (APR) together with a permanent } \\
\text { colostomy }\end{array}$ & 叒 \\
\hline
\end{tabular}




\section{Postoperative recovery}

Neville et al. (26) suggest that the postoperative recovery begins at the time of surgery and is completed when the patient has returned to his or her baseline function or to population norms. Korttila (27) divides the recovery into three phases. Early recovery refers to the awakening from anaesthesia. This phase is completed when the patient has regained vital reflexes. The intermediate phase of recovery then takes over and ends when the patient reaches home readiness and gets discharged from hospital. Late recovery refers to the period after discharge and to the point when the patient has returned to normal functioning and resumed normal, daily activities. In both definitions, recovery ends when the patient has reached some sort of normal, baseline status. However, this state seems to be defined only in terms of functionality. After a concept analysis, Allvin et al. (28) define postoperative recovery as:

an energy-requiring process of returning to normality and wholeness as defined by comparative standards, achieved by regaining control over physical, psychological, social and habitual functions, which results in returning to preoperative levels of independence/dependence in activities of daily living and an optimum level of psychological well-being. (p. 557)

For this thesis, the definition proposed by Allvin et al. (ibid.) is adopted, since this definition incorporates a holistic approach to postoperative recovery.

\section{Stress as a consequence of surgery}

After a trauma to the body, irrespective of whether it is caused by an acute injury or an elective surgical procedure, stress hormones and cytokines are released (29). Those reactions cause a loss of the normal anabolic actions of insulin, and the subsequent state of catabolism causes a breakdown of muscle tissue. The stress and the inflammatory response have several other negative consequences. Tachycardia, hypoxia, hypothermia, hyperglycaemia, impaired homeostasis, ileus, and altered fibrinolysis, are, among others, consequences with a negative impact on recovery (29-31).

\section{Strategies to reduce stress and enhance recovery}

In the beginning of the $21^{\text {st }}$ century, an evidence-based, multimodal strategy of perioperative care, Enhanced Recovery After Surgery, ERAS, was formulated (32). Factors with a negative impact on recovery had been identified and, thereafter, a 
set of interventions was gathered with the aim of reducing the physiologic stress and supporting the return to normal functioning (32). The main preoperative interventions are prehabilitation, patient education, optimisation of organ dysfunction, carbohydrate load, and avoidance of laxatives $(33,34)$. Intraoperative interventions are, for example, minimally invasive surgery, regional anaesthesia, short-acting opioids, glycaemic control, and avoidance of fluid overload. After surgery, it is recommended that the patient should avoid opioids, be allowed an early intake of food, and be encouraged to early and intense mobilisation. In addition, the use of tubes, drains, and catheters should be reflected on (ibid.).

The ERAS strategy has been successfully implemented in hospitals all over the world, not only reducing the response to surgical stress (35) but also length of stay, LoS, and complication rates (36-38). A two-day LoS was reported to be feasible after colonic resection, according to ERAS, already in the late 1990s (39, 40). Later studies have reported a reduction in LoS of 2.5 days in patients cared for according to ERAS (36). This can be put in comparison to a LoS of 7-10 days in patients not cared for according to ERAS (33).

\section{Anxiety}

Besides the physical burden of surgery, there is an emotional burden related to the cancer diagnosis, surgery, and unpleasant symptoms. It has been suggested that psychological stress depresses the immune system and increases vulnerability to diseases, and, as a consequence, the risk of complications after surgery (41).

In several studies, anxiety and psychological stress in connection to surgery have been shown to have a negative impact on postoperative outcomes, such as wound healing $(42,43)$, infection-related complications, and rehospitalisation $(44,45)$. Also, it is reported that depression has a negative impact on wound healing (46) and the personality trait extroversion has been shown to predict an increase in LoS in patients after CRC surgery (47).

Preoperative anxiety is a natural emotion. Fear of surgery itself, fear of complications after surgery, and fear of pain and physical disability, have been described as reasons for anxiety in connection to surgery (48). Persons with a high trait anxiety tend to respond to stressful situations with a more intense elevation of stress (49). Studies have also described how patients experience the encounter with RNs as valuable, not least because RNs can provide information, and preoperative information appears to reduce the fear prior to surgery $(4,25,50)$. Within the 
ERAS concept, preoperative patient information is an essential element (30). The information given to patients before surgery, mainly from the $\mathrm{CN}$ but also from surgeons and physiotherapists, prepares them for what is to happen during hospitalisation. For patients with an elevated level of trait or state anxiety, it would be beneficial if health care professionals acknowledged the anxiety at an early stage. Then the patients would have the chance to cope with their emotions in order to prevent the negative impact on recovery. However, the impact of anxiety as a personality trait on postoperative recovery after CRC surgery has not been sufficiently investigated. In addition, there is a lack of knowledge regarding whether patients' emotions of anxiety differ due to type of surgical intervention or whether they change during the postoperative period after colorectal cancer surgery.

\section{Factors with an impact on postoperative recovery}

Owing to studies conducted with the intention to evaluate the effectiveness of ERAS, knowledge has been gathered about the impact of different factors on recovery. It has been shown that a higher age (above 75 years) can predict a prolonged LoS (51, 52), 30-day morbidity, and 30-day mortality (51). In addition, a high comorbidity, as measured by the American Society of Anesthesiologists' (ASA) physical status classification system, can predict a prolonged LoS (51-53) and 30-day morbidity $(51,52)$. Also, male gender, rectal surgery, and the presence of an ileostomy, are factors with a negative impact on LoS and 30-day morbidity $(51,52)$. Preoperative radiation therapy has been reported to result in a fourfold risk of readmissions within 30 days after surgery (54). Besides those factors described above, it is known that smoking, alcohol consumption, overweight, and physical inactivity, increase the risk for postoperative complications, such as impaired wound healing, anastomotic leakage, deep wound infection, and thrombosis (55-58).

\section{Measures of postoperative recovery}

Factors measuring LoS, morbidity, or readmissions, are important outcome measures, as they are indicators of the effectiveness and safety of the care. However, since the patients are the subjects of care, it is important to include patient-reported outcomes as a measure. Despite this, there are no studies, besides those performed for developing instruments (59), using patient-reported recovery as an outcome measure after CRC surgery. More commonly, quality of life (QoL) or health-related quality of life (HRQoL) have been used as outcome measures of surgery (60). 


\section{Quality of life as an outcome measure}

Quality of life has been referred to as a multidimensional measure of physical, functional, emotional, and social well-being (61). The HRQoL is an aspect of QoL that is directly related to a person's health (62).

Smith-Gagen et al. (63) investigated whether postoperative HRQoL differed in patients after rectal surgery due to CRC. It was shown that male patients had significantly lower social well-being scores than female patients. Furthermore, patients who received adjuvant treatment had lower physical and emotional well-being scores than patients who did not receive adjuvant treatment. Younger patients ( $<65$ years) showed lower scores in physical and emotional well-being than older patients ( $<65$ years). Brown et al. (64) investigated the impact of 30-day complications on QoL and HRQoL. Mean scores of QoL in patients with complications were consistently lower over time compared to patients with no complication. In addition, patients with a complication were between two and almost four times more likely to experience at least some long-term ( $>18$ months) problem with mobility, self-care, pain, or discomfort.

Some studies have focused on changes in QoL over time. One study by Tsunoda et al. (65) found that preoperative values of global QoL, emotional function, social function, insomnia, appetite loss, diarrhoea, and financial difficulties, had improved significantly within one to four months after surgery. Moreover, scores regarding physical function, role function, fatigue, pain, and dyspnoea, deteriorated one month after surgery in comparison to before surgery. The scores returned to preoperative values within two or three months following surgery. The result from this study illustrates the impact colorectal cancer has on the affected person and the impact of surgery on health.

Conceptually, QoL and HRQoL are not the same as postoperative recovery, even though they are important aspects in the care of patients after CRC surgery. If QoL, or HRQoL, is used as a measure of postoperative recovery, this might induce a risk of not reflecting the postoperative recovery accurately, since postoperative recovery also includes factors such as different postoperative symptoms. On the other hand, health, defined as the relation between subjective health-related wellbeing and the ability to live an ordinary life (66), will most likely be impaired to a varying extent during the recovery after surgery, as the study by Tsonuda et al. (65) shows. An impairment in health causes an impairment in the HRQoL (66). If patients recovering from CRC can be empowered to cope and be in control of 
possible postoperative symptoms that restrict their ability to live an ordinary life, this might also have a positive effect on the HRQoL during recovery.

\section{Patients' experiences of postoperative recovery}

Patients in a study by Norlyk and Harder (67) described their recovery up to two months after CRC surgery as a transition process in which they changed their focus from only caring about overcoming surgery to being on a course of recovery. During recovery, they were healing their lifeworld that had been torn apart as a result of the diagnosis. Recovery from surgery itself was, for those patients, just one dimension of this process.

In a grounded theory study, Beech et al. (24) described recovery in patients after CRC surgery as divided into three phases. The first phase, starting before diagnosis with the first sign of symptoms and ending at discharge, was described as a disruption of the self. Symptoms, medical procedures, and hospital routines undermined the sense of autonomy and confidence. The loss of control of the situation and of the body has also been described in several other studies (67-70).

In phase two, that, as described by Beech et al. (24), lasted from discharge until three to six months after surgery, patients began to repair the self. During this period, the attention towards the body was increased, concerning how the body was functioning as well as the frequency and intensity of bodily sensations. In other studies, body functioning and bodily sensations, such as nausea, fatigue, dyspnoea, and a dysfunctional bowel motility, have been described in connection to postoperative recovery after CRC surgery (70-72). Furthermore, discharge has been recognised as a major milestone in recovery $(68,69)$. However, even if patients are eager to recover independence with regard to physical activities as quickly as possible in order to regain autonomy (24), dealing with postoperative symptoms at home can cause insecurity and worry $(67,71,72)$. A lack of knowledge of what is considered "normal" during recovery may cause ambivalence with regard to the decision to seek professional advice or not $(24,69,73)$. In care settings where the strategy of ERAS is adopted, patients are hospitalised only for a few days. However, it has been described how it can be difficult to make sense of information provided by doctors and RNs, among others, during the first days after surgery, due to drowsiness and difficulties in concentration $(24,68,70)$. It has also been described how it can be a trouble getting in contact with health care professionals after discharge $(72,74)$, which leaves the patients in a vulnerable position (74). A need to know what to expect during recovery has been expressed. 
This is particularly important for those patients who do not receive a stoma, since they usually do not become scheduled for a nursing follow-up (73).

In the last and third phase described by Beech et al. (24), that is, restoring the self, recovery could be seen from two perspectives, where the patient focused either on a sense of wellness or on a sense of illness. Having a sense of wellness did not always mean to have a complete restoration of one's physical health, but patients felt confidence in the body and enjoyed different aspects of life. On the other hand, patients who focused on the disease, and on the burden of their disease, adopted a sense of illness. This could be a response to persistent symptoms, for example, altered bowel habits. Patients tried to restore control of their bowel activity by adjusting their dietary intake. Nevertheless, the bowel activity caused emotional distress and embarrassment, leading to a withdrawal from social activities.

The studies performed by Beech et al. (24) and by Norlyk and Harder (67) describe the perceived life situation during recovery, which is an important aspect in understanding the patients. However, the studies do not provide actual facts about postoperative symptoms that can be adopted in a clinical setting when preparing the patients for what they can expect during recovery. The other studies mentioned above $(68-71,73,74)$ describe those symptoms, but there is still a lack of knowledge about how recovery, including postoperative symptoms, proceeds over time. In order to prepare the patients for the recovery period and thereby facilitate their restoration of control of their situation and their body, there is a need to gain knowledge of the natural features of recovery, as well as of the change in recovery over time.

\section{Implications of person-centred and empowering nursing}

Care strategies such as ERAS are intended to ensure that all patients receive evidence-based, high-quality care. According to ERAS, the patients are assigned a clear role in their own recovery. This means that they, before surgery, are given specific tasks to perform in hospital after surgery, including daily targets for food intake and mobilisation, and also a predefined day of discharge. However, all patients are unique and therefore it cannot be assumed that all patients with the same disease, and undergoing the same sort of surgical intervention, can be cared for in the same way. Instead, as far as possible, the care should be individualised and person-centred. In a person-centred care, PCC, it is important to acknowledge the persons behind the patients, their life-world, their experience of illness, and the consequences of symptoms and treatment $(75,76)$. In nursing practice, PCC 
includes communicating and listening, teaching and learning, respecting values, and responding to patient needs $(76,77)$. Patients should be involved from the beginning in defining their needs, goals, and priorities $(76,78)$. This is also a prerequisite in order to engage the patient as an active partner in his or her care $(75,78)$. However, combining structured care strategies with PCC is challenging, since the structure makes individuality difficult. Nevertheless, if patients are given a possibility to influence their own care, this can empower them, so that they become able to reach the goals for, by way of example, food intake, mobilisation, or managing everyday life, thereby enhancing their recovery.

Empowerment has been described as both a goal and a method (79). Empowerment as a goal refers to the individual's ability to control life. The "ability to control" has to do with deciding and acting, and having the opportunity to influence processes and situations $(79,80)$. "Life" refers to one's health, home, work, close relationships, leisure time, and values. An increase in control is an increase in empowerment. Knowledge, consciousness raising, and skills development all contribute to a possibility of control (79). In the definition of postoperative recovery by Allvin et al. (28), the return to normality and wholeness is achieved by "regaining control over physical, psychological, social and habitual functions". Empowerment can be a method to help the patients to regain control in life, which could be seen as an important goal not only for patients in hospital but also after discharge.

Empowerment in the sense of a method is a process in which patients are given opportunities to influence and control decisions concerning their own lives (81, 82). This requires a collaborative relationship between the multiprofessional team and the patients, where the team help the patients to be actively involved in their care by providing them with information, support, and opportunities to learn, as well as facilitating collaboration with health providers and family (82).

As the length of hospital stay for patients undergoing CRC surgery is decreasing, as a result of minimal invasive surgical techniques and enhanced recovery strategies, the patients become more responsible for their own recovery. In such situations, empowerment plays a prominent role. If empowered, the patients are more likely to be in control of their situation while recovering from surgery. 


\section{AIM}

The overall aim of this thesis was to describe and compare how patients recovering from different forms of colorectal cancer surgery experience their postoperative recovery, general health, and anxiety, up to six months after surgery. In addition, the aim was to describe the influence of patient- and surgery-related factors on patient-reported recovery.

\section{Specific aims}

To describe patient-reported recovery after colorectal cancer surgery in the context of ERAS from the day of discharge until one and six months after surgery (I).

To describe and compare general health and state of anxiety before surgery and up to six months after surgery in patients with colorectal cancer undergoing elective rectal resection, abdominoperineal resection, or colonic resection, in an enhanced recovery context (II).

To describe the lived experience of recovery during the first six months after colorectal cancer surgery (III).

To describe patient characteristics and surgery-related factors associated with patient-reported recovery at one and six months after colorectal cancer surgery (IV). 


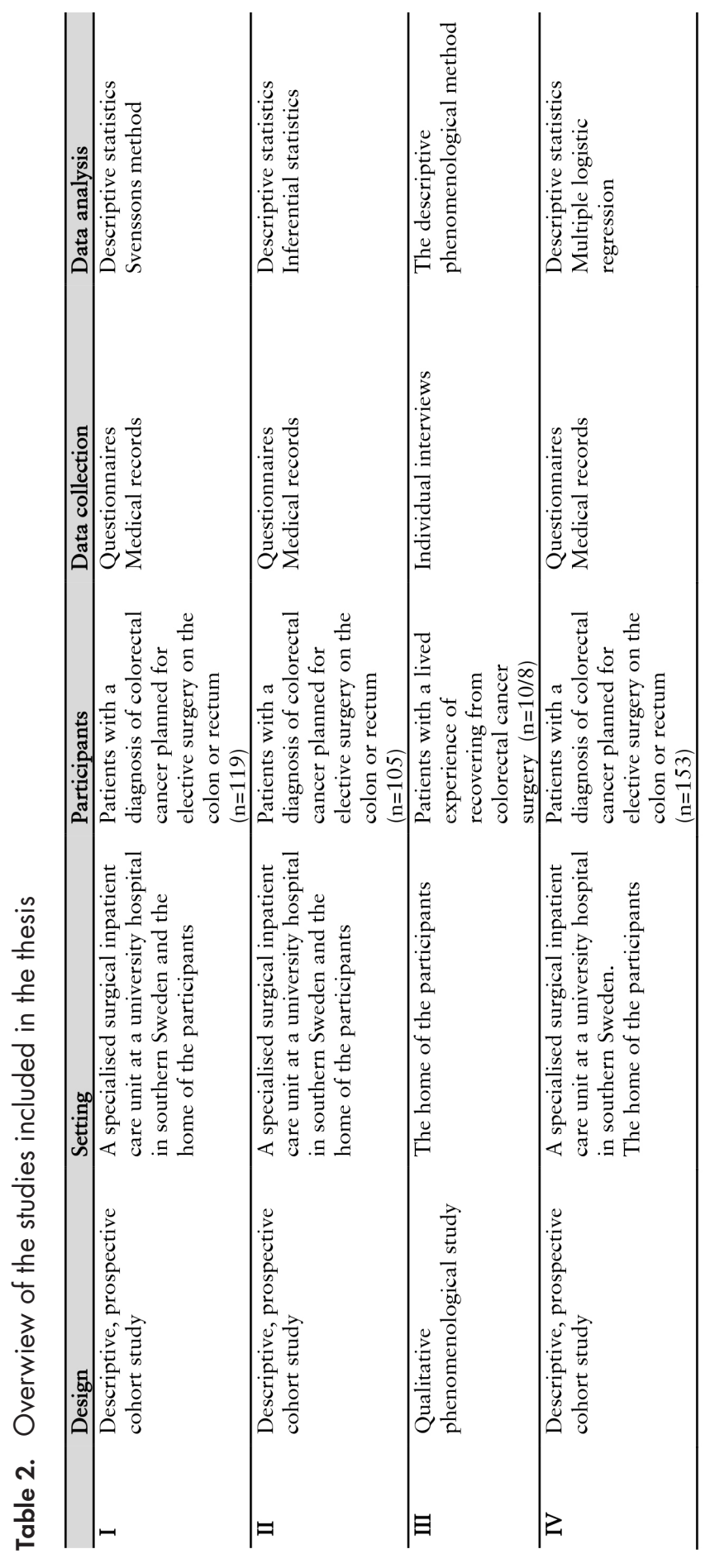




\section{METHOD}

This thesis was designed to describe postoperative recovery after CRC surgery as experienced by patients. Since previous research has defined recovery as a process (28), all four studies comprised in the thesis had a longitudinal follow-up design. The studies were conducted using both a quantitative (I, II, and IV) and a qualitative (III) approach in order to capture different aspects of recovery. An overview of the studies is presented in Table 2.

\section{Context}

The studies were conducted at a university hospital in southern Sweden. The hospital serves about 1.7 million inhabitants and performs highly specialised emergency and elective care. Within some areas, it also provides national specialised medical care.

\section{Setting}

Data was collected from patients receiving care at a surgical unit specialised in colorectal surgery. Annually, nearly 300 patients with cancer in the colon or rectum undergo surgery at the unit. The patients are cared for according to a locally developed perioperative strategy in which the intention is to follow the ERAS guidelines.

\section{Participants}

Patients were considered for inclusion if they had been diagnosed with a tumour in the colon or rectum. Consequently, eligible patients were about to undergo elective CRC surgery with an intention to follow the ERAS concept (I, II, and IV) or had the experience of recovering from elective CRC surgery (III). Further criteria for inclusion were the ability to understand and complete questionnaires in Swedish (I, II, and IV) or the expected ability to take part in an interview describing the experience verbally (III). 
Figure 2. Data collection process regarding study I, II, and IV

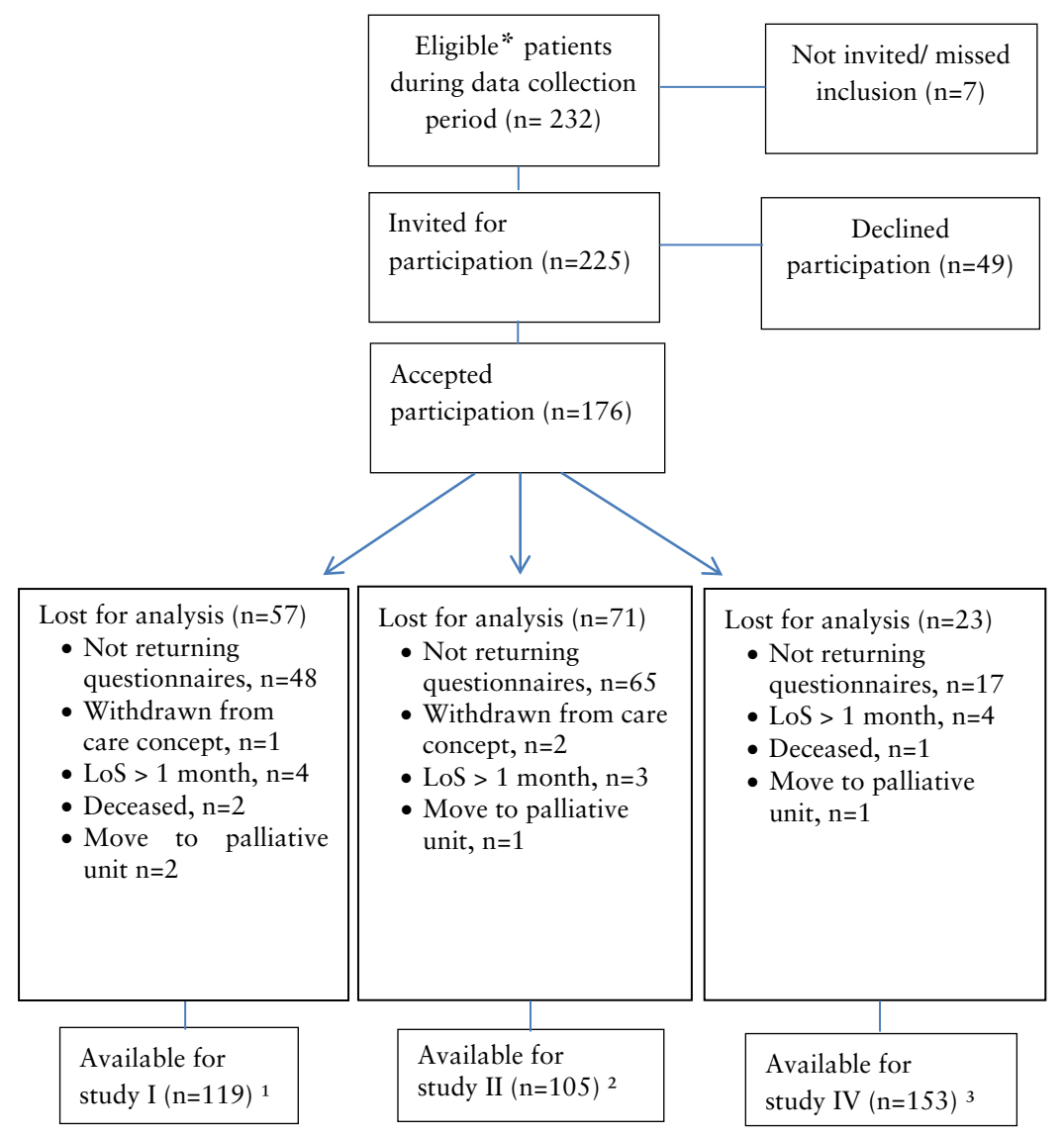

* Meeting the inclusion criteria

${ }^{1}$ Answering the PRP questionnaire in all three assessments

${ }^{2}$ Answering the EQ-5D-3L and STAI questionnaires in all four assessments

${ }^{3}$ Answering the EQ-5D-3L and STAI preoperatively 


\section{Recruitment}

Quantitative data (I, II, and IV) was retrieved from a mutual data collection. Patients were consecutively recruited by the contact nurses $(\mathrm{CN})$ at the surgical outpatient clinic. Written information was first distributed by mail to patients scheduled for surgery, together with the notice of appointment for the preoperative informational visit. This informational visit took place at the surgical outpatient clinic about one week prior to surgery. At the visit, patients met one of the CNs, in order to receive information about the upcoming surgery. During recruitment, the $\mathrm{CN}$ gave oral information about the study and collected written informed consent from patients who chose to participate.

Regarding qualitative data (III), a purposeful sampling strategy was used, since the methodology required participants having the lived experience of recovering from CRC surgery (83). Patients were recruited during their hospital stay after surgery and were then provided with oral and written information. If participation was accepted, the patients agreed to be contacted at home after discharge in order to decide on a time and place for the first interview.

\section{Data collection}

All quantitative data was collected from October 2011 to September 2013. A flowchart of the data collection is presented in Figure 2. During the data collection period, 232 patients were available for inclusion (I, II, and IV). A questionnaire containing instruments measuring general health, state and trait anxiety, and postoperative recovery, was used, as visualised in Figure 3.

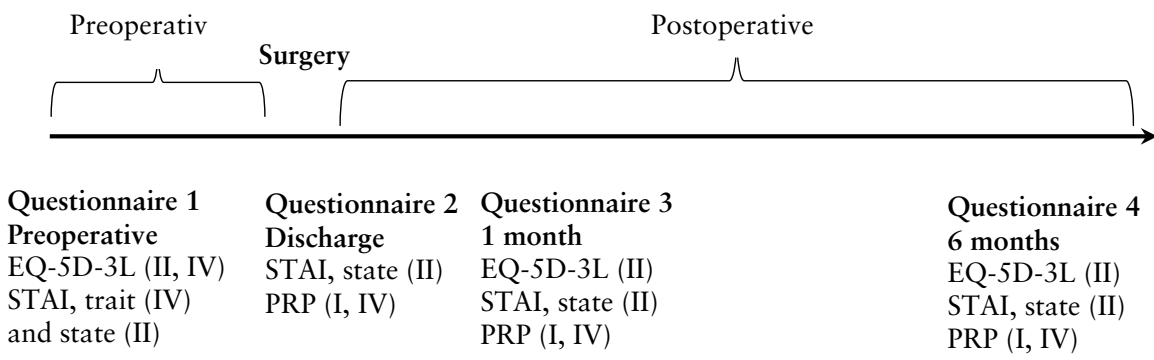

Figure 3. Overview of data collection regarding distribution of the instruments (I, II, IV) 
Patients who chose to participate $(n=176)$ received the first questionnaire from the $\mathrm{CN}$ at the preoperative informational visit. This way, preoperative values of general health and of state and trait anxiety could be collected. After surgery, on the day of discharge, a ward $\mathrm{RN}$ gave the participating patients the second questionnaire including the instruments measuring state anxiety and postoperative recovery. The questionnaire was to be completed and returned to the ward $\mathrm{RN}$ before leaving hospital. At one and six months after surgery, patients received a third and fourth questionnaire including the instruments measuring general health, state anxiety, and postoperative recovery. The questionnaires were distributed by mail together with a prepaid envelope for return. Non-responders received two reminders. If a patient did not return the questionnaire, despite the two reminders, this was interpreted as a withdrawal.

In order to describe the lived experience of recovering from CRC surgery (III), data was collected through in-depth, face-to-face interviews one and six months after surgery. The number of participants included in the study was kept low, in accordance with the used methodology that recommends a number of approximately three participants (83). However, considering potential differences in experiences between the three types of surgical interventions, a higher number of participants was chosen. The distribution of different types of surgical interventions was even among the participants, as visualised in Table 3.

Table 3. Patient demographics regarding each of the four studies

\begin{tabular}{lcccc}
\hline & $\begin{array}{r}\text { Study I } \\
(\mathbf{n}=119)\end{array}$ & $\begin{array}{c}\text { Study II } \\
(\mathbf{n}=105)\end{array}$ & $\begin{array}{c}\text { Study III } \\
(\mathbf{n}=10)\end{array}$ & $\begin{array}{c}\text { Study IV } \\
(\mathbf{n}=153)\end{array}$ \\
\hline Age, mean (SD) & $68,3(11,0)$ & $68,5(10,8)$ & $70,5(5,8)$ & $69,0(10,8)$ \\
\hline $\begin{array}{l}\text { Gender, n (\%) } \\
\text { Men }\end{array}$ & $56(47,1)$ & $52(50,5)$ & $3(30,0)$ & $78(51,0)$ \\
Women & $63(52,9)$ & $53(50,1)$ & $7(70,0)$ & $75(49,0)$ \\
& & & & \\
\hline Surgical intervention, $n(\%)$ & $27(22,7)$ & $19(18,1)$ & $3(30,0)$ & $31(20,3)$ \\
APR & $44(37,0)$ & $40(38,1)$ & $3(30,0)$ & $60(39,2)$ \\
Rectal resection & $48(40,3)$ & $46(43,8)$ & $4(40,0)$ & $62(40,5)$ \\
Colonic resection & & & & \\
& & & &
\end{tabular}

$\mathrm{n}=$ number, $\mathrm{SD}=\mathrm{Standard}$ deviation 
Patients who accepted participation $(n=13)$ when they were asked during the hospital stay, were contacted by telephone about three weeks after surgery. During this conversation, the agreement to participate was confirmed. The aim of the interview, that is, the research question, was repeated in order to give the participants a chance to reflect on their experience before the interview. This procedure can result in a richer description of the experience (84). Lastly, the patients chose a time and location for the first interview. Three patients, one man and two women, withdrew from participation because they felt too ill to cope with an interview situation.

The first interviews were carried out one month after surgery in the home of the participants $(n=6)$ or in a secluded room at the surgical outpatient clinic $(n=2)$. Two participants were interviewed at the hospital ward, since they were still hospitalised due to complications after surgery. Written consent was collected before starting the interviews. The interviews began with the question "Could you describe how you have experienced your recovery after surgery from the time that you woke up from anesthesia until now?" Additional questions, such as "What do you mean by...?" or "Could you tell me more about...?", were asked to obtain clarifications or a deepened description of the experiences (85). The second interview took place six months after surgery at a place chosen by the participants. Thus, the majority of the interviews were conducted in the homes of the participants, except for two participants, who chose to be interviewed at the surgical outpatient clinic. The same question as for the one-month interview was asked again, in order to reach for a description containing the longitudinal perspective of recovery. The interviews lasted for 18 to 58 minutes, with a median of 47 minutes for the one-month interviews and 35 minutes for the six-month interviews. All interviews were digitally recorded and transcribed verbatim.

\section{Pre-understanding}

The descriptive phenomenological method developed by Giorgi (83) was used for the qualitative study (III). According to this method, it is essential to assume the attitude of the phenomenological reduction throughout the whole research process. This means putting aside previous knowledge of the phenomenon, in this case postoperative recovery after colorectal cancer surgery, in order to be able to treat the phenomenon and everything that is said about it as something that is given, without making subjective interpretations (86). At the time of the data collection, I had been a surgical RN for many years although I had only occasionally been involved in the care for patients undergoing CRC surgery. In 
order to control my previous knowledge as a surgical RN, I strived to listen to the patients' narratives naïvely during the interviews. At the same time, I was reflecting on how I perceived the narratives, so that descriptions were not taken for granted due to my previous experiences. During analysis, this reflection continued, but then it was also important to be aware of the risk of making my own interpretations when describing what the participants had said.

\section{Instruments}

In order to collect data about general health, state and trait anxiety (II, IV), and postoperative recovery (I, IV), three different instruments were used.

\section{The EuroQol 5-Dimensions 3-levels (EQ-5D-3L)}

General health was measured before surgery and one and six months after surgery, using the EuroQol 5-Dimensions 3-levels (EQ-5D-3L) instrument (87). The EQ-5D-3L is a generic instrument that is developed and validated in several languages, among others in Swedish. It has been used in general settings and also for patients with colorectal cancer $(64,88)$.

The instrument consists of two parts. The first part includes five dimensions, namely mobility, self-care, usual activities, pain/discomfort, and anxiety/ depression. Each dimension has three predefined levels of problems, that is, "no problem", "some problems", and "extreme problems". The patients were asked to indicate their level of problem by marking it.

When scoring the answers, "no problem" is scored as 1, "some problems" as 2 , and "extreme problems" as 3. A health status, defined by a five-digit number based on the scores from the five dimensions, for each patient is achieved (89). From the health status, a health index can be calculated using the time trade-off valuation technique (TTO) (90). This index can range from $-0,59$, indicating the worst health, to 1 , indicating the best health (ibid.).

The second part of the EQ-5D-3L consists of a visual analogue scale ranging from worst imaginable health, VAS 0, to best imaginable health, VAS 100. The patients were asked to rate their self-experienced state of health by setting a mark on the scale. 


\section{The State-Trait Anxiety Inventory (STAl)}

Self-reported state and trait anxiety were measured by the State-Trait Anxiety Inventory for Adults (STAI) (49). The STAI instrument is a well-recognised instrument that is validated, extensively used, also regarding CRC $(91,92)$, and developed in over 30 languages (49). Prior to the data collection for this thesis, license to use the instrument was purchased from Mind Garden, Inc.

The instrument consists of two separate forms measuring state anxiety, Form Y-1, (II, IV) and trait anxiety, Form Y-2, (IV). Both forms include 20 items formulated as statements indicating how anxious patients feel "right now" (state anxiety) or "generally" (trait anxiety). Answers can be set at a four-point descriptive scale composed of the alternatives "not at all", "somewhat", "moderately so", and "very much so". When scoring the answers, each statement receives a weighted score ranging from 1, "not at all", to 4, "very much so". Ten items are negatively phrased, so that a high score reflects a lower level of anxiety. For those items, the weighted scores are reversed.

To obtain a value of state and trait anxiety, weighted scores from all 20 statements in the respective forms were added together. Missing values were covered by calculating the average of the answered statements multiplied by 20 (49). Cases with more than three missing answers were excluded from further analysis. In all, values from STAI can vary from 20, indicating an absence of anxiety, to 80 , indicating a high level of anxiety.

State anxiety was measured in all four assessments (II), whereas trait anxiety was measured only before surgery (IV) since it has been suggested that a personality trait is consistent over time (49).

\section{The Postoperative Recovery Profile (PRP)}

Postoperative recovery was measured on three occasions - on the day of discharge and at one and six months after surgery (I, IV) - using the Postoperative Recovery Profile (PRP). This is a multi-item, multidimensional instrument designed for the self-assessment of postoperative recovery (93). The PRP exists in two versions: one with 17 items intended for assessments during hospital stay and one with 19 items developed for measuring postoperative recovery after discharge. Items added to the 19-item version are "re-establish everyday life" and "sexual activity". Both versions were used after approval from the author of the instrument. 
The items within PRP, which corresponds to postoperative symptoms, are formulated as statements, for example, "Right now I feel a pain that is ..." (59). When answering the questionnaire, patients mark the self-perceived severity of the items on a four-point descriptive scale of "none", "mild", "moderate", and "severe". The items can be categorised into five dimensions, named "physical symptoms", "physical functions", "psychological”, "social”, and "activity", as shown in Table 4 (ibid.).

Table 4. Items within each recovery dimension in the PRP questionnaire (93).

\begin{tabular}{ll}
\hline Item & Dimension \\
\hline Pain & Physical symptoms \\
Nausea & \\
Fatigue & \\
Appetite change & \\
Sleeping difficulties & Physical functions \\
\hline Gastrointestinal function & \\
Bladder function & \\
Muscle weakness & \\
Sexual activity & \\
Mobilisation & Psychological \\
\hline Anxiety and worry & \\
Feeling down & \\
Feeling lonely/abandoned & \\
Difficulties in concentration & Social \\
\hline Social activities & \\
Dependence on others & \\
Interest in surroundings & Activities \\
\hline Re-establish everyday life & \\
Personal hygiene &
\end{tabular}

$\mathrm{PRP}=$ Postoperative Recovery Profile

A Global Score of Recovery (GSR) can be calculated by counting the items responded to with "none" (59). This results in an indicator sum ranging from 0 "none" to 19 "none", measuring a general level of recovery. If all items, that is, 19 items, are responded to by "none", this corresponds to a "fully recovered" patient in the GSR. Further, an indicator sum of 18-15 corresponds to an "almost fully recovered" patient, 14-8 to "partly recovered", 7 to "slightly recovered", and less than 7 to a patient that is "not at all recovered". 
The PRP can also be scored regarding the dimensional levels (94). The level of recovery for each dimension is then defined by the most severe problem assessed among the items within the dimension; for example, the dimension physical symptoms consists of five items. If the responses for the items are none, mild, mild, moderate, and none, this means that the level of recovery in the dimension physical symptoms is moderate (94).

The PRP instrument was recently developed and validated for patients undergoing elective lower abdominal and orthopaedic surgery in a Swedish setting (93). It has been shown to have a good content and construct validity as well as intra-patient reliability $(59,93)$.

\section{Patient characteristics and factors related to surgery}

In addition to general health and state and trait anxiety, data concerning patient characteristics, namely, age, gender, household size, Body Mass Index (BMI), and grade of ASA, was abstracted from the patients' medical journals. Information was also collected about factors related to surgery, such as preoperative neoadjuvant therapy, length of surgery, loss of blood during surgery, type of surgical intervention, presence of stoma, day of first mobilisation, oral intake, and defecation, as well as length of hospital stay and postoperative adjuvant therapy.

\section{Data analysis}

Statistical calculations were conducted using the Statistical Package for the Social Sciences (SPSS version 22 [IBM Corp., Chicago, IL., USA]). In addition, a statistical software referred to as "Svensson's method" (95) was used when evaluating paired, ordered data (II). All tests for significance were two-sided and a $p$-value $\leq 0.05$ was considered statistically significant. Missing cases were excluded pairwise.

\section{Variables concerning patient characteristics and factors related to surgery}

Descriptive statistics was used when calculating variables regarding patient characteristics and factors related to surgery (I-IV). Frequency distribution was described in number, percentage, median, or mean, together with standard deviation (SD).

In order to allow for comparisons between groups of patients concerning patient characteristics and factors related to surgery (I, II), patients were divided into three groups based on surgical procedure, namely, rectal resection, APR, and 
colonic resection (Table 1). Distribution of normality was calculated using the Kolmogorov-Smirnov test (96). Differences between groups of patients were calculated using one-way ANOVA for normally distributed data at an interval level, Chi-square for nominal data, or the Kruskal-Wallis test for non-normally distributed data, at least at an ordinal level $(96,97)$. To further evaluate significant differences that occurred between groups of patients, pairwise comparisons were made by an independent samples $T$-test for normally distributed samples, and a Mann-Whitney $U$ test for non-normally distributed samples (96).

\section{Postoperative recovery and patterns of changes}

Calculations of postoperative recovery were made for the three groups of patients separately in order to illustrate the potential difference in the pattern of recovery between groups (I).

A general level of recovery for each assessment was calculated and displayed by the GSR. Regarding the pattern of changes between assessments for each PRP item, values from the PRP, measured on the day of discharge as well as one and six months after surgery, were analysed using "Svensson's method" (95). This method enables calculations for changes between joint pairs of assessments (98). It specifies the size and direction of the change, if the change is systematic and homogenous on a group level, and if there are individual divergences from the systematic pattern of change (ibid.).

For pairs of assessment, the distribution is preferably visualised in a contingency table. If there have not been any changes from the first assessment to the second, values are distributed on the main diagonal oriented from the lower left corner to the upper right corner, depending on the original severity of the problem. The proportion of unchanged assessments between two assessments is referred to as a Percentage Agreement (PA) and expressed in number and percentage (98).

If there has been a systematic change from the first to the second assessment, there is a shift in the Relative Position (RP) (98). This means that the position of the pairs has changed homogenously either to a lower position, indicating milder problems on the second assessment, or to a higher, indicating more severe problems. In cases where the group of patients has indicated lower levels of problems on the second assessment, the distribution is shifted towards the right side of the diagonal, indicating a systematic improvement for patients regarding that item. The RP value is then preceded by a subtraction sign (ibid.). If the patients have indicated a higher level of problems on the second assessment, the RP value is positive. The 
RP value expresses the differences between the probabilities of an increased or decreased level of problems between assessments. Therefore, possible values of RP range between -1 and 1 . A negative value close to -1 indicates a high probability of a shift towards lower levels of problems on the second assessment (98).

Individual patients can of course deviate from the systematic pattern of change. This is referred to as a relative rank variance (RV). The RV value, which can be up to 1 , indicates to what extent individual patients deviate from the expected homogenous group change. An RV value close to 1 indicates that there are individual variations in the pattern of change that must be considered in the interpretation of results (98).

\section{Calculating and comparing health and anxiety}

Before the analysis of values from the instruments EQ-5D-3L and STAI (state anxiety form), patients were divided into three groups, namely, rectal resection, APR, and colonic resection (II).

Values from the EQ index, EQ VAS, and state anxiety, measured before surgery, on the day of discharge, and one and six months after surgery, were calculated and described in means and standard deviations (SD). Due to a general skewed distribution as well as groups of unequal size, differences between groups of patients and assessments were calculated using the Kruskal-Wallis test. Differences within groups of patients and between assessments were calculated using Friedman's ANOVA (96). Due to multiple tests, the risk for Type I errors was reduced by adjusting each significant value according to Bonferroni's method (99).

\section{The lived experience of recovery}

The descriptive phenomenological method developed by Giorgi (83) was used to describe the lived experience of recovery during the first six months after colorectal cancer surgery (III). The analytic part of the method consists of four steps. First, all interviews were read in order to get a holistic understanding of the participants' descriptions. Second, the interviews were reread. However, this time, the reading was made with the intention to constitute meaning units in the text. This was made by setting a mark in the text every time the meaning within the descriptions changed. This step is above all practical in order to produce units that are manageable in further steps. 
In step three, which has been mentioned as the core of the method (83), the text in each meaning unit was transformed into a description of what the participants said about recovering from CRC surgery. The transformation was made by the technique of free imaginative variation, which can be explained as analytically testing the description until the most exact description of the meaning appears.

In the last and fourth step, still using the free imaginative variation technique, constituents of the phenomenon of postoperative recovery after colorectal cancer surgery were identified based on the descriptions of the meaning units from step three. Further, a general description of the phenomenon was formulated with the constituents as interdependent parts (83).

\section{Factors of influence}

In order to describe the influence of patient characteristics and surgery-related factors on patient-reported recovery (IV), a multiple logistic regression using the backward stepwise Likelihood Ratio method was performed (96). Potential predictors related to patient characteristics were age, gender (male/female), household size (one-person household/multi-person household), BMI, grade of ASA, EQ index, EQ VAS, and trait anxiety. Factors related to surgery were neoadjuvant therapy (none/radiation therapy), length of surgery (minutes), blood loss during surgery (millilitres), type of surgical intervention (rectal resection/ APR/ colonic resection), presence of stoma (absence of stoma/colostomy/loop ileostomy), LoS (days), and postoperative adjuvant therapy (none/chemotherapy). Additionally, it was assumed that recovery in one assessment could predict recovery in the following assessments. Therefore, the level of recovery in each dimension (none, mild, moderate, severe) on the day of discharge was entered into the models, predicting recovery both at one and six months after surgery. Likewise, the levels of recovery one month after surgery were entered into the models, predicting recovery six months after surgery. Associations between dimensions were only tested for corresponding dimensions.

The five PRP dimensions were entered as outcome variables into separate models both for one month and six months after surgery. Since the dimensions consist of four levels of recovery, they were dichotomised into good recovery (none/mild) and poor recovery (moderate/severe). 


\section{ETHICAL CONSIDERATIONS}

The International Council of Nurses (ICN) (100) define the fundamental responsibilities of nursing, which are: to promote health, to prevent illness, to restore health, and to alleviate suffering. In the ICN Code of Ethics for Nurses (ibid.), it says that the nurse, among other things, should be active in gathering knowledge based on research in order to meet the standards of ethical conduct. When combining research-based practice with an ethical approach, it is essential that the research is grounded in ethical principles. The four studies that comprise this thesis were conducted in accordance with the Declaration of Helsinki (101) with respect to the four moral principles of autonomy, non-maleficence, beneficence, and justice (102). All studies were approved by the Regional Ethics Board, Lund, Sweden (Reg.no. 2011/451).

Patients who were considered for inclusion were approached with information about the studies both orally and in writing. The information contained the aim of the studies, the procedure, potential risks and benefits, as well as an assurance of confidentiality and the right to withdraw at any time. Written informed consent was retrieved from participants before distributing questionnaires, reading medical journals (I, II, and IV), or conducting interviews (III). Autonomy refers to the right of individuals to make choices and to take actions based on personal values and beliefs (102). If patients did not return questionnaires despite an initial written informed consent and two subsequent reminders, this was considered a withdrawal. Thus, no further questionnaires were distributed and no information was collected from medical records. Regarding the interviews, the participants were asked a second time about their willingness to participate, when they were contacted by telephone prior to the interviews. Written consent was collected before starting the one-month interview. Through this approach, the voluntariness of participation was acknowledged, enabling the participants to act autonomously (ibid.). 
To protect integrity, privacy, and confidentiality of personal information, in accordance with the Declaration of Helsinki (101) and the principle of nonmaleficence (102), all data was treated so as to ensure that no individual could be identified. Questionnaires, interviews, and information from medical journals were marked with a number and did not contain any personal records. All original data was kept safe and only available to the authors. Data was computerised, analysed, and presented on a group or general level. The interviews were conducted with no others than the participant and the researcher present, and they were transcribed excluding any names. Quotes that were published were presented anonymously with the intention to avoid the possibility for others than the participants themselves to recognise and identify the person behind the quote.

In-depth interviews might provoke feelings within participants that otherwise would not be brought forth. This could be a dilemma, especially for the phenomenological researcher wanting rich data, in that there is a risk of impinging on the participants' integrity by digging deeper into their descriptions (85). Therefore, the handling of such situations was reflected on before starting the interviews. During the interviews, attention was paid to verbal or non-verbal signs of participants who either did not have anything more to say or did not want to say anything more about the topic. The author who did the interviews also set aside a good amount of time to doing the interviews, so that it would be possible to stay and talk with the participants after the interviews. Furthermore, a counsellor was available at the surgical clinic if it was considered necessary for the participants to establish such contact.

Medical research involving human subjects may only be conducted if the importance of the objective outweighs the risks and burdens to the research subjects (101). Except for the potential provocation of feelings during interviews, participation in the studies was not expected to have any negative impact on the patients. The beneficence, on the other hand, was the possibility to produce scientific knowledge that will benefit both health care professionals and future patients.

The fourth principle, justice (102), was considered in the recruitment process of the studies. Participants in the questionnaire data collection (I, II, and IV) were consecutively invited to participate. This gave all patients who met the inclusion criteria during the data collection period equal rights to accept or decline participation. In study III, equality could not be ensured in the same way since participants were purposefully chosen, in accordance with the methodology used for that study. In addition, there is a chance that some patients want to share their experience but do not feel comfortable participating in an interview and therefore decline participation. 


\section{RESULTS}

For this thesis, patients were followed during the first six months after their surgical procedure. The postoperative recovery was described as a progressive process (III). Experiences of physical powerlessness, difficulties with food intake, altered bowel function, and a dependence on others, were prominent, thereby constituting the phenomenon of postoperative recovery (Figure 4). The patients experienced postoperative symptoms that changed from being intense in the beginning of the process to becoming less intense and then disappearing or becoming part of everyday life.

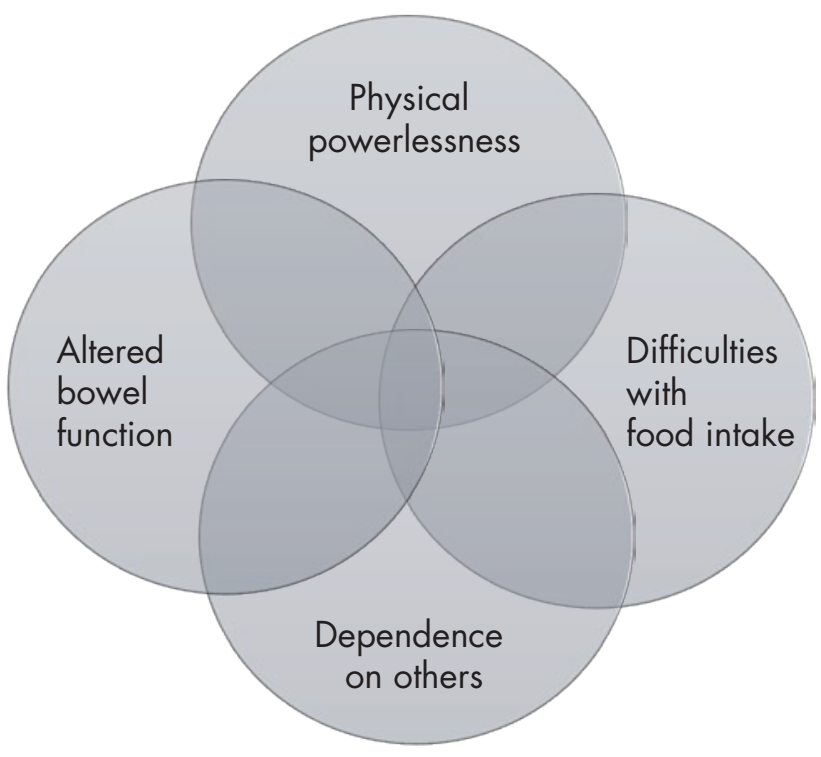

Figure 4. Constituents forming the phenomenon of postoperative recovery (III) 
As shown in Table 5, the pattern of recovery differed with regard to different types of surgical interventions (I). During the first month after surgery, patients recovering from colonic resection showed significant improvements in more items within the PRP instrument (11/17) than patients did after rectal resection (4/17) and APR (0/17).

From one month to six months after surgery, the relation was reversed (Table 6). Patients after colonic resection then showed significant improvements in two out of nineteen items, while patients after rectal resection and APR showed significant improvements in seven and ten items respectively.

In order to follow the process of recovery, the result of the thesis is presented so that different aspects of recovery along the patients' recovery trajectory are described. The four studies comprising the thesis are referenced in brackets (I-IV).

\section{Patient demographics and preoperative levels of health and anxiety}

The 176 patients who initially chose to participate in the questionnaire data collection had a mean age of 69.6 years (SD 10.8). Out of those, $95(54.0 \%)$ were men and $81(46.0 \%)$ women. The majority of patients $(\mathrm{n}=72,40.9 \%)$ underwent a colonic resection followed by rectal resection $(n=68,38.6 \%)$ and APR $(n=36$, $20.5 \%$ ). In addition, the ten patients that participated in the interviews had a mean age of 70.5 years (SD 5.8). Three of them (30.0\%) were men and seven $(70.0 \%)$ women. Patient demographics regarding each respective study (I-IV) were presented earlier in the thesis, in Table 3.

All three groups of patients had a high level of health before surgery, as measured by the EQ index (II). There were no significant differences between groups $(\mathrm{p}=0.348)$, as shown in Table 7 . The EQ index ranged from 0.81 for patients planned for colonic resection to 0.86 for patients before an APR. Regarding the self-rated health, measured by EQ VAS (II), there was a preoperative significant difference between groups ( $\mathrm{p}=0.009$ ), as patients planned to undergo an APR rated their preoperative health higher than patients planned for colonic resection $(\mathrm{p}<0.001)$ and rectal resection $(\mathrm{p}=0.014)$. In general, anxiety as a trait was shown to be low among the patients (IV). When measuring trait anxiety before surgery, a mean of 34.63 (SD 10.04) was obtained. Furthermore, all three groups of patients showed low levels of state anxiety before surgery (II) and there were no differences between groups (Table 7). 


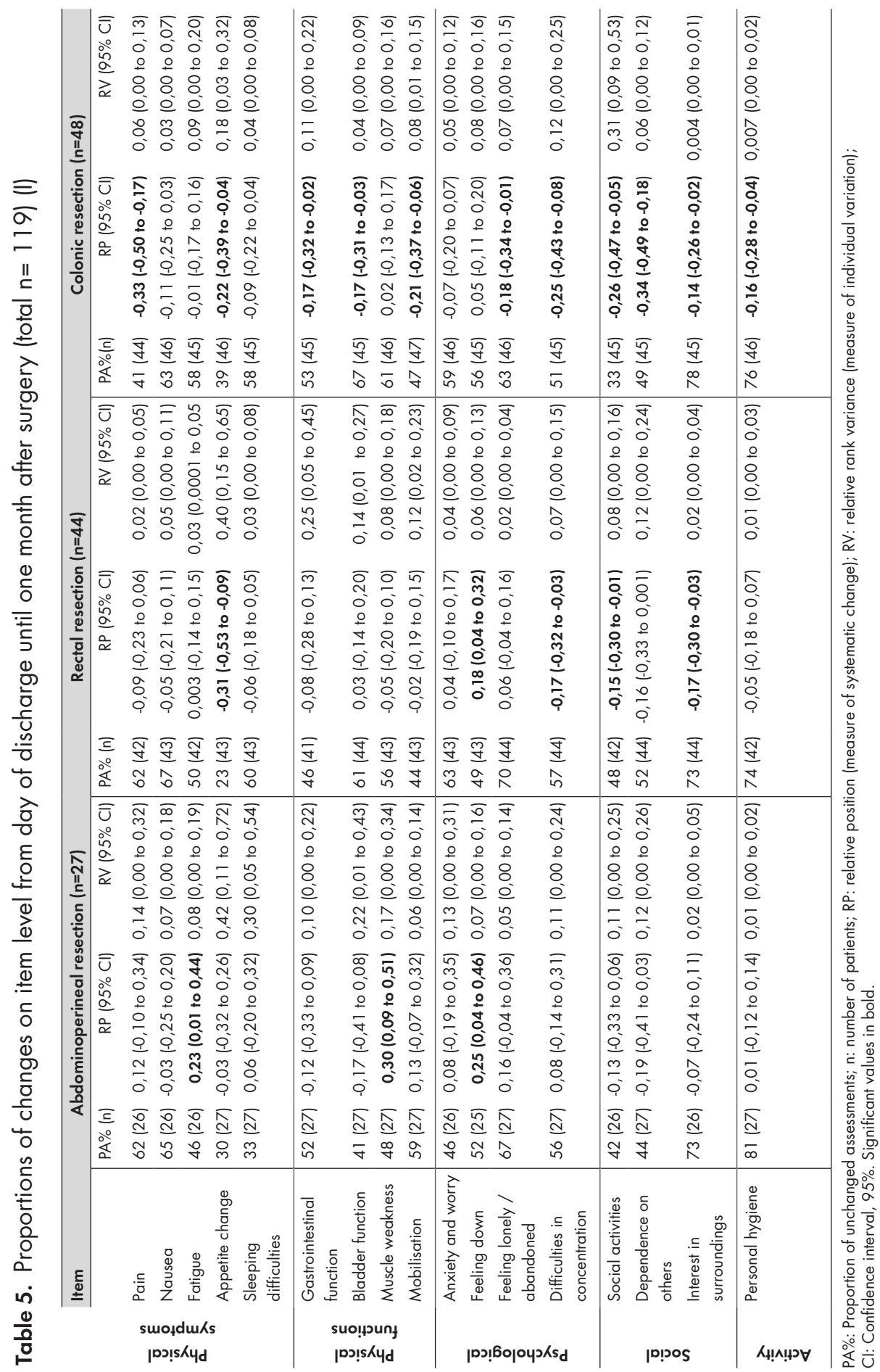




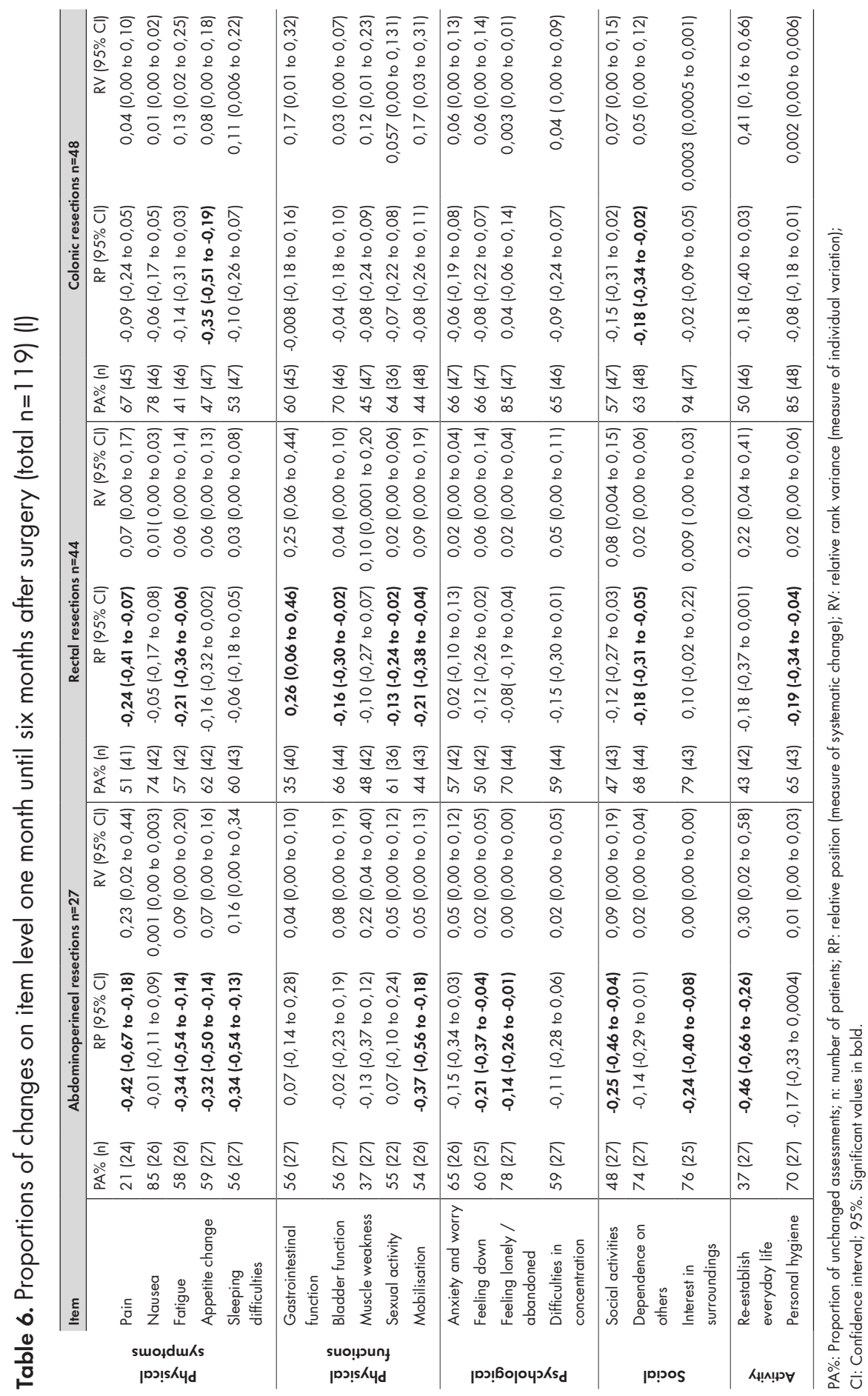




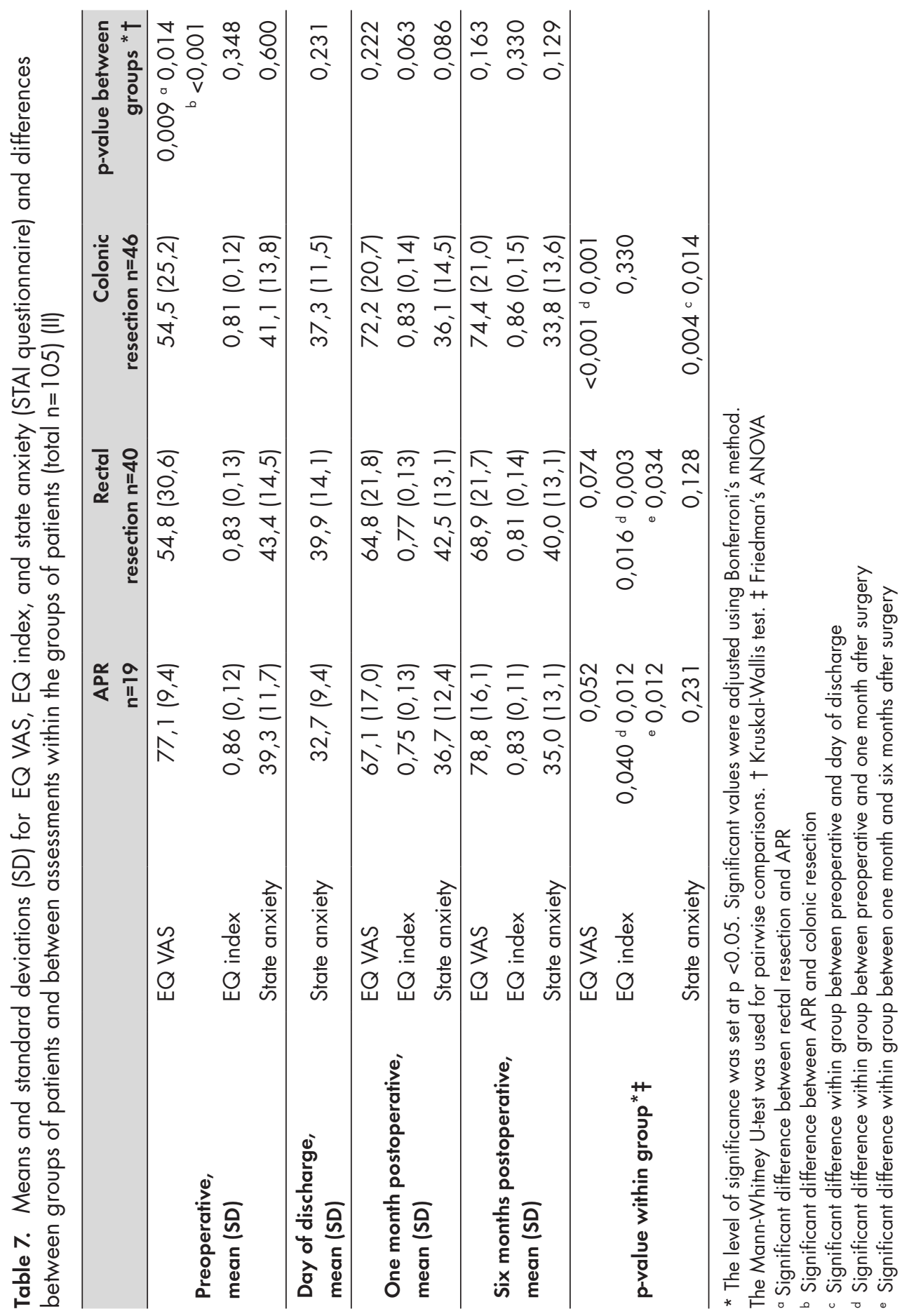




\section{In-hospital recovery}

The constituents of the phenomenon of postoperative recovery - physical powerlessness, difficulties with food intake, bowel function, and dependence on others - were described by the patients as dominating recovery during hospital stay (III).

\section{Physical powerlessness}

Initially after surgery, patients described how they felt dizzy and experienced a reduced capacity to control their body. In addition, they experienced an overwhelming physical powerlessness. The patients were supposed to mobilise intensively already during the first day after surgery. However, this was experienced as difficult, not only due to the feelings described above but also because of the presence of tubes and drains, and, sometimes, pain. In order to be able to get out of bed, the patients felt dependent on the ward staff to support them. Before surgery, the patients had received information from the $\mathrm{CN}$ about the benefits of intense mobilisation. This knowledge, together with the encouragement from ward staff, motivated the patients to master the experiences of dizziness, lack of bodily control, and powerlessness, by trying to get up and move around or sit in an armchair. Eventually, the patients regained the strength to mobilise on their own, but often with support from devices such as a walking frame because of an insecurity induced by the remaining feeling of powerlessness.

\section{Difficulties with food intake}

The patients were supposed to eat and drink directly after surgery and to such an extent that they could manage without intravenous infusion. However, a loss of appetite and changes in taste were experienced. Also, the use of analgesics induced nausea. After only a few mouthfuls of food, the patients felt full and as a consequence they had trouble eating as much as they should. The help from ward staff, as well as the knowledge received from the preoperative information, were of importance also regarding the motivation to eat and drink despite feelings of resistance. The ward staff were encouraging and supportive in pushing the patients to, at least, drink. As a result, the patients tried to drink as much as they could and they chose dietary supplements in the shape of beverages in order to obtain a sufficient intake of calories. Since the food in hospital was experienced as distasteful, patients sometimes chose to eat more appetising things, such as ice cream, crispbread with marmalade, or candy, for the sake of the calories. 


\section{Bowel function}

The bowel function was an area of some concern both for patients without and with a stoma. One criterion for discharge from hospital was the evacuation of faeces. This event was a topic of discussion among patients. It was anticipated but also a little feared due to worries that it might hurt. Further, the practical management of the stoma was experienced as difficult in the beginning.

\section{The recovery period between discharge from hospital and one month after surgery}

Length of stay differed significantly $(\mathrm{p}=0.005[\mathrm{I}])$ and $\mathrm{p}=0.009[\mathrm{II}]$ respectively) between patients recovering from the three types of surgical interventions (I, II). Patients after colonic resection had the shortest LoS (9.0 days [I] and 8.9 days [II] respectively), followed by patients after APR (10.6 [I] and 10.1 days [II] respectively) and rectal resection (11.0 [I] and 11.3 days [II] respectively).

\section{Discharge}

Recovery was measured with the PRP instrument. The GSR, which was retrieved from the PRP instrument (I), showed that no patient was considered fully recovered at discharge, as displayed in Figure 5. For patients after colonic resection, in spite of having the shortest LoS, a higher proportion of patients were considered not at all recovered $(41.4 \%)$ than partly recovered $(36.6 \%)$. Patients recovering from rectal resection had the same relation, as $46.3 \%$ were not at all recovered in comparison with $36.6 \%$ who were partly recovered. Further, patients after APR had the highest proportion of being partly recovered at discharge $(59.3 \%)$.

Regarding the state anxiety on the day of discharge (II), patients after colonic resection reported significantly lower levels of state anxiety compared to before surgery $(\mathrm{p}=0.014)$. Between the three groups of patients, there were no significant differences (Table 7). 


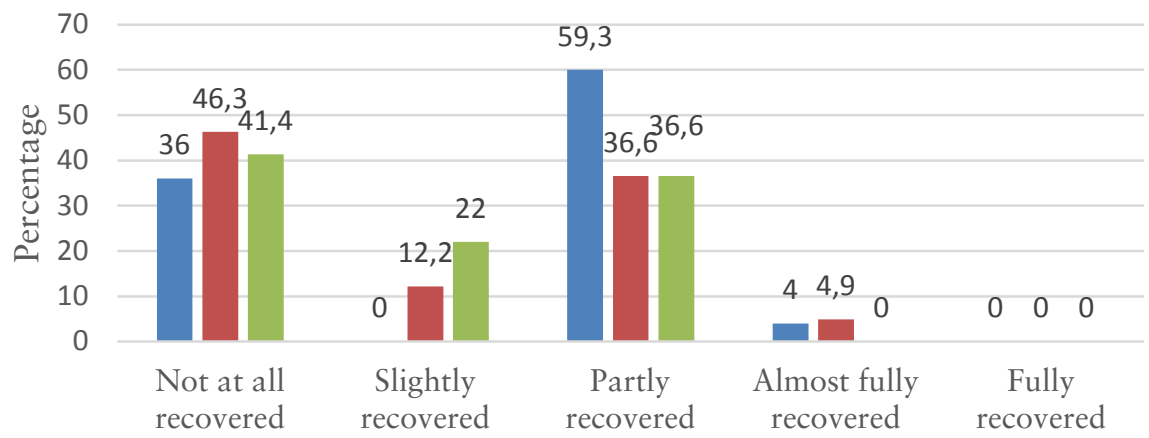

1 month after surgery

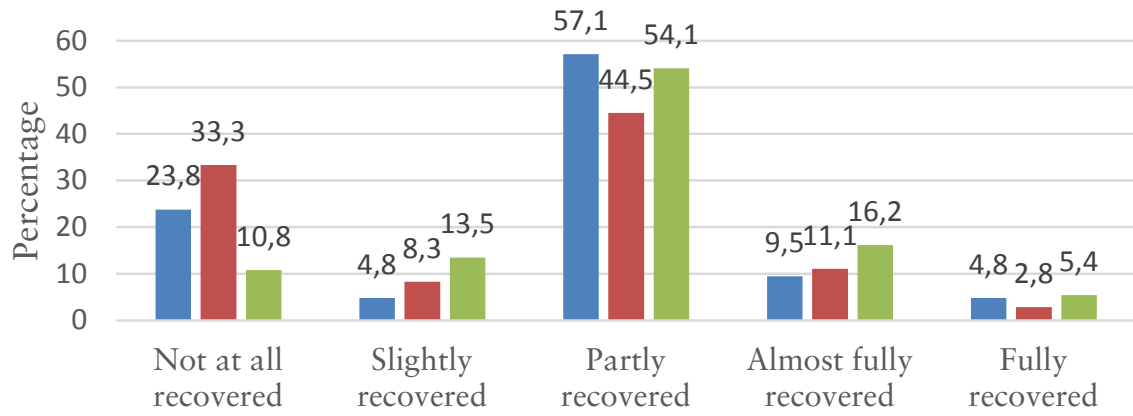

6 months after surgery

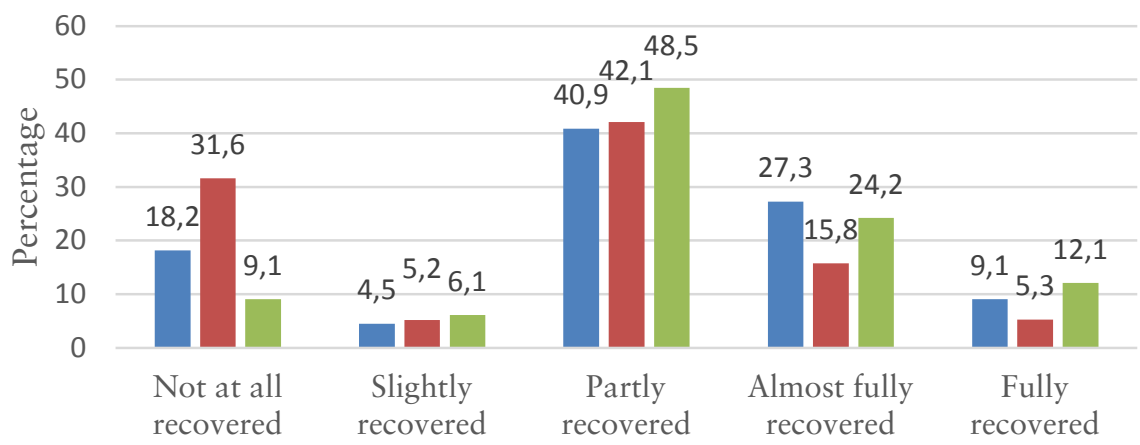

APR Rectal resection $\quad$ Colonic resection

Figure 5. The Global Score of Recovery (I) 


\section{Physical powerlessness, dependence, and social impairments}

Once at home, the patients described how they continued to experience physical powerlessness, which caused a need to rest (III). The patients did not have enough strength to perform household activities, go for a walk, or go shopping for groceries. They became dependent on relatives or friends in order to manage everyday life. The powerlessness also caused feelings of frustration and limitation. The patients did not want to have visitors, since the fact that they needed to rest made them feel impolite. On the other hand, the inactivity was also experienced as boring, inducing a desire to have more strength. Patients who were recovering from an APR procedure said that they had some restrictions on sitting down the first weeks after surgery. This caused feelings of being even more inactive, since they had to rest lying down. Also, some patients had to eat standing up, which made food intake difficult because of their lack of strength.

In the interviews (III), patients described the powerlessness as substantial, at least during the first month after surgery. This condition was confirmed by the result from the PRP instrument (I), since none of the three groups of patients showed any improvements in the item muscle weakness from the day of discharge to one month after surgery (Table 5). In addition, patients after an APR showed significant deteriorations regarding the items fatigue (RP 0.23), muscle weakness (RP 0.30), and feeling down (RP 0.25). Also, for this group of patients, no significant improvements in the items within the recovery dimension social (containing the items social activities, dependence on others, and interest in surroundings) could be seen during the period, which indicates an impairment in social life. In contrast, the patients recovering from colonic resection showed improvements in the items mobilisation (RP -0.21), social activities (RP -0.26), dependence on others (RP -0.34), and personal bygiene (RP -0.16). This reflects that patients after a colonic resection improved faster regarding physical powerlessness than the two other groups. However, for the item social activities, an RV value of 0.31 indicated that there were individual variations within the group recovering from colonic resection that must be considered when interpreting the result.

\section{Difficulties with food intake}

The intake of food was experienced as difficult also after discharge (III). Patients described a continued lack of appetite and they ate merely because they knew it was necessary. Just as in hospital, they could only eat a little before they felt full. In addition, the patients did not have the strength to stand up long enough to cook or to go to the grocery, which, initially, made them dependent on relatives. Some 
patients who were living alone had filled the freezer with meals before surgery or had as a daily goal to go to the nearest store.

The patients' appetite improved during the first month after surgery, according to the PRP instrument (I), as shown in Table 5. For patients recovering from rectal resection and colonic resection, the appetite had improved significantly compared to the day of discharge (RP - 0.31 and RP - 0.22 respectively), although there were signs of individual variations for patients after rectal resection (RV 0.40).

\section{Altered bowel function}

During at least the first month after surgery, the function of the bowels gave rise to feelings of insecurity and concern (III). The patients were troubled by diarrhoea that caused a need to be close to a toilet, especially before noon when the bowel activity was the most intense. Activities were planned based on the bowel behaviour, which restricted the ability to leave home and, consequently, social contacts. Sometimes, the diarrhoea was replaced by constipation. Being constipated, the patients had the need to push, which was accompanied by concerns that the surgical wound or the intestinal anastomosis would burst.

Patients with a stoma were concerned about the practical management of the stoma. They had worries over unexpected faecal leakage and the management of such events when out in public (III). In spite of this, patients after a rectal resection, who are the ones that receive a loop ileostomy, showed significant improvements in two out of three PRP items (I) within the recovery dimension social (social activities: RP - 0.15, and interest in surroundings: RP -0.17) one month after surgery (I), in comparison with the day of discharge (Table 5). For the item gastrointestinal function, only patients recovering from colonic resection reached significant improvements one month after surgery (RP -0.17).

\section{Health and state anxiety one month after surgery}

Although there were no differences between the three groups of patients regarding EQ index or EQ VAS one month after surgery (II), it was shown that the EQ index had deteriorated significantly for patients after rectal resection $(p=0.003)$ and APR ( $p=0.012)$ compared to preoperative values (Table 7). In contrast, patients after colonic resection showed a significant improvement in EQ VAS $(\mathrm{p}<0.001)$. Regarding state anxiety, there were no differences between groups one month after surgery (II), nor were there any differences between the assessment on the day of discharge and the assessment one month after surgery in any of the groups 
(Table 7). However, results from the PRP instrument (I) showed that both patients after rectal resection and after APR deteriorated significantly in the item feeling down (RP 0.18 and 0.25 respectively) between the day of discharge and one month after surgery (Table 5).

\section{Factors associated with recovery one month after surgery}

The odds for a good recovery regarding the five PRP recovery dimensions are presented in Table 8 (IV). It was shown that a higher preoperative health, measured by EQ VAS, was associated with a good recovery one month after surgery in the recovery dimensions physical symptoms (OR 1.282), psychological (OR 1.398), and activity (OR 1.286). A higher grade of ASA predicted low odds for a good recovery in the dimension social (OR 0.416), while a higher BMI was associated with higher odds for a good recovery in the dimension psychological (OR 1.144).

Regarding factors related to surgery, an APR procedure was associated with low odds for a good recovery in the dimensions physical symptoms (OR 0.103), psychological (OR 0.186), and social (OR 0.196). In addition, the presence of a stoma was associated with low odds regarding the dimensions social (loop ileostomy, OR 0.076) and activity (loop ileostomy, OR 0.185; colostomy, OR 0.158). Further, a prolonged LoS was a factor that was associated with lowered odds for a good recovery for the recovery dimensions physical symptoms (OR 0.829 ) and psychological (OR 0.868).

Patients who had a poorer level of recovery at discharge, regarding all five recovery dimensions, were shown to have lower odds for a good recovery within the dimensions also one month after surgery. 
Table 8. Final models showing patient characteristics and surgery-related factors associated with recovery on a dimensional level of PRP one month after surgery (IV)

\begin{tabular}{|c|c|c|c|c|}
\hline Dimension & Factor & OR & $95 \% \mathrm{Cl}$ & P-value \\
\hline \multirow{4}{*}{ 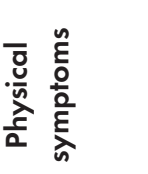 } & EQ VAS $\dagger$ & 1.282 & $1.013-1.623$ & $0.039 *$ \\
\hline & Length of stay & 0.829 & $0.737-0.933$ & $0.002 *$ \\
\hline & Abdominoperineal resection & 0.103 & $0.024-0.453$ & $0.003^{*}$ \\
\hline & Dimension physical symptoms 1 & 0.186 & $0.080-0.436$ & $<0.001^{*}$ \\
\hline \multirow{4}{*}{ 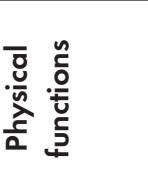 } & EQ VAS $\dagger$ & 1.208 & $0.968-1.508$ & 0.095 \\
\hline & Duration of surgery & 0.995 & $0.990-1.000$ & $0.031 *$ \\
\hline & Length of stay & 0.932 & $0.838-1.036$ & 0.189 \\
\hline & Dimension physical function ${ }^{1}$ & 0.433 & $0.223-0.843$ & $0.014^{*}$ \\
\hline \multirow{6}{*}{ 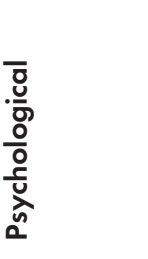 } & EQ VAS † & 1.398 & $1.045-1.872$ & $0.024 *$ \\
\hline & $\mathrm{BMI} \dagger$ & 1.144 & $1.005-1.303$ & $0.042 *$ \\
\hline & Length of stay & 0.868 & $0.761-0.990$ & $0.035^{*}$ \\
\hline & Abdominoperineal resection & 0.186 & $0.042-0.811$ & $0.025^{*}$ \\
\hline & Loop ileostomy & 0.349 & $0.079-1.553$ & 0.167 \\
\hline & Dimension psychological 1 & 0.272 & $0.128-0.578$ & $0.001 *$ \\
\hline \multirow{4}{*}{. } & ASA $\dagger$ & 0.416 & $0.173-0.999$ & $0.050 *$ \\
\hline & Abdominoperineal resection & 0.196 & $0.040-0.951$ & $0.043^{*}$ \\
\hline & Loop ileostomy & 0.076 & $0.017-0.347$ & $0.001 *$ \\
\hline & Dimension social 1 & 0.150 & $0.064-0.350$ & $<0.001^{*}$ \\
\hline & EQ VAS $†$ & 1.286 & $1.034-1.600$ & $0.024 *$ \\
\hline & Length of stay & 1.106 & $0.981-1.248$ & 0.099 \\
\hline & Colostomy & 0.158 & $0.043-0.573$ & $0.005^{*}$ \\
\hline & Loop ileostomy & 0.185 & $0.048-0.716$ & $0.015^{*}$ \\
\hline & Dimension activity ${ }^{1}$ & 0.390 & $0.174-0.873$ & $0.022 *$ \\
\hline
\end{tabular}

OR, Odds ratio; Cl, Confidence Interval; ASA, the American Society of Anesthesiologists' physical status classification system; BMI, Body Mass Index; PRP, Postoperative Recovery Profile. Variables were included in the final models if $p \leq 0.2$. Significance was set at $p \leq 0.05$

1 Day of discharge

* Significant association

$\dagger$ Measured before surgery 


\section{The recovery period between one month and six months after surgery}

The GSR showed that $36.3 \%$ of the patients recovering from colonic resection were considered fully or almost fully recovered six months after surgery, as shown in Figure 5 (I). For patients after APR, the corresponding proportion was $36.4 \%$. It also became clear that patients who had had a rectal resection had not recovered to the same extent as the two other groups. For those patients, a proportion of $21.1 \%$ were fully or almost fully recovered, but a higher proportion were considered not at all recovered $(31.6 \%)$.

Health and state anxiety six months after surgery

Between the three groups of patients, there were no significant differences in health or state anxiety six months after surgery, as shown in Table 7 (II). The EQ index, which had deteriorated one month after surgery in patients after rectal resection and APR, had now improved significantly to become close to preoperative values for both groups $(\mathrm{p}=0.034$ and $\mathrm{p}=0.012$ respectively).

\section{Regaining physical strength}

The physical powerlessness was perceived to be almost non-existent six months after surgery (III). Although patients described how their strength began to return about one month after surgery, some patients said that they had experienced powerlessness for quite a while. Even though the physical powerlessness decreased and for most patients disappeared during the first six months after surgery, the improvement was experienced as fragile. For some patients, events such as complications, health disorders, or chemotherapy, resulted in a recrudescence of the physical powerlessness.

Both patients after rectal resection and after APR showed significant improvements in the PRP item mobilisation (RP - 0.21 and RP - 0.37 respectively) six months after surgery (I), in comparison with one month after surgery (Table 6). In addition, those two groups showed improvements in the recovery dimension activity that contains the items re-establish everyday life (RP -0.18 for rectal resection and $\mathrm{RP}-0.46$ for APR) and personal bygiene (RP - 0.19 for rectal resection and nonsignificant for APR).

\section{Regaining appetite}

Regarding the initial difficulties with food intake, patients described how they had an appetite that was considered normal six months after surgery (III). Even though they had lost some weight due to their initial eating problems, they now 
felt that they had put on undesired weight again. Restoration of food intake was also shown in the results from the PRP instrument (I), since patients both after colonic resection and APR presented improvements in the item appetite change (RP -0.35 and RP -0.32 respectively) (Table 6).

\section{Bowel function}

Patients described how the bowel function stabilised and became normal or close to normal six months after surgery (III), and how at that time the management of the stoma had become familiar. Still, for some patients, bowel emptying required certain adaptations, but those had become a part of the daily morning routine. However, the situation was shown to be different for the patients who were recovering from rectal resection (I). In the PRP item gastrointestinal function, this group showed significant deteriorations (RP 0.26), with some individual variations (RV 0.25), six months after surgery (Table 6).

Factors associated with recovery six months after surgery

Associations between patient characteristics, factors related to surgery, and recovery at a dimensional level six months after surgery, are presented in Table 9 (IV). Regarding patient characteristics, an increase in age was associated with higher odds for a good recovery six months after surgery in the dimensions physical symptoms (OR 1.099), physical functions (OR 1.121), and activity (OR 1.063). A higher grade of ASA was associated with lower odds for a good recovery in the dimensions physical symptoms (OR 0.406) and activity (OR 0.387), while a higher BMI lowered the odds in the dimension activity (OR 0.857). 
Table 9. Final models showing patient characteristics and surgery-related factors associated with recovery on a dimensional level of PRP six months after surgery (IV)

\begin{tabular}{|c|c|c|c|c|}
\hline Dimension & Factor & OR & $95 \% \mathrm{Cl}$ & P-value \\
\hline \multirow{6}{*}{ 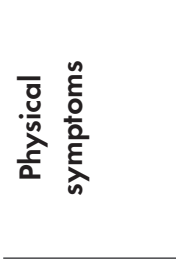 } & Age $\dagger$ & 1.099 & $1.030-1.173$ & 0.004 * \\
\hline & ASA $†$ & 0.406 & $0.176-0.935$ & 0.034 * \\
\hline & Household size $†$ & 0.272 & $0.065-1.132$ & 0.074 \\
\hline & Absence of stoma & 0.243 & $0.069-0.858$ & 0.028 * \\
\hline & Dimension physical symptoms ${ }^{2}$ & 0.122 & $0.047-0.320$ & $<0.001$ * \\
\hline & Postoperative treatment 3 & 0.152 & $0.044-0.527$ & $0.003^{*}$ \\
\hline \multirow{8}{*}{ 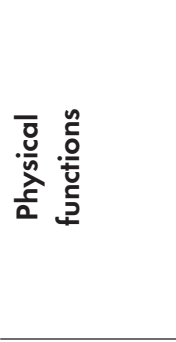 } & Age $†$ & 1.121 & $1.036-1.214$ & $0.005^{*}$ \\
\hline & ASA $\dagger$ & 0.350 & $0.108-1.127$ & 0.079 \\
\hline & $\mathrm{EQ}$ index $\dagger$ & 0.006 & $0.000-0.570$ & 0.028 * \\
\hline & $\mathrm{EQ}$ VAS $†$ & 1.492 & $0.965-2.308$ & 0.072 \\
\hline & Length of stay & 0.763 & $0.644-0.903$ & $0.002 *$ \\
\hline & Dimension physical functions 1 & 0.223 & $0.084-0.589$ & $0.002 *$ \\
\hline & Dimension physical functions ${ }^{2}$ & 0.321 & $0.145-0.712$ & $0.005^{*}$ \\
\hline & Postoperative treatment ${ }^{3}$ & 0.195 & $0.044-0.861$ & 0.031 * \\
\hline \multirow{6}{*}{ 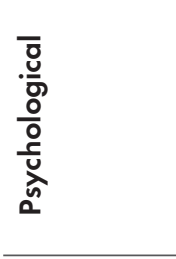 } & Trait anxiety $\dagger$ & 0.940 & $0.872-1.014$ & 0.108 \\
\hline & Gender $†$ & 0.328 & $0.069-1.547$ & 0.159 \\
\hline & Length of stay & 0.791 & $0.664-0.942$ & $0.009 *$ \\
\hline & Colostomy & 0.123 & $0.020-0.776$ & 0.026 * \\
\hline & Dimension psychological 1 & 0.078 & $0.018-0.329$ & 0.001 * \\
\hline & Postoperative treatment ${ }^{3}$ & 0.175 & $0.034-0.895$ & $0.036 *$ \\
\hline \multirow{4}{*}{$\begin{array}{l}\bar{\sigma} \\
\bar{\delta} \\
\text { c }\end{array}$} & Household size $†$ & 0.316 & $0.085-1.171$ & 0.085 \\
\hline & Absence of stoma & 0.288 & $0.076-1.086$ & 0.066 \\
\hline & Dimension social 2 & 0.217 & $0.092-0.511$ & $<0.001$ * \\
\hline & Postoperative treatment ${ }^{3}$ & 0.438 & $0.139-1.376$ & 0.158 \\
\hline \multirow{6}{*}{ 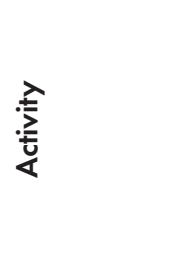 } & Age $\dagger$ & 1.063 & $1.005-1.125$ & $0.033 *$ \\
\hline & $\mathrm{BMI} \dagger$ & 0.857 & $0.749-0.981$ & $0.025^{*}$ \\
\hline & $\mathrm{ASA} \dagger$ & 0.387 & $0.156-0.962$ & 0.041 * \\
\hline & $\mathrm{EQ}$ VAS † & 1.275 & $1.027-1.584$ & 0.028 * \\
\hline & Length of stay & 0.857 & $0.758-0.968$ & $0.013^{*}$ \\
\hline & Postoperative treatment 3 & 0.231 & $0.061-0.876$ & 0.031 * \\
\hline
\end{tabular}

OR, Odds Ratio; $\mathrm{Cl}$, Confidence Interval; ASA, the American Society of Anesthesiologists' physical status classification system; BMI, Body Mass Index; PRP, Postoperative Recovery Profile. Variables were included in the final models if $p \leq 0.2$. Significance was set at $p \leq 0.05$

1 Day of discharge

21 month after surgery

${ }^{3}$ Chemotherapy

* Significant association

$\dagger$ Measured before surgery 
Regarding factors related to surgery, the LoS was associated with low odds for a good recovery in the dimensions physical functions (OR 0.763), psychological (OR 0.791), and activity (OR 0.857). Patients that were in need of additional postoperative chemotherapy had started this treatment six months after surgery. In the analysis, chemotherapy was shown as a factor that lowered the odds for a good recovery six months after surgery in the dimensions physical symptoms (OR 0.152), psychological (OR 0.175), and activity (OR 0.231).

For three of the five recovery dimensions, physical symptoms (OR 0.122), physical functions (OR 0.321), and social (OR 0.217), it was found that a poorer level of recovery one month after surgery predicted low odds for a good recovery six months after surgery in the corresponding dimension. 


\section{METHODOLOGICAL CONSIDERATIONS}

For this thesis, both quantitative and qualitative methods were applied in order to gain an understanding, a body of knowledge, in a field that is relatively unexplored. By the use of patient-reporting instruments and the additional collection of information from medical journals, the wide aspect of recovery could be described. This also allowed for comparisons showing the diverse aspects of recovery. Further, interviewing patients provided a profound insight into what it is like to recover. Together, the different methodologies complemented each other, resulting in a comprehensive description of the postoperative period after CRC surgery.

\section{Participants}

Patients were recruited from one single surgical unit. This unit is large and serves a multicultural region. In addition, it follows national guidelines regarding the care for patients with colorectal cancer (11), as well as the internationally acknowledged ERAS strategy (32). The setting can therefore be seen as comparable to others, both nationally and internationally.

The inclusion for the questionnaire data collection lasted for seventeen months. The patients were included consecutively and during a longer period of time, which enhanced the possibility to recruit patients with a variety of characteristics (I, II, IV). However, it is likely that there were patients who could not understand or complete questionnaires in Swedish. Since this was a criterion for inclusion, there is a risk that the final sample failed to reflect a multicultural population accurately. Further, no power analysis was performed because of the descriptive approach of the intended studies. Among the final eligible patients $(n=232)$, 176 patients accepted participation. Since the inclusion was missed in seven patients, this meant that 49 patients $(21 \%)$ declined participation. The reason 
for this is unknown and no explanation was requested because of the voluntary participation. In addition, no drop-out analysis was performed and therefore we do not know if those patients differed from the patients that participated.

The sample retrieved from the questionnaire data collection was divided into three groups prior to analysis, based on the fact that colorectal cancer is a heterogeneous disease (I, II). A sample is supposed to reflect the population and it is desirable that the sample in a study is large enough to reduce the risk for sampling error $(99,103)$. A small sample might not truly reflect the variation in the population. The division of the sample into three groups resulted in relatively small groups but they also became more homogenous, thus enhancing the possibility to reflect the population.

The participants for the interview data collection (III) were recruited from the same setting as for the questionnaire data collection (I, II, IV). The inclusion criterion was set because the intention was to describe the phenomenon of postoperative recovery after elective CRC surgery, and therefore patients were included if they had the experience of recovering from elective CRC surgery. According to the phenomenological methodology, a phenomenon can only be understood by how it presents itself to the person that has experienced it and that is also the prerequisite for a phenomenological study to be transferable (83). Regarding the findings from qualitative studies, it has been suggested that it is the readers that decide whether the result is transferable to their context or not (104). This decision is practicable if the researcher has provided sufficient data about the setting and the participants.

Ten patients were interviewed. Within phenomenology, the number of participants is not a priority since it is the phenomenon that is generalised, and not the sample, as in quantitative studies (83). However, since we knew that CRC is a heterogeneous disease, we wanted to include patients with different cancer sites in order to be able to reflect a possible variability in recovery. Three patients chose to withdraw before the first interview. The reason for this was that they felt too ill to be able to manage an interview. One disadvantage in collecting data through interviews is the risk that only patients who are well enough participate. As a consequence of this, the findings might only reflect the "good examples", which can affect the credibility and the transferability of the findings. However, among the patients that participated, there were two patients who suffered from complications and who were still hospitalised at the one-month interview. Therefore, not only the "good examples" were represented; on the other hand, those two patients were after all well enough to participate despite their complications. 


\section{Data collection}

Data was collected through questionnaires, extracts from medical records, and interviews. As stated above, this approach gives the opportunity to describe different aspects of postoperative recovery. The different data collections can also complement each other, resulting in a rich description enhancing generalisability/ transferability $(103,104)$. All data was collected during an extended period of time with repeated assessments before surgery, on the day of discharge, and one and six months after surgery (I, II, and IV). Interviews were performed at one and six months after surgery (III). The longitudinal approach was chosen in order to capture how recovery evolved over time (103). The absence of such information was considered a weakness in earlier research.

Despite advantages with a longitudinal data collection, there is always a risk of attrition and this risk is repeated in every assessment. In the questionnaire data collection, there was a loss of patients throughout the study period mainly because patients did not return their questionnaires. The main part of this loss occurred at the assessment on the day of discharge and was due to the fact that the ward RNs forgot to distribute the questionnaires to the patients before they were discharged. Larger samples enable a more precise evaluation (99) and, regardless of the reason, a large number of withdrawals risks making the sample small and therefore less likely to reflect the population accurately and to allow the detection of significant differences $(99,103)$. To reduce the risk of further withdrawals during the data collection period, reminders were sent twice to patients who did not return questionnaires at the one and six month assessments.

After analysis of all data, it was found that some of the patients had not yet recovered after six months and therefore it could have been of value to follow the patients until they were considered fully recovered. In addition, it was found that the period between one month and six months after surgery was a period in which recovery progressed considerably. Since no assessment or interview was made between those two points in time, there is still a lack of detailed information about the recovery during this period. Furthermore, when a long period of time elapses between two assessments, in this case five months, there is a risk that events that are external to but concurrent with recovery have happened and they may affect the memory of the recovery. Such history bias poses a threat to the credibility/internal validity (103). 


\section{Questionnaires}

For the quantitative data collection (I, II, and IV), three different instruments were used: EQ-5D-3L, STAI, and PRP. All instruments were designed for selfassessment, which gave access to patient-reported data. They were also validated and previously used in patients with CRC $(64,88,91-93)$, which enhanced the validity of the data. The combination of the three instruments was chosen in order to produce a holistic description of recovery. At the same time, to reduce the burden for the patients undergoing and recovering from major surgical procedures, it was important to use instruments that were appealing and easy to fill in. Otherwise, there might be a risk of withdrawals due to the composition of the questionnaires and the fact that patients might not have the strength to complete them.

\section{Interviews}

According to Dahlberg et al. (105), the researcher's task is to facilitate participants in telling their stories. The first author recruited the participants herself, and during the first meeting the participants had the chance to be acquainted with the researcher, which could facilitate the following, first interview. The participants were able to choose the location of the interviews. Thus, they could choose a location that was suitable for them and where they felt comfortable. The majority of the participants chose to be interviewed in their homes. The fact that they had met the researcher before might have made them more comfortable with this private location.

Participants were interviewed twice. In order to maintain the focus of the research also in the six-month interview and thereby avoid inconsistency, the same question was asked in the introduction of this interview as for the one-month interview. However, the six-month interviews became short. It seemed like the participants had begun to put the surgical and postoperative experience behind them. As the result showed, normality was back in life and it was difficult for the participants, especially for those who had not received chemotherapy, to add anything to what had been described in the one-month interview. It could also be that the experiences from the earlier recovery were so intense that they overshadowed the later, milder experiences. The amount of data that is necessary for a result to be credible depends on the complexity of the phenomenon of interest and the quality of the data (106). In this thesis, recovery was found to be complex, but the fact that the participants were interviewed twice resulted in rich descriptions and this, together with the phenomenological approach, provided an opportunity to produce credible and authentic findings, based on the participants' descriptions (104). 


\section{Patient characteristics and factors related to surgery}

Factors related to patient characteristics and surgery were collected from the patients' medical journals. The advantage of this method is that a great deal of information can be collected from one source without placing a burden on the patients, as may be the case when asking them to fill in questionnaires. However, this approach is dependent on whether the requested information has been recorded in the medical journals. Lifestyle factors, for example, are known to have an impact on postoperative complications, but such factors could not be collected since that kind of information was sparse in the medical journals.

\section{Data analysis}

The type of available data is an important aspect in the choice of statistical method, and the use of appropriate methods enhances the validity of results. Based on this, different statistical methods were used to analyse the data from the questionnaires and the extracts from medical records.

Statistical methods are used to describe relationships between variables. Even though an inquiry is not designed to hypothesise causal linkages, as for this thesis, the statistical methods are grounded in hypothesis testing. Therefore, the potential threats to statistical conclusion validity must be considered (99, 103). The statistical power decides the ability to detect relationships between variables. In small samples, the statistical power is low, posing a risk that the test for significance shows that no relationship exists even if it actually does. This is referred to as a Type II error (99). In order to describe differences in recovery between patients after different forms of CRC surgery, inferential statistics was used when analysing data from the questionnaires (I, II). However, there were withdrawals during the data collection period and this, together with the fact that the three groups became relatively small and unequal, increased the risk of a Type II error. In addition, when comparing more than two groups or assessments (II) there is a higher probability of finding a significant difference by chance, referred to as a Type I error. To avoid this risk and enhance reliability, significant values were adjusted using the Bonferroni method (99).

Among the three instruments that were used in collecting data, the EQ-5D-3L and STAI are well-known and extensively used instruments. The PRP instrument has recently been developed and at the time of data collection and analysis it had only been tested in connection with the development procedure (93). When analysing the data retrieved from this instrument, some difficulties were detected 
that could pose a threat to the reliability and validity of the results. The GSR, displaying the level of recovery, is based on the indicator sum. This is calculated by counting the items within the PRP instrument that are answered by "none", that is, no problem. However, in a scenario when a patient has answered all items by marking the option "mild" (problem), the indicator sum and, subsequently the GSR, indicate a patient that is "not at all recovered". Clinically, this patient might feel and experience him- or herself as being well recovered. This problem can be analogous to a Type II error and it exists also when calculating the dimensional level of recovery.

The analysis of the data from the interviews was made by the first author alone in order to reduce the risk of inconsistency. During analysis, the use of the phenomenological reduction and of the technique of free imaginative variations was continued. This allowed the raw data to be constantly present throughout the analysis, which enhances the confirmability and credibility of the findings (104). The analytic procedure and the pre-understanding were continuously discussed with the co-authors. The co-authors also read all transcripts from the interviews and thereby they could confirm that the final description of recovery represented the participants' narratives. 


\section{DISCUSSION OF RESULT}

The overall aim of this thesis was to describe and compare how patients recovering from different forms of colorectal cancer surgery experience their postoperative recovery, general health, and anxiety, up to six months after surgery. It was found that the postoperative recovery was a phenomenon that could be described as a progressive process. Recovery has been described in such words before this, and not least in the definition of postoperative recovery by Allvin et al. (28). The description of recovery within this thesis accords well with the definition by Allvin et al (ibid.), as it includes the features of returning to normality, regaining control over functions, and regaining independence.

The phenomenon of postoperative recovery was described in this thesis as constituted by experiences of physical powerlessness, difficulties with food intake, altered bowel function, and a dependence on others. This finding is supported by the fact that patients in other studies have described a number of postoperative symptoms that can be related to those constituents $(67-72,107,108)$. For example, symptoms such as fatigue, a feeling of weakness, and problems in mobilisation, have been reported and can be related to physical powerlessness. Nausea and inability to eat and drink can be related to difficulties with food intake. Further, in relation to the constituent "altered bowel function", symptoms such as constipation, diarrhoea, incontinence, erratic bowel movements, and difficulties in managing a stoma, have been frequently described in studies. So have symptoms related to the dependence on others, that is, the need for practical and emotional support from family and friends (ibid.).

A process that is progressive implies that there is a change, in the shape of some kind of forward movement. The pattern of change in recovery, for patients after three different types of surgical interventions, was described in the result of this 
thesis. On the day of discharge, no patient was considered fully recovered and only a few almost fully recovered, as measured by the GSR. It can be argued that a patient should not be fully or almost fully recovered when it is time to leave hospital. If that is the case, it might be that the patient has been hospitalised for too long. However, in the result of the thesis, it was shown that there was a high rate of patients among the three groups being not at all recovered, although this result should be interpreted with some cautiousness. As discussed previously, the GSR is calculated by counting the PRP items responded to by "none", that is, no problem. This means that the patients considered not at all recovered have responded to the PRP instrument with less than seven "none". It could well be that the other items were responded to with a "mild" problem but this level does not count. This leads to the risk of showing a false negative result, which poses a threat to the validity.

The pattern of change in recovery after CRC surgery was shown to be different depending on which type of surgery had been performed. From the detailed result of the PRP instrument, concerning changes in postoperative symptoms at an itemlevel, it was shown that patients after a colonic resection recovered in a number of items already during the first month. In a study by Wennstrom et al. (72), a similar result was reported. In that study, patients after a colonic resection had troubles with fatigue, nausea, defecation, and functional ability during the first four weeks after surgery. However, after four weeks, the only disturbing symptom was fatigue, and this accords well with the result from the PRP instrument in this thesis. Further, in the result from the PRP instrument, patients recovering from an APR were shown to deteriorate in recovery during the first month, but after six months they had recovered to a great extent. Patients after rectal resection seemed to have recovered acceptably after six months, but it was also clear that problems with gastrointestinal function had increased. It has been shown in other studies that rectal surgery differs from colonic surgery regarding the gastrointestinal function postoperatively. Di Fabio et al. (109) reported that patients after rectal resection more frequently had defecation-related problems, such as incontinence, pain, or a feeling of incomplete evacuation, during the first year after surgery, compared to patients after colonic resection. Tsunoda et al. (65) showed that constipation was worse for patients after rectal resection than after colonic resection in seven out of twelve monthly assessments (4-6 months and 9-12 months). It is a well-known fact that rectal resection procedures are associated with problems concerning defecation, including faecal incontinence, frequent bowel movements, urgency, and emptying difficulties. This is mentioned as the Low Anterior Resection Syndrome, LARS, affecting mainly patients with a low anastomosis (110-112). It has been 
described how LARS symptoms are prominent during the first year after surgery and how this affects the QoL (113). For the patients who were recovering from rectal resection in this thesis, it is not clear exactly which form of rectal resection had been performed. It could be that the problems were caused by other things than the LARS. Many patients undergoing a rectal resection receive a temporary loop ileostomy in order to protect the anastomosis while it is healing. After two to four months, this type of stoma is supposed to be reversed. However, it has been reported that the bowel function can be troublesome after a stoma reversal. In a review study by Taylor and Morgan (114), it was found that bowel function was the principle concern for patients six weeks after a stoma reversal. It was also shown that gastrointestinal problems, similar to those in the LARS, could last for up to a year. Based on this, it is possible that the problems with gastrointestinal function, shown in this thesis, could be caused by a recent stoma reversal. A third possibility is that the patients' loop ileostomies had not yet been reversed. In that case, the deterioration in gastrointestinal function could be a reflection of practical or emotional problems associated with the loop ileostomy.

The result in this thesis showed that the patients, without any difference between the three groups, had a high level of health preoperatively, as displayed by the EQ index (II). However, when the patients rated their level of health on the EQ VAS, lower levels of health were shown. It could also be seen that there were differences between groups. Even though the results from the two parts of the EQ-5D-3L instrument are not supposed to be equivalent, it could be argued that they should be at least similar. In addition, after analysing the association between the EQ index and recovery six months after surgery (IV), the result became difficult to explain, as a better health was shown to be associated with a poor recovery. The instrument EQ-5D-3L is known to have some shortcomings (115) and the erratic results described above could be a consequence of this. The five dimensions in the first part of the instrument have three levels of responses. A patient can improve or deteriorate in a dimension but not so much that he or she reaches a higher or lower level, and this makes the instrument less sensitive to smaller changes in health (115). Further, the EQ index is calculated using a health status that is derived from the scores in the five dimensions in the instrument. It could be that the results regarding the EQ index become too high or too low as a consequence of the sensitivity problems. Considering this, the result from the EQ index in this thesis should be accepted with some reservations. A new version of the instrument has been developed, with five levels of response - EQ-5D-5L - but when the data collection for the thesis was performed, this version was not available in Swedish. 
The additional aim of this thesis was to describe the influence of patient- and surgery-related factors on patient-reported recovery. The result showed that some factors that are related to patient characteristics, as well as to surgery, were associated with the level of recovery in various dimensions both at one and six months after surgery. However, the factors were not unambiguously associated with one specific dimension, which points to the complexity of recovery. One of the factors, namely, age, was found to be positively associated with recovery, that is, a higher age was associated with a better recovery. This association was found regarding the dimensions physical symptoms, physical functions, and activity, at six months after surgery. The result was unexpected, since previous research has reported that the risk of a prolonged LoS, 30-day morbidity, and 30-day mortality, increases in patients with a high age $(51,52)$. One explanation of the result in this thesis could be that the older patients have had a slowly growing tumour at a site where it has been developing for a long time without giving any typical symptoms. For example, tumours located in the right side of the colon usually do not manifest until they have grown large in size and thereby obstruct the colon. Until then, subtle symptoms, such as anaemia, fatigue, or abdominal pain, have developed. It has been proposed that atypical or vague symptoms may lead to the risk that a person does not contact the health care because of a misinterpretation of the symptoms (116). In addition, older patients might perceive the symptoms as normal in the ageing process, especially if the symptoms develop slowly (117). Nevertheless, even if the symptoms might be vague, it could well be that they lead to deteriorations in items within the dimensions physical symptoms, physical functions, and activity already prior to surgery. After the tumour had been removed, it could therefore be that the older patients in this thesis, with more general preoperative symptoms, perceived their recovery as better than the younger patients did because of the general symptom relief. Another explanation could be that there is a difference in how the outcome was defined and measured. In this thesis, patient-reported recovery was used as an outcome measure, while the two previous studies used LoS, 30-day mortality, and morbidity. Recovery and LoS or 30-mortality/morbidity are not the same thing, which might be exemplified by the contradictory results regarding age between this thesis and earlier research. Although previous research has pointed out some characteristics that affect LoS, this does not necessarily mean that patients with those characteristics are also at risk for a poor recovery. This further emphasises the importance of using appropriate measurements when evaluating recovery. 
Altogether, this thesis describes postoperative symptoms that are common, or even general, for patients recovering from CRC surgery. The result also shows how postoperative symptoms, as well as health and anxiety, change during the recovery process and how the process differs between patients recovering from different colorectal surgical procedures. Usually, patients do not have any personal experience of what it is like to recover from CRC surgery. Therefore, it can be difficult for them to predict how possible postoperative symptoms might affect them in their daily lives. It is important that information about postoperative symptoms and experiences is included in the preoperative information to patients, so that they can be prepared for it and thereby avoid unnecessary concerns. The knowledge gained from this thesis can facilitate for RNs in providing patients with such information. One cornerstone in PCC is to respond to patients' needs and involve them in defining their needs (76-78). When caring for patients in a person-centred manner, the RN should listen to the patients' narratives of how the cancer diagnosis and, subsequently, surgery and possible impairments during the recovery after surgery, affect them in their daily lives (76). In a situation where the RN, based on, for example, a patient's characteristics, knows that the patient under care is at risk for a poor recovery, this is an opportunity to discuss such issues with the patient. Together with the patients, and preferably also their relatives, it is then possible to find strategies and to empower the patients to be able to cope with postoperative symptoms that might restrict them from being independent, living a normal life, and being in control of their situation. 


\section{CONCLUSIONS}

Postoperative recovery after CRC surgery was described as a progressive process. It was also shown to be different, on a detailed level, depending on which type of surgery had been performed. Nevertheless, common to all patients were experiences of physical powerlessness, difficulties with food intake, altered bowel function, and a dependence on others. Those experiences were most intense in the beginning of recovery.

No patient was considered fully or even almost fully recovered on the day of discharge. It was shown that the group of patients after colonic resection recovered faster than patients after rectal resection or APR, especially during the first month after surgery. In that period of time, the group demonstrated improvements in the majority of measured items. Patients after APR deteriorated somewhat in recovery during the first month.

Six months after surgery, the experiences described above had gradually disappeared and the patients felt that everyday life had returned to a great extent. At this point in time, it was shown that the proportion of patients considered fully or almost fully recovered had increased. Concerning the period between one and six months after surgery, patients after rectal resection and APR demonstrated improvements regarding half of the items. However, gastrointestinal function in patients after rectal resection had deteriorated.

Health and anxiety were not shown to be of any concern for the three groups of patients. The only difference between groups occurred preoperatively, as patients planned for APR rated their health as higher than the two other groups did. Patients after rectal resection and APR had a temporary reduction in EQ index one month after surgery, compared to preoperative values. In the same period of 
time, patients after colonic resection improved significantly regarding EQ VAS. Six months after surgery, health in all groups had returned to levels similar to, or better than, preoperative values. Anxiety was low during the whole study period, without any difference between measurements.

It was also shown that recovery could be predicted at a dimensional level using patient characteristics and factors related to surgery. Patient characteristics associated with recovery were age, grade of ASA, EQ VAS, EQ index, and BMI. Factors related to surgery were duration of surgery, APR procedure, presence of stoma, LoS, and postoperative treatment. In addition, the dimensional levels of recovery could to a great extent predict recovery in corresponding dimensions. 


\section{CLINICAL IMPLICATIONS AND FUTURE RESEARCH}

When adopting a person-centred care, RNs should invite each patient to discuss how recovery generally proceeds and what symptoms or experiences are likely to occur or remain for that individual person. This thesis provides a base of knowledge for health care professionals caring for patients undergoing surgery due to colorectal cancer. Together, and preferably also together with relatives, the patient and the RN should set an agenda for the individual needs during recovery. It is important to initiate those conversations already before surgery and to continue with them during hospitalisation. Including patients in their own care can empower them to cope with postoperative symptoms or obstacles in the daily living after discharge. The results from this thesis make it clear that follow-up routines need to be individualised and formulated together with the patient and, preferably, his or her relatives, as the pattern of recovery differs between patients.

A number of proposals for future research generated by the results from this thesis are the following:

The PRP instrument was recently developed. It has been shown to have some shortcomings, especially regarding analysis of the result. Therefore, it needs to be further evaluated concerning the usability for both clinical and research purposes.

Knowledge about the time between one and six months after CRC surgery is still lacking. It would be of value to describe recovery during this period of time but also the period after six months. 
Recovery was shown to be intensely progressing for some patients but regressing for others, during the first month after surgery. Since the patients are hospitalised a minor part of this period, it would be of interest to describe recovery in this period as well as the variation between patients recovering from different types of CRC surgery.

This thesis describes recovery in patients undergoing common surgical procedures. In patients with a more invasive CRC, far more extensive and complicated procedures are performed. Recovery, as approached in this thesis, is unexplored for this group of patients, which is why it would be of great value to describe also their recovery. 


\section{POPULÄRVETENSKAPLIG SAMMANFATTNING}

Att drabbas av cancer kan framkalla känslor av chock, misstro, rädsla och en osäkerhet inför framtiden. Att drabbas av kolorektal cancer, cancer i tjock- eller ändtarm, innebär dessutom att man upplever obehagliga symtom, såsom ändrade avföringsvanor, rektalblödningar, magsmärtor, viktnedgång eller trötthet.

Varje år drabbas ungefär 1,4 miljoner män och kvinnor i världen av kolorektal cancer. Sjukdomen utgör därmed den tredje vanligaste cancersjukdomen efter lungcancer och bröstcancer. I Sverige drabbas årligen drygt 6000 personer, men så länge tumören upptäcks på ett tidigt stadium räknas kolorektal cancer som botbar om den opereras bort. Vilken typ av operation som blir aktuell beror på var på tarmen tumören sitter. Den del av tarmen där tumören finns opereras bort, tillsammans med de dränerande lymfkörtlarna som hör till den delen av tarmen.

En person som återhämtar sig efter att ha blivit opererad på grund av kolorektal cancer upplever sannolikt såväl postoperativa symtom som en psykologisk påfrestning vilket påverkar livet $\mathrm{i}$ varierande utsträckning. Eftersom vårdtiderna i dag är korta, befinner sig patienterna i hemmet under den största delen av sin återhämtning. Detta innebär en utmaning inte bara för patienterna utan även för sjukvårdspersonalen, som behöver förbereda patienterna både inför deras operation och inför tiden efter operation då patienterna befinner sig utanför sjukvården. För att kunna göra detta är det nödvändigt att sjukvårdspersonalen har kunskap om återhämtningen i sin helhet. 
Tidigare studier har beskrivit hur cancerdiagnosen upplevdes som att den rev sönder livsvärlden för den drabbade. Symtom, medicinska procedurer och sjukhusrutiner underminerade patienternas känsla av autonomi och självförtroende. Att bli utskriven från sjukhus efter operation har beskrivits som en viktig milstolpe $\mathrm{i}$ återhämtningen. Men trots att patienterna varit ivriga att återta sitt oberoende och sin autonomi efter operationen och sjukhusvistelsen, har de också varit tvungna att hantera postoperativa symtom själva, vilket förorsakat osäkerhet och oro. Deras uppmärksamhet riktades mot kroppen, hur den fungerade, liksom mot frekvensen och intensiteten av kroppsliga symtom. Fysiska symtom, såsom illamående, trötthet, andfåddhet och en störd tarmfunktion, har ofta beskrivits i studier om postoperativ återhämtning. En brist på kunskap om vad som är att beteckna som normalt under återhämtningen kan orsaka en ambivalens angående huruvida symtomen rättfärdigar att kontakta sjukvården. I dag används ofta vårdkoncept där patienterna kan skrivas ut efter några få dagar. Det har dock beskrivits att det kan vara svårt för patienterna att ta till sig information under dessa första dagar efter operation på grund av att de är omtöcknade och har svårt att koncentrera sig. Det har också beskrivits att det är svårt att komma i kontakt med sjukvården efter utskrivning, vilket lämnar patienterna i en sårbar situation.

Det övergripande syftet med denna avhandling var att beskriva och jämföra hur patienter som återhämtar sig efter kolorektal cancerkirurgi upplever sin återhämtning efter operation, sin generella hälsa samt sin oro, upp till sex månader efter operation. Vidare avsågs att beskriva patient- och kirurgirelaterade faktorers påverkan på patientrapporterad återhämtning.

Samtliga patienter som inkluderades i de delstudier som ligger till grund för avhandlingen blev opererade på grund av cancer i tjocktarm eller ändtarm och vårdades därefter på en kirurgisk avdelning specialiserad på kolorektal kirurgi. Insamling av data genomfördes på olika sätt. En enkät bestående av tre olika instrument som mätte postoperativ återhämtning, generell hälsa samt oro, både som karaktärsdrag och i stunden, delades ut före operation, på utskrivningsdagen samt en och sex månader efter operation. Till detta genomfördes en journalgranskning för att samla data angående faktorer kopplade till patienternas karaktäristika liksom till själva kirurgin. Insamlade uppgifter användes till delstudie I, II och IV. Totalt 176 patienter tackade ja till att delta i enkätundersökningen med tillhörande journalgranskning. I två av delstudierna (studie I och II) delades patienterna upp i tre grupper beroende på vilken typ av kirurgi de genomgått. De tre grupperna bestod av patienter som genomgått rektumresektion, rektumamputation 
respektive kolonresektion. För att kunna beskriva återhämtningen mer ingående genomfördes också intervjuer med tio patienter både en och sex månader efter operation. Resultatet från dessa intervjuer utgjorde delstudie III.

I den första delstudien beskrevs hur den postoperativa återhämtningen förändrades från utskrivningsdagen till en och sex månader efter operation. En statistisk metod speciellt utvecklad för att hantera kategorisk data användes, kallad Svenssons metod. Dessutom beskrevs återhämtningen vid de tre olika tillfällena med hjälp av en global återhämtningsskala, där patienterna tillskrevs en återhämtningsnivå baserad på hur mycket symtom de uppgav att de besvärades av vid de olika tillfällena. Resultatet visade att inga patienter kunde anses som helt eller delvis återhämtade på utskrivningsdagen. Därefter syntes att de patienter som genomgått en kolonresektion förbättrades gällande merparten av postoperativa symtom redan under den första månaden efter operation, medan de patienter som genomgått en rektumamputation försämrades något. Patienter efter en rektumresektion återhämtade sig bättre under den första månaden än de efter en rektumamputation men inte lika bra som patienterna efter en kolonresektion. Under perioden mellan en månad och sex månader efter operation kunde man se förbättringar i återhämtningen för samtliga patienter och speciellt för de som genomgått rektumamputation. Däremot kunde man också se att patienter efter rektumresektion inte hade återhämtat sig i samma utsträckning som de två andra patientgrupperna.

I den andra delstudien beskrevs generell hälsa och oro som tillstånd för de tre patientgrupperna vid mättillfällena före operation, på utskrivningsdagen (endast oro som tillstånd) samt en och sex månader efter operation. Dessa parametrar jämfördes både mellan patientgrupperna och inom patientgrupperna mellan de olika mättillfällena. Beskrivande och jämförande statistik användes för att bearbeta materialet. Det visade sig att samtliga patientgrupper hade en god hälsa före operation. Mellan grupperna skiljde det sig endast då patienterna själva hade graderat sin hälsa på en tiogradig skala. I det fallet hade de patienter som skulle genomgå en rektumamputation en signifikant bättre hälsa jämfört med de andra två grupperna. I övrigt fanns det inga skillnader mellan patientgrupperna vid något mättillfälle. Däremot kunde man se att hälsan hos de patienter som sedermera genomgick rektumresektion och rektumamputation hade försämrats en månad efter operationen. Denna försämring var tillfällig och sex månader efter operation hade de, liksom patienterna efter kolonresektion, uppnått en hälsa som var likvärdig med eller bättre än den var före operationen. Vad gäller oro som 
tillstånd fanns det ingen skillnad mellan patientgrupperna vid något mättillfälle. Däremot syntes det att de patienter som genomgått en kolonresektion var signifikant mindre oroliga på utskrivningsdagen jämfört med före operationen.

De intervjuer som gjordes med tio patienter en månad och sex månader efter operation användes till den tredje delstudien för att beskriva den upplevda erfarenheten av att återhämta sig efter kolorektal cancerkirurgi. Intervjuerna analyserades med en kvalitativ metod, fenomenologi, där patienternas autentiska beskrivning av återhämtningen, uttryckt som den generella strukturen av ett fenomen, är central utan att den person som analyserar intervjuerna gör en tolkning av det som beskrivits. Den postoperativa återhämtningen beskrevs av patienterna i den tredje delstudien som en framåtskridande process. Upplevelser av fysisk kraftlöshet, svårigheter med matintag, förändrad tarmfunktion och ett beroende av andra var framträdande och förändrades från att vara intensiva i början av återhämtningen till att minska allt eftersom tiden gick. Då patienterna kom hem från sjukhuset upplevde de en fortsatt svårighet att få i sig mat, och den fysiska kraftlösheten gjorde att de i början var beroende av familj och vänner för att klara vardagslivet. Tarmfunktionen såväl som den praktiska hanteringen av en eventuell stomi orsakade känslor såsom osäkerhet och oro. Sex månader efter operationen hade den fysiska kraftlösheten däremot minskat till att vara i princip helt borta och aptiten upplevdes som normal. Tarmfunktionen hade stabiliserats och patienterna med en stomi hade vant sig vid hanteringen av stomin.

Materialet från enkätundersökningen samt journalgranskningen låg till grund även för den fjärde delstudien. Här avsågs att beskriva den påverkan olika faktorer, som hör ihop med patientkaraktäristika samt det kirurgiska ingreppet, har på återhämtningen en månad respektive sex månader efter operation. Som utfallsvariabler i en sambandsanalys användes för varje mättillfälle (en månad respektive sex månader) fem olika dimensioner av återhämtning, vilka kunde erhållas från återhämtningsinstrumentet. I resultatet framkom att faktorer såsom en bättre hälsa och ett högre BMI var associerade med en god återhämtning i flera dimensioner en månad efter operation, medan en högre ASA-grad, längre vårdtid, längre operationstid, förekomst av en kolostomi eller loop-ileostomi, liksom ingreppet rektumamputation var associerade med en sämre återhämtning vid samma tidpunkt. Dessutom kunde man se att i de fall då patienterna befanns vara sämre återhämtade i en dimension den dag de skrevs ut från sjukhuset, var detta associerat med en sämre återhämtning för den dimensionen även en månad efter operation. Detta gällde för samtliga dimensioner. Vid mättillfället sex 
månader efter operation kunde man se att en högre ålder och en bättre hälsa var associerat med en god återhämtning i olika dimensioner. Däremot var en högre ASA-grad, längre vårdtid, postoperativ behandling, förekomsten av en kolostomi men också frånvaron av en stomi associerat med en sämre återhämtning. I tre av de fem återhämtningsdimensionerna kunde man, också vid detta mättillfälle, se att de patienter som var sämre återhämtade i en dimension en månad efter operation även var dåligt återhämtade i samma dimension efter sex månader.

Det sammanlagda resultatet från denna avhandling visar att återhämtningsmönstret skiljer sig åt mellan patienter. Icke desto mindre finns det också en del likheter. Detta beskriver komplexiteten i den postoperativa återhämtningen. Som beskrivits är återhämtningsperioden, speciellt den första månaden efter operation, en period med många förändringar. Ibland är dessa förändringar till det bättre men ibland också till det sämre. För att undvika onödig oro hos patienterna är det viktigt att sjukvårdspersonalen finns med som ett stöd för patienterna och förser dem med den information de behöver genom hela återhämtningsperioden. Det är också viktigt att det finns en möjlighet att utforma uppföljningsrutiner som är baserade på patienternas individuella behov. 


\section{ACKNOWLEDGEMENTS}

I would like to thank the Department of Care Science at the Faculty of Health and Society, Malmö University, for giving me the opportunity to write this thesis. Also, I wish to express my sincere gratitude to:

My main supervisor Christine Kumlien, Professor at the Department of Care Science. You have shown me the way not only during my research education but also during many years before that. Thank you for your time, support, and guidance.

My co-supervisor Ewa Idvall, also Professor at the Department of Care Science. Thank you for believing in me, for your encouragement, good advice, and support.

Hafrún Finnbogadóttir and Mia Hylén for your thorough work reading and commenting on the draft for the thesis.

Cecilia Faritzson, senior area manager at the Department of Surgery, Skåne University Hospital. You were the one who got me into this from the beginning when you asked me if I wanted to become a Research Trainee. Since then, you have always been supportive. For this I am grateful and I am sorry if I have caused you some extra work occasionally.

Lars Wablgren, statistician and Director of Studies at the Department of Statistics, Lund University. Thank you for making logistic regression comprehensible.

Katarina Graah-Hagelbäck for your fantastic work revising the English text both in the thesis and in paper IV. It has been a pleasure to work with you. 
Renée Allvin, School of Medical Sciences, Örebro University, "mother" of the PRP instrument. Thank you for letting me use the PRP instrument and for all support and good advice along the way.

My doctoral colleagues and senior lecturers at the Department of Care Science for all your support, for the laughter we have shared, and not least for reading and commenting on my manuscripts.

Anna, Lena, and Marika, contact nurses at the surgical outpatient clinic in Malmö. Thank you for helping me with the inclusion of patients.

Colleagues and ward managers at the Department of Surgery for your interest and support and also for your help during data collection.

Monzer El-Dakkak and Vedran Boscovic for your patience and for calming me down when I don't understand IT, Helena Bogazzi for your help with all practical matters, Maria Brandström for the help with the layout of the thesis, and Mikael Matteson for reading and commenting on the popular science summary.

All of my friends and my in-laws.

Peter, my husband.

Lukas and Emma, my children. I love you to the end of the universe and back. 


\section{REFERENCES}

1. American Society of Anesthesiologists. American Society of Anesthesiologists (ASA) physical status classification system. 2014 [http://www.asahq.org/resources/clinicalinformation/asa-physical-status-classification-system] Accessed 2016, 05/26.

2. World Health Organization. BMI Classification. 2016 [http://apps.who.int/bmi/index. jsp? introPage=intro_3.html] Accessed 2016, 10/28.

3. The National Board of Health and Welfare. Nationella riktlinjer för bröst-, prostata-, tjocktarms- och ändtarmscancervård. Stöd för styrning och ledning. The National Board of Health and Welfare; 2014.

4. Moene M, Bergbom I, Skott C. Patients' existential situation prior to colorectal surgery. J Adv Nurs. 2006; 54: 199-207.

5. Shaha M, Cox CL. The omnipresence of cancer. Eur J Oncol Nurs. 2003; 7: 191-196.

6. Worster B, Holmes S. The preoperative experience of patients undergoing surgery for colorectal cancer: a phenomenological study. Eur J Oncol Nurs. 2008; 12: 418-424.

7. Debas HT. Gastrointestinal Surgery. Pathophysiology and Management. Springer e-books. 2004.

8. Burkitt HG, Quick CRG, Reed JB. Essential Surgery. Problems, diagnosis and management. London: Elsevier Ltd; 2007.

9. Pawa N, Cathcart PL, Arulampalam TH, Tutton MG, Motson RW. Enhanced recovery program following colorectal resection in the elderly patient. World J Surg. 2012; 36: 415-423.

10. Delaney CP, Fazio VW, Senagore AJ, Robinson B, Halverson AL, Remzi FH. 'Fast track' postoperative management protocol for patients with high co-morbidity undergoing complex abdominal and pelvic colorectal surgery. Br J Surg. 2001; 88: 1533-1538.

11. Regionala Cancercentrum i samverkan. Gällande vårdprogram tjock- och ändtarmscancer. 2016 [http://www.cancercentrum.se/samverkan/cancerdiagnoser/tjockoch-andtarm/vardprogram/gallande-vardprogram/] Accessed 2016, 09/14. 
12. Mulholland MW. (Edt) Greenfield's surgery: Scientific principles and practice: Fifth edition. Philadelphia: Lippincott Williams and Wilkins; 2010.

13. Levine JS, Ahnen DJ. Clinical practice. Adenomatous polyps of the colon. N Engl J Med. 2006; 355: 2551-2557.

14. The National Board of Health and Welfare. Cancerincidens i Sverige- Nya diagnosticerade cancerfall år 2014. The National Board of Health and Welfare; 2015.

15. Ferlay J, Soerjomataram I, Dikshit R, Eser S, Mathers C, Rebelo M et al. Cancer incidence and mortality worldwide: sources, methods and major patterns in GLOBOCAN 2012. Int J Cancer. 2015; 136: E359-86.

16. Engholm G, Ferlay J, Christensen N, Kejs AMT, Hertzum-Larsen R, Johannesen TB et al. NORDCAN: Cancer incidence, mortality, prevalence and survival in the nordic countries. Association of the Nordic Cancer Registries. Danish Cancer Society. 2016 [http://www-dep.iarc.fr/NORDCAN/english/frame.asp] Accessed 2016, 09/07.

17. Aran V, Victorino AP, Thuler LC, Ferreira CG. Colorectal cancer: Epidemiology, disease mechanisms and interventions to reduce onset and mortality. Clin Colorectal Cancer. 2016; 15: 195-203.

18. Center MM, Jemal A, Smith RA, Ward E. Worldwide variations in colorectal cancer. CA Cancer J Clin. 2009; 59: 366-378.

19. Pericleous M, Mandair D, Caplin ME. Diet and supplements and their impact on colorectal cancer. J Gastrointest Oncol. 2013; 4: 409-423.

20. Wang Y, Duan H, Yang H, Lin J. A pooled analysis of alcohol intake and colorectal cancer. Int J Clin Exp Med. 2015; 8: 6878-6889.

21. Kim E, Coelho D, Blachier F. Review of the association between meat consumption and risk of colorectal cancer. Nutr Res. 2013; 33: 983-994.

22. Walter V, Jansen L, Hoffmeister M, Ulrich A, Chang-Claude J, Brenner H. Smoking and survival of colorectal cancer patients: population-based study from Germany. Int J Cancer. 2015; 137: 1433-1445.

23. Regionala Cancercentum i Samverkan. Tjock- och ändtarmscancer. Beskrivning av standardiserat vårdförlopp. 2015 [http://www.cancercentrum.se/globalassets/ cancerdiagnoser/tjock-och-andtarm/vardforlopp/standardiserat_vardforlopp_tjockandtarm_20151221.pdf] Accessed 2016, 09/15.

24. Beech N, Arber A, Faithfull S. Restoring a sense of wellness following colorectal cancer: a grounded theory. J Adv Nurs. 2012; 68: 1134-1144.

25. Aasa A, Hovback M, Bertero CM. The importance of preoperative information for patient participation in colorectal surgery care. J Clin Nurs. 2013; 22: 1604-1612.

26. Neville A, Lee L, Antonescu I, Mayo NE, Vassiliou MC, Fried GM et al. Systematic review of outcomes used to evaluate enhanced recovery after surgery. Br J Surg. 2014; 101: 159-170.

27. Korttila K. Recovery from outpatient anaesthesia. Anaesthesia. 1995; 50: 22-28.

28. Allvin R, Berg K, Idvall E, Nilsson U. Postoperative recovery: a concept analysis. J Adv Nurs. 2007; 57: 552-558. 
29. Thorell A, Nygren J, Ljungqvist O. Insulin resistance: a marker of surgical stress. Curr Opin Clin Nutr Metab Care. 1999; 2: 69-78.

30. Feldman LS, Delaney CP, Ljungqvist O, Carli F. (eds) The SAGES/ERAS Society manual of enhanced recovery programs for gastrointestinal surgery. Switzerland: Springer International Publishing; 2015.

31. Kehlet H, Wilmore DW. Evidence-based surgical care and the evolution of fast-track surgery. Ann Surg. 2008; 248: 189-198.

32. Fearon KC, Ljungqvist O, Von Meyenfeldt M, Revhaug A, Dejong CH, Lassen K et al. Enhanced recovery after surgery: a consensus review of clinical care for patients undergoing colonic resection. Clin Nutr. 2005; 24: 466-477.

33. Nygren J, Thacker J, Carli F, Fearon KC, Norderval S, Lobo DN et al. Guidelines for perioperative care in elective rectal/pelvic surgery: Enhanced Recovery After Surgery (ERAS®) Society recommendations. World J Surg. 2013; 37: 285-305.

34. Gustafsson UO, Scott MJ, Schwenk W, Demartines N, Roulin D, Francis N et al. Guidelines for perioperative care in elective colonic surgery: Enhanced Recovery After Surgery (ERAS®) Society recommendations. World J Surg. 2013; 37: 259-284.

35. Ren L, Zhu D, Wei Y, Pan X, Liang L, Xu J et al. Enhanced Recovery After Surgery (ERAS) program attenuates stress and accelerates recovery in patients after radical resection for colorectal cancer: a prospective randomized controlled trial. World J Surg. 2012; 36: 407-414.

36. Varadhan KK, Neal KR, Dejong CH, Fearon KC, Ljungqvist O, Lobo DN. The enhanced recovery after surgery (ERAS) pathway for patients undergoing major elective open colorectal surgery: a meta-analysis of randomized controlled trials. Clin Nutr. 2010; 29: 434-440.

37. ERAS Compliance Group. The impact of enhanced recovery protocol compliance on elective colorectal cancer resection: Results from an international registry. Ann Surg. 2015; 261: 1153-1159.

38. King PM, Blazeby JM, Ewings P, Longman RJ, Kipling RM, Franks PJ et al. The influence of an enhanced recovery programme on clinical outcomes, costs and quality of life after surgery for colorectal cancer. Colorectal Dis. 2006; 8: 506-513.

39. Basse L, Hjort Jakobsen D, Billesbolle P, Werner M, Kehlet H. A clinical pathway to accelerate recovery after colonic resection. Ann Surg. 2000; 232: 51-57.

40. Kehlet H, Mogensen T. Hospital stay of 2 days after open sigmoidectomy with a multimodal rehabilitation programme. Br J Surg. 1999; 86: 227-230.

41. Ramos MI, Cardoso MJ, Vaz F, Torres MD, Garcia F, Blanco G et al. Influence of the grade of anxiety and level of cortisol on post-surgical recovery. Actas Esp Psiquiatr. 2008; 36: 133-137.

42. Kiecolt-Glaser JK, Marucha PT, Malarkey WB, Mercado AM, Glaser R. Slowing of wound healing by psychological stress. Lancet. 1995; 346: 1194-1196. 
43. Ebrecht M, Hextall J, Kirtley LG, Taylor A, Dyson M, Weinman J. Perceived stress and cortisol levels predict speed of wound healing in healthy male adults. Psychoneuroendocrinology. 2004; 29: 798-809.

44. Doering LV, Moser DK, Lemankiewicz W, Luper C, Khan S. Depression, healing, and recovery from coronary artery bypass surgery. Am J Crit Care. 2005; 14: 316-324.

45. Tindle H, Belnap BH, Houck PR, Mazumdar S, Scheier MF, Matthews KA et al. Optimism, response to treatment of depression, and rehospitalization after coronary artery bypass graft surgery. Psychosom Med. 2012; 74: 200-207.

46. Bosch JA, Engeland CG, Cacioppo JT, Marucha PT. Depressive symptoms predict mucosal wound healing. Psychosom Med. 2007; 69: 597-605.

47. Sharma A, Sharp DM, Walker LG, Monson JR. Patient personality predicts postoperative stay after colorectal cancer resection. Colorectal Dis. 2008; 10: 151-156.

48. Yilmaz M, Sezer H, Gurler H, Bekar M. Predictors of preoperative anxiety in surgical inpatients. J Clin Nurs. 2012; 21: 956-964.

49. Spielberger CD. State-Trait Anxiety Inventory for Adults. Manual, Instrument and Scoring guide. 1983.

50. Shahmansouri N, Janghorbani M, Salehi Omran A, Karimi AA, Noorbala AA, Arjmandi A et al. Effects of a psychoeducation intervention on fear and anxiety about surgery: randomized trial in patients undergoing coronary artery bypass grafting. Psychol Health Med. 2014; 19: 375-383.

51. Feroci F, Lenzi E, Baraghini M, Garzi A, Vannucchi A, Cantafio S et al. Fast-track surgery in real life: how patient factors influence outcomes and compliance with an enhanced recovery clinical pathway after colorectal surgery. Surg Laparosc Endosc Percutan Techniq. 2013; 23: 259-265.

52. Hendry PO, Hausel J, Nygren J, Lassen K, Dejong CH, Ljungqvist O et al. Determinants of outcome after colorectal resection within an enhanced recovery programme. Br J Surg. 2009; 96: 197-205.

53. Ahmed J, Lim M, Khan S, McNaught C, Macfie J. Predictors of length of stay in patients having elective colorectal surgery within an enhanced recovery protocol. Int J Surg. 2010; 8: 628-632.

54. Francis NK, Mason J, Salib E, Allanby L, Messenger D, Allison AS et al. Factors predicting 30-day readmission after laparoscopic colorectal cancer surgery within an enhanced recovery programme. Colorectal Dis. 2015; 17: O148-54.

55. Althumairi AA, Canner JK, Gearhart SL, Safar B, Sacks J, Efron JE. Predictors of perineal wound complications and prolonged time to perineal wound healing after abdominoperineal resection. World J Surg. 2016; 40: 1755-1762.

56. Sorensen LT, Jorgensen T, Kirkeby LT, Skovdal J, Vennits B, Wille-Jorgensen P. Smoking and alcohol abuse are major risk factors for anastomotic leakage in colorectal surgery. Br J Surg. 1999; 86: 927-931.

57. Nickelsen TN, Jorgensen T, Kronborg O. Lifestyle and 30-day complications to surgery for colorectal cancer. Acta Oncol. 2005; 44: 218-223. 
58. Amri R, Bordeianou LG, Sylla P, Berger DL. Obesity, outcomes and quality of care: body mass index increases the risk of wound-related complications in colon cancer surgery. Am J Surg. 2014; 207: 17-23.

59. Allvin R, Svensson E, Rawal N, Ehnfors M, Kling AM, Idvall E. The Postoperative Recovery Profile (PRP)- a multidimensional questionnaire for evaluation of recovery profiles. J Eval Clin Pract. 2011; 17: 236-243.

60. Marventano S, Forjaz M, Grosso G, Mistretta A, Giorgianni G, Platania A et al. Health related quality of life in colorectal cancer patients: state of the art. BMC Surg. 2013; 13 Suppl 2: S15-2482-13-S2-S15.

61. Cella DF. Quality of life: concepts and definition. J Pain Symptom Manage. 1994; 9: 186-192.

62. Fayers P, Hays R. (eds) Assessing quality of life in clinical trials: Analysis and interpretation. New York: Oxford University Press; 2005.

63. Smith-Gagen J, Cress RD, Drake CM, Romano PS, Yost KJ, Ayanian JZ. Quality-oflife and surgical treatments for rectal cancer-a longitudinal analysis using the California Cancer Registry. Psychooncology. 2010; 19: 870-878.

64. Brown SR, Mathew R, Keding A, Marshall HC, Brown JM, Jayne DG. The impact of postoperative complications on long-term quality of life after curative colorectal cancer surgery. Ann Surg. 2014; 259: 916-923.

65. Tsunoda A, Nakao K, Hiratsuka K, Tsunoda Y, Kusano M. Prospective analysis of quality of life in the first year after colorectal cancer surgery. Acta Oncol. 2007; 46: 7782.

66. Tengland PA. A two-dimensional theory of health. Theor Med Bioeth. 2007; 28: $257-$ 284.

67. Norlyk A, Harder I. Recovering at home: participating in a fast-track colon cancer surgery programme. Nurs Inq. 2011; 18: 165-173.

68. Worster B, Holmes S. A phenomenological study of the postoperative experiences of patients undergoing surgery for colorectal cancer. Eur J Oncol Nurs. 2009; 13: 315 322.

69. Taylor C, Richardson A, Cowley S. Restoring embodied control following surgical treatment for colorectal cancer: a longitudinal qualitative study. Int J Nurs Stud. 2010; 47: 946-956.

70. Jonsson CA, Stenberg A, Frisman GH. The lived experience of the early postoperative period after colorectal cancer surgery. Eur J Cancer Care. 2011; 20: 248-256.

71. Krogsgaard M, Dreyer P, Egerod I, Jarden M. Post-discharge symptoms following fast-track colonic cancer surgery: a phenomenological hermeneutic study. Springerplus. 2014; 3: 276-1801-3-276.

72. Wennstrom B, Stomberg MW, Modin M, Skullman S. Patient symptoms after colonic surgery in the era of enhanced recovery-a long-term follow-up. J Clin Nurs. 2010; 19: 666-672. 
73. Beaver K, Latif S, Williamson S, Procter D, Sheridan J, Heath J et al. An exploratory study of the follow-up care needs of patients treated for colorectal cancer. J Clin Nurs. 2010; 19: 3291-3300.

74. Blazeby JM, Soulsby M, Winstone K, King PM, Bulley SH, Kennedy RH. A qualitative evaluation of patients' experiences of an enhanced recovery programme for colorectal cancer. Colorectal Dis. 2009: e236-e242.

75. Ekman I, Swedberg K, Taft C, Lindseth A, Norberg A, Brink E et al. Person-centered care-ready for prime time. Eur J Cardiovasc Nurs. 2011; 10: 248-251.

76. McCormack B, McCane T. (eds) Person-Centred Practice in Nursing and Health Care. Chichester: John Wiley \& Sons Ltd; 2016.

77. Lusk JM, Fater K. A concept analysis of patient-centered care. Nurs Forum. 2013; 48: 89-98.

78. Leplege A, Gzil F, Cammelli M, Lefeve C, Pachoud B, Ville I. Person-centredness: conceptual and historical perspectives. Disabil Rehabil. 2007; 29: 1555-1565.

79. Tengland PA. Empowerment: a goal or a means for health promotion? Med Health Care Philos. 2007; 10: 197-207.

80. Rodwell CM. An analysis of the concept of empowerment. J Adv Nurs. 1996; 23: 305 313.

81. Zimmerman MA. Psychological empowerment: Issues and illustrations. Am J Community Psychol. 1995; 23: 581-599.

82. Spence Laschinger HK, Gilbert S, Smith LM, Leslie K. Towards a comprehensive theory of nurse/patient empowerment: applying Kanter's empowerment theory to patient care. J Nurs Manag. 2010; 18: 4-13.

83. Giorgi A. The Descriptive Phenomenological Method in Psychology: a modified Husserlian approach. Pittsburg: Duquenese University press; 2009.

84. Englander M. The interview: Data collection in descriptive phenomenological human scientific research. Journal of Phenomenological Psychology. 2012; 43: 13-35.

85. Kvale S, Brinkmann S. Interviews: Learning the craft of qualitative research interviewing. Thousand Oaks: Sage Publications Inc; 2009.

86. Giorgi A. The Descriptive Phenomenological Psychological Method. Journal of Phenomenological Psychology. 2012; 43: 3.

87. The EuroQol Group. EuroQol- a new facility for the measurement of health-related quality of life. Health Policy. 1990; 16: 199.

88. Dowson HM, Ballard K, Gage H, Jackson D, Williams P, Rockall TA. Quality of life in the first 6 weeks following laparoscopic and open colorectal surgery. Value Health. 2013; 16: 367-372.

89. Brooks R. EuroQol: the current state of play. Health Policy. 1996; 37: 53.

90. Dolan P. Modeling valuations for EuroQol health states. Med Care. 1997; 35: 1095. 
91. Elkins G, Staniunas R, Rajab MH, Marcus J, Snyder T. Use of a numeric visual analog anxiety scale among patients undergoing colorectal surgery. Clin Nurs Res. 2004; 13 : 237-244.

92. Wallace LM. Pre-operative state anxiety as a mediator of psychological adjustment to and recovery from surgery. Br J Med Psychol. 1986; 59: 253-261.

93. Allvin R, Ehnfors M, Rawal N, Svensson E, Idvall E. Development of a questionnaire to measure patient-reported postoperative recovery: content validity and intra-patient reliability. J Eval Clin Pract. 2009; 15: 411-419.

94. Allvin R, Kling AM, Idvall E., Svensson E. Patient Reported Outcome Measures (PROMs) after total hip- and knee replacement surgery evaluated by the Postoperative Recovery Profile questionnaire (PRP)- improving clinical quality and personcenteredness. The International Journal of Person Centered Medicine. 2012; 2: 368376.

95. Avdic A. Interactive software supporting Svenssons method. 2010.

96. Field A. Discovering statistics using IBM SPSS statistics. London: Sage Publications Ltd; 2013.

97. Argyrous G. Statistics for research. With a guide to SPSS. London: Sage Publications Ltd; 2011.

98. Svensson E. Ordinal invariant measures for individual and group changes in ordered categorical data. Statist Med. 1998; 17: 2923-1936.

99. Altman DG. Practical statistics for medical research. London: Chapman \& Hall; 1999.

100. International Council of Nurses (ICN). The ICN code of ethics for nurses. 2012 [http:// www.icn.ch/images/stories/documents/about/icncode_english.pdf] Accessed 2016 $06 / 13$.

101. World Medical Association. World Medical Association Declaration of Helsinki: ethical principles for medical research involving human subjects. JAMA. 2013; 310: 2191-2194.

102. Beauchamp TL, Childress JF. (eds) Principles of Biomedical Ethics. New York: Oxford University Press; 2012.

103. Polit DF, Beck CT. Nursing research: Generating and assessing evidence for nursing practice. Philadelphia: Lippincott Williams \& Wilkins; 2008.

104. Lincoln YS, Guba EG. Naturalistic Inquiry. London: Sage Publications; 1985.

105. Dahlberg K, Dahlberg H, Nyström M. Reflective lifeworld research. Lund: Studentlitteratur; 2008.

106. Graneheim UH, Lundman B. Qualitative content analysis in nursing research: concepts, procedures and measures to achieve trustworthiness. Nurse Educ Today. 2004; 24: 105-112.

107. Allvin R, Ehnfors M, Rawal N, Idvall E. Experiences of the postoperative recovery process: an interview study. Open Nurs J. 2008; 2: 1-7.

108. Olsson U, Bergbom I, Bosaeus I. Patients' experiences of the recovery period 3 months after gastrointestinal cancer surgery. Eur J Cancer Care. 2002; 11: 51-60. 
109. Di Fabio F, Koller M, Nascimbeni R, Talarico C, Salerni B. Long-term outcome after colorectal cancer resection. Patients' self-reported quality of life, sexual dysfunction and surgeons' awarness of patients' needs. Tumori. 2008; 94: 30-35.

110. DeSnoo L, Faithfull S. A qualitative study of anterior resection syndrome: the experiences of cancer survivors who have undergone resection surgery. Eur J Cancer Care. 2006; 15: 244-251.

111. Karanjia ND, Schache DJ, Heald RJ. Function of the distal rectum after low anterior resection for carcinoma. Br J Surg. 1992; 79: 114-116.

112. Hallbook O, Sjodahl R. Surgical approaches to obtaining optimal bowel function. Semin Surg Oncol. 2000; 18: 249-258.

113. Emmertsen KJ, Laurberg S, Rectal Cancer Function Study Group. Impact of bowel dysfunction on quality of life after sphincter-preserving resection for rectal cancer. $\mathrm{Br} \mathrm{J}$ Surg. 2013; 100: 1377-1387.

114. Taylor C, Morgan L. Quality of life following reversal of temporary stoma after rectal cancer treatment. Eur J Oncol Nurs. 2011; 15: 59-66.

115. Herdman M, Gudex C, Lloyd A, Janssen M, Kind P, Parkin D et al. Development and preliminary testing of the new five-level version of EQ-5D (EQ-5D-5L). Qual Life Res. 2011; 20: 1727-1736.

116. Oberoi DV, Jiwa M, McManus A, Hodder R, de Nooijer J. Help-seeking experiences of men diagnosed with colorectal cancer: a qualitative study. Eur J Cancer Care. 2016; 25: 27-37.

117. Whitaker KL, Macleod U, Winstanley K, Scott SE, Wardle J. Help seeking for cancer 'alarm' symptoms: a qualitative interview study of primary care patients in the UK. Br J Gen Pract. 2015; 65: e96-e105. 
APPENDICES 
Appendix 1: The EuroQol 5-Dimensions 3-levels, EQ-5D-3L, (II, IV)

\section{EO-5D-3L}

Health Questionnaire

English version for the UK

(Validated for Ireland) 
By placing a tick in one box in each group below, please indicate which statements best describe your own health state today.

\section{Mobility}

I have no problems in walking about

I have some problems in walking about

I am confined to bed

\section{Self-Care}

I have no problems with self-care

I have some problems washing or dressing myself

I am unable to wash or dress myself

Usual Activities (e.g. work, study, housework, family or leisure activities)

I have no problems with performing my usual activities

I have some problems with performing my usual activities

I am unable to perform my usual activities

\section{Pain / Discomfort}

I have no pain or discomfort

I have moderate pain or discomfort

I have extreme pain or discomfort

\section{Anxiety / Depression}

I am not anxious or depressed

I am moderately anxious or depressed

I am extremely anxious or depressed 
To help people say how good or bad a health state is, we have drawn a scale (rather like a thermometer) on which the best state you can imagine is marked 100 and the worst state you can imagine is marked 0 .

We would like you to indicate on this scale how good or bad your own health is today, in your opinion. Please do this by drawing a line from the box below to whichever point on the scale indicates how good or bad your health state is today.
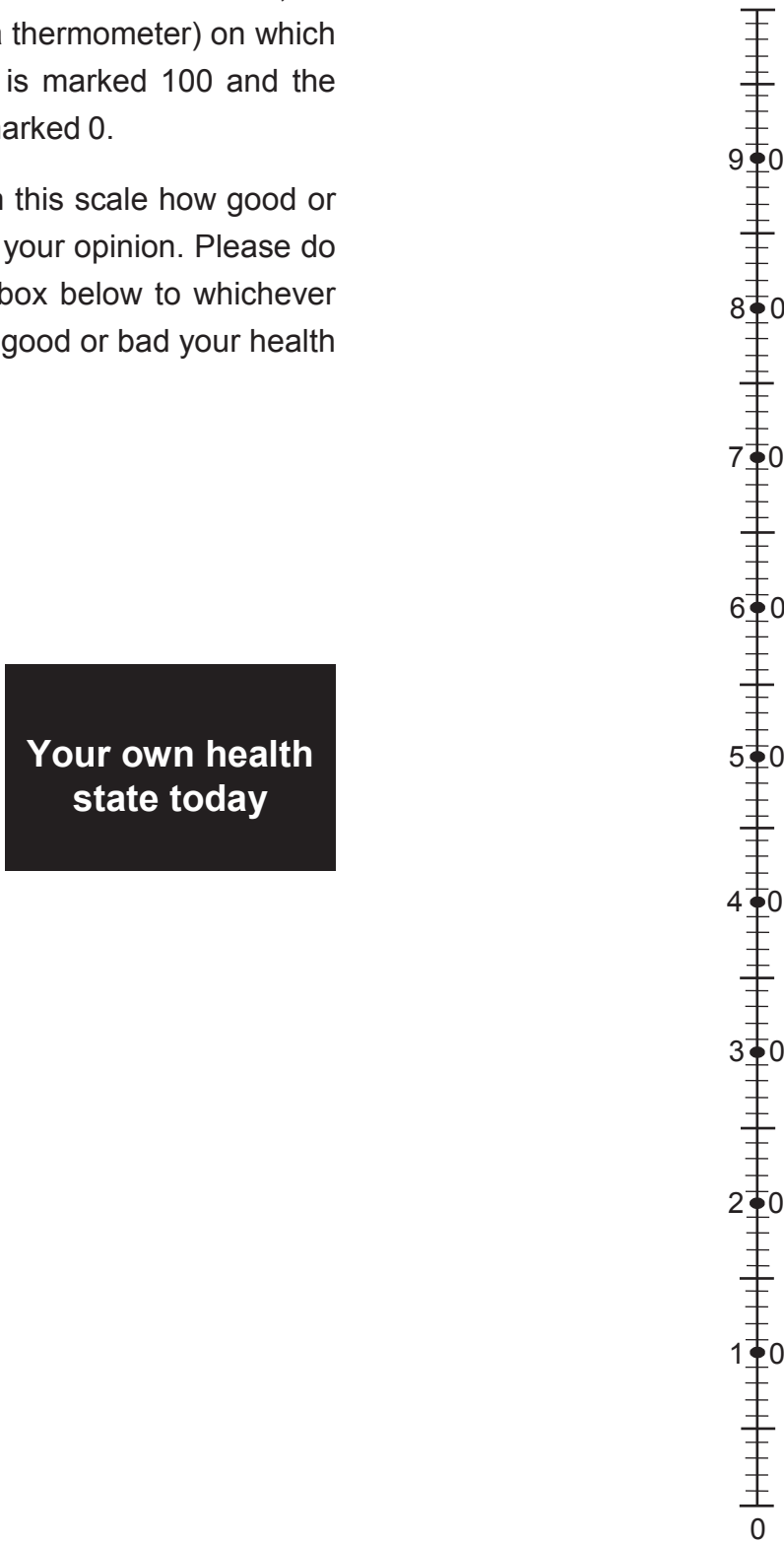

Worst imaginable health state 
Appendix 2: The State-Trait Anxiety Inventory, Form Y-1, STAI, (II)

\section{SELF-EVALUATION QUESTIONNAIRE STA Form Y-1}

Please provide the following information:

Name

Date S

Age

Gender (Circle) M F

T

DIRECTIONS:

A number of statements which people have used to describe themselves are given below. Read each statement and then blacken the appropriate circle to the right of the statement to indicate how you feel night now, that is, at this moment. There are no right or wrong answers. Do not spend too much time on any one statement but give the answer which seems to describe your present feelings best.

1. I feel calm $\begin{array}{llll}1 & 2 & 3 & 4\end{array}$

2. I feel secure 1234

3. I am tense 1234

4. I feel strained 1234

5. I feel at ease 1234

(C) 1968, 1977 by Charles D. Spielberger. All rights reserved. Published by Mind Garden, Inc. www.mindgarden.com 


\section{Appendix 3: The Postoperative Recovery Profile, PRP (I, IV)}

\section{Postoperative Recovery Profile (PRP) questionnaire}

Nedan följer en rad påståenden. Läs igenom dem noga och välj de svarsalternativ som passar bäst in på hur Du har det efter Din operation.

Just nu upplever jag en/ett som är:

\begin{tabular}{|c|c|c|}
\hline $1 \quad$ Smärta & $\begin{array}{l}\square \\
\square \\
\square \\
\square\end{array}$ & $\begin{array}{l}\text { Svår } \\
\text { Medelsvår } \\
\text { Lindrig } \\
\text { Ingen }\end{array}$ \\
\hline 2 Illamående & $\begin{array}{l}\square \\
\square \\
\square \\
\square\end{array}$ & $\begin{array}{l}\text { Svår } \\
\text { Medelsvår } \\
\text { Lindrig } \\
\text { Ingen }\end{array}$ \\
\hline 3 Rubbning i min mag-tarmfunktion (t ex förstoppning, diarré) & $\begin{array}{l}\square \\
\square \\
\square \\
\square\end{array}$ & $\begin{array}{l}\text { Svår } \\
\text { Medelsvår } \\
\text { Lindrig } \\
\text { Ingen }\end{array}$ \\
\hline 4 Orkeslöshet & $\begin{array}{l}\square \\
\square \\
\square \\
\square\end{array}$ & $\begin{array}{l}\text { Svår } \\
\text { Medelsvår } \\
\text { Lindrig } \\
\text { Ingen }\end{array}$ \\
\hline 5 Muskelsvaghet & $\begin{array}{l}\square \\
\square \\
\square \\
\square\end{array}$ & $\begin{array}{l}\text { Svår } \\
\text { Medelsvår } \\
\text { Lindrig } \\
\text { Ingen }\end{array}$ \\
\hline $6 \quad$ Påverkan på min aptit & $\begin{array}{l}\square \\
\square \\
\square \\
\square\end{array}$ & $\begin{array}{l}\text { Svår } \\
\text { Medelsvår } \\
\text { Lindrig } \\
\text { Ingen }\end{array}$ \\
\hline 7 Sömnsvårighet & $\begin{array}{l}\square \\
\square \\
\square \\
\square\end{array}$ & $\begin{array}{l}\text { Svår } \\
\text { Medelsvår } \\
\text { Lindrig } \\
\text { Ingen }\end{array}$ \\
\hline 8 Oro och ängslan & $\begin{array}{l} \\
\square \\
\square \\
\square\end{array}$ & $\begin{array}{l}\text { Svår } \\
\text { Medelsvår } \\
\text { Lindrig } \\
\text { Ingen }\end{array}$ \\
\hline 9 Nedstämdhet & $\begin{array}{l}\square \\
\square \\
\square \\
\square\end{array}$ & $\begin{array}{l}\text { Svår } \\
\text { Medelsvår } \\
\text { Lindrig } \\
\text { Ingen }\end{array}$ \\
\hline $\begin{array}{l}10 \text { Inskränkningar i mitt vardagsliv (t ex } \\
\text { hushållsarbete/fritidsaktiviteter/arbete) }\end{array}$ & $\begin{array}{l}\square \\
\square \\
\square \\
\square\end{array}$ & $\begin{array}{l}\text { Svår } \\
\text { Medelsvår } \\
\text { Lindrig } \\
\text { Ingen }\end{array}$ \\
\hline
\end{tabular}




\begin{tabular}{|c|c|}
\hline 11 Påverkan på mitt sexualliv & $\begin{array}{ll} & \text { Svår } \\
\square & \text { Medelsvår } \\
\square & \text { Lindrig } \\
\square & \text { Ingen }\end{array}$ \\
\hline 12 Inskränkningar i mitt sociala liv (t ex i umgänget med familj och vänner) & $\begin{array}{ll}\square & \text { Svår } \\
\square & \text { Medelsvår } \\
\square & \text { Lindrig } \\
\square & \text { Ingen }\end{array}$ \\
\hline 13 Svårighet att sköta min personliga hygien & $\begin{array}{ll} & \text { Svår } \\
\square & \text { Medelsvår } \\
\square & \text { Lindrig } \\
\square & \text { Ingen }\end{array}$ \\
\hline $\begin{array}{l}14 \text { Svårighet att följa med i vad som händer i omvärlden (t ex genom } \\
\text { tidningar och TV) }\end{array}$ & $\begin{array}{ll}\square & \text { Svår } \\
\square & \text { Medelsvår } \\
\square & \text { Lindrig } \\
\square & \text { Ingen }\end{array}$ \\
\hline 15 Problem med att tömma urinblåsan & $\begin{array}{ll}\square & \text { Svår } \\
\square & \text { Medelsvår } \\
\square & \text { Lindrig } \\
\square & \text { Ingen }\end{array}$ \\
\hline 16 Problem med att vara uppe och i rörelse & $\begin{array}{ll}\square & \text { Svår } \\
\square & \text { Medelsvår } \\
\square & \text { Lindrig } \\
\square & \text { Ingen }\end{array}$ \\
\hline 17 Känslan av att vara ensam och utelämnad & $\begin{array}{ll}\square & \text { Svår } \\
\square & \text { Medelsvår } \\
\square & \text { Lindrig } \\
\square & \text { Ingen }\end{array}$ \\
\hline 18 Beroende av hjälp från andra & $\begin{array}{ll}\square & \text { Svår } \\
\square & \text { Medelsvår } \\
\square & \text { Lindrig } \\
\square & \text { Ingen }\end{array}$ \\
\hline 19 Koncentrationsproblem & $\begin{array}{ll}\square & \text { Svår } \\
\square & \text { Medelsvår } \\
\square & \text { Lindrig } \\
\square & \text { Ingen }\end{array}$ \\
\hline
\end{tabular}



ORIGINAL PAPERS I- IV 



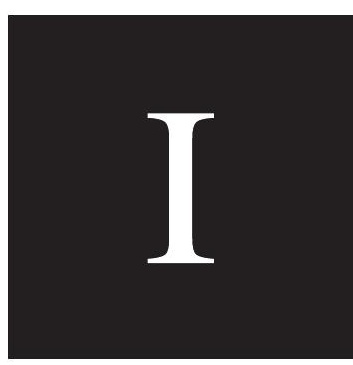





\title{
Patient-reported recovery after enhanced colorectal cancer surgery: a longitudinal six-month follow-up study
}

\author{
Jenny Jakobsson • Ewa Idvall • Christine Wann-Hansson
}

Accepted: 12 June 2014 / Published online: 4 July 2014

(C) Springer-Verlag Berlin Heidelberg 2014

\begin{abstract}
Purpose The concept of enhanced recovery after surgery (ERAS) is a modern regime of care, and numerous studies have proved its beneficial impact on recovery after colorectal surgery. However, little is known about patients' continuing recovery after discharge. Therefore, the purpose of this study was to describe patient-reported recovery after colorectal cancer surgery in the context of ERAS from the day of discharge until 1 and 6 months after surgery.

Method Assessments were made at discharge, at 1 month and at 6 months after surgery using the questionnaire Postoperative Recovery Profile (PRP). In all, 119 patients recovering from abdominoperineal resection, rectal resection, or colonic resection completed all three assessments.

Results The global score of recovery showed that no patient experienced being fully recovered at discharge. After rectal resection, patients frequently reported being not at all recovered. One month after surgery, patients recovering from colonic resection reported significant improvements regarding 11 of 17 questionnaire items, whereas abdominoperineal resection patients reported no significant improvements regarding any item. Instead, significantly higher levels of problems were reported in the items fatigue, muscle weakness and
\end{abstract}

\footnotetext{
J. Jakobsson $(\bowtie)$

Department of Surgery, Skane University Hospital, Inga Marie Nilssons gata 47, 20502 Malmö, Sweden e-mail: Jenny.Jakobsson@mah.se

J. Jakobsson · E. Idvall · C. Wann-Hansson

Department of Care Science, Malmö University, Malmö, Sweden

E. Idvall

Department of Intensive Care and Perioperative Medicine, Skane University Hospital, Malmö, Sweden

C. Wann-Hansson

The Swedish Institute for Health Sciences, Lund University, Lund, Sweden
}

feeling down. Rectal resection patients reported significant improvements between 1 and 6 months after surgery regarding 7 of 19 items. However, the item gastrointestinal function distinguished, as patients reported significant deterioration towards higher levels of problems 6 months after surgery. Conclusion This study elucidates the difference between groups of colorectal patients and the diverse patterns of their recovery, implying different needs in terms of prolonged support after discharge.

Keywords Postoperative recovery $\cdot \mathrm{PRP} \cdot$ Colorectal surgery $\cdot$ ERAS

\section{Introduction}

Enhanced recovery after surgery (ERAS) has been a successful approach to modern perioperative care, and numerous studies have shown a beneficial impact on early recovery, especially for colorectal surgery [1]. Most research has focused on physiological factors, and there is limited knowledge about patient-reported postoperative recovery at home from a longitudinal perspective. Furthermore, most knowledge of the postdischarge period is based on studies focusing on quality of life after colorectal cancer surgery using instruments developed for that purpose. However, consciousness about the meaning of the concept investigated is important. Quality of life is not synonymous with postoperative recovery, which has been described as "an energy requiring process to return to a state of normality and wholeness. It is characterized by regaining control over physical, psychological, social and habitual functions resulting in a return to preoperative level of independency/dependency in activities of daily living and regaining one's optimum level of wellbeing" [2, p. 557].

Early postoperative recovery is affected by a number of factors, such as the patient's age, the type and extent of surgery 
and the patient's preoperative habitus [3]. A relatively young age, in combination with a low grade on the American Society of Anesthesiologists (ASA) physical status classification system [4], is associated with fewer complications after surgery $[5,6]$. Further, pain is a factor with considerable negative effects on recovery, given that it can cause immobilization, paralytic ileus, nausea, vomiting and (in the long run) cardiopulmonary complications $[7,8]$.

The ERAS concept was developed after identification of physiological factors affecting postoperative recovery [9]. Interventions such as preoperative patient counselling, optimizing the patient's preoperative habitus and conducting minimally invasive surgery, along with adapted anaesthesia, optimal pain treatment, early oral intake and early intense mobilization, resulted in a quick return of physiological functions and thus a shorter hospital stay [10].

Studies show both positive and negative experiences of ERAS interventions and early discharge. Preoperative patient counselling and information have resulted in feelings of security, making admission and surgery less frightening, contributing to realistic expectations and empowering patients to take personal responsibility for their recovery after major colorectal surgery $[11,12]$. However, a need for additional information about dealing with bowel symptoms, nutrition, medication, skin care, physical activities and emotional difficulties after discharge has been reported [13]. Early discharge has been experienced as a challenge in that patients must reflect on and cope with unfamiliar bodily reactions. Moreover, discomfort created a conflict between living an active life and listening to a body calling for rest [14]. On the other hand, early discharge after colorectal surgery has also been experienced as positive as patients felt their recovery enhanced by their being at home because they had the opportunity to eat, drink and rest without the disturbance of hospital routines. However, some patients with minor complications expressed difficulties gaining access to specialist care and expert advice after discharge, leading to a feeling of vulnerability [15].

Postdischarge vulnerability and a need for an accessible source of specialized support were also highlighted by patients in the study by Taylor and Burch [12]. Areas of concern in the postoperative period involve the surgical wound, the bowels, the stoma, a lack of energy and pain [16]. Minor pain has been reported, peaking 1 week after surgery and disappearing after 5 weeks. Problems with nausea, vomiting, defecation and most dominantly fatigue were also reported 1 to 2 weeks postoperatively. Five weeks after surgery, fatigue was still the most disturbing symptom, whereas the other symptoms had decreased or even disappeared [17].

Given that the greater part of recovery in the era of enhanced recovery takes place outside of the hospital, there is a need for knowledge about postoperative symptoms and the pattern of recovery over the long term. Therefore, the aim of this study was to describe patient-reported recovery after colorectal cancer surgery in the context of ERAS from the day of discharge until 1 and 6 months after surgery.

\section{Patients and methods}

A descriptive, longitudinal questionnaire study was carried out at a university hospital in southern Sweden. Approximately 270 patients with cancer of the colon or rectum annually undergo surgery at the hospital and are cared for according to the ERAS concept, which was implemented at the unit in 2005. Patients were eligible for inclusion if they had been diagnosed with colorectal cancer, were undergoing an elective surgical procedure involving the colon or rectum and were considered for perioperative care according to the ERAS concept. Further criteria were the ability to understand and complete questionnaires in Swedish. Patient recruitment lasted from October 2011 until February 2013. During this period, 232 patients were available for inclusion, and 225 patients were asked to participate (Fig. 1). Approval was gained from the Regional Ethics Board, Lund, Sweden (Dnr 2011/451).

Data collection

Postoperative recovery was measured by the Postoperative Recovery Profile (PRP), a Swedish questionnaire developed for the self-assessment of general postoperative recovery [18]. The questionnaire consists of 19 items formulated as statements (e.g., "Right now I experience pain that is..."). A fourpoint descriptive scale of none, mild, moderate and severe is used. Results from the answers in the questionnaire can be transformed into a global score of recovery (GSR) based on the number of items in the questionnaire answered with none (indicator sum) [19].

The PRP questionnaire is produced in two versions, one comprising 17 items, considered for assessment during hospitalization, and the other comprising 19 items, used for measurement after discharge. Items not represented in the 17-item version are re-establishing everyday life and sexual activity.

Data regarding demographic variables such as age, gender, ASA classification, type of cancer, surgical procedure and compliance with the ERAS concept were collected from the patients' medical records.

\section{Procedure}

Patients were recruited consecutively. Written information about the study was sent out together with the notice of appointment for the preoperative visit at the surgical outpatient clinic 1 week prior to surgery. Additional oral information was given during the preoperative visit by a colorectal nurse specialist, and written informed consent was obtained regarding study participation. 
Fig. 1 Data collection process

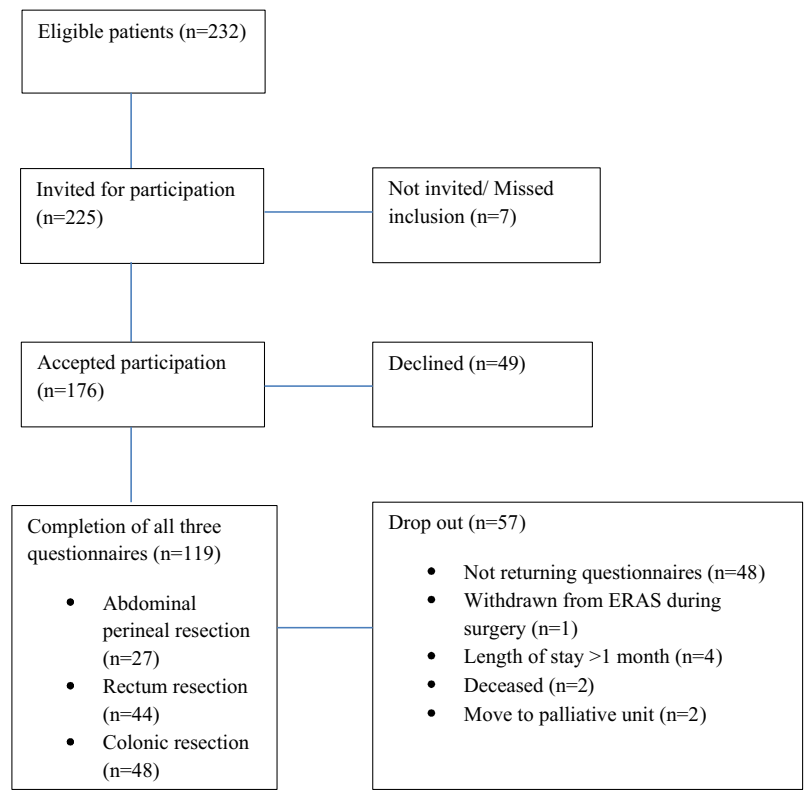

After surgery, patients received the first 17-item questionnaire from the ward nurse on the day of discharge. The questionnaire was to be filled in and returned to the ward nurse before each patient left the hospital. One month and 6 months after surgery, each patient received the 19-item questionnaire by mail, along with a prepaid envelope. Nonresponders received two reminders.

\section{Statistical analysis}

Patients were divided into three groups based on type of surgical procedure: abdominoperineal resections (APR), rectal resections and colonic resections.

\section{PRP analysis}

Values from the PRP assessments at discharge, at 1 month and at 6 months after surgery were analysed using statistical software for evaluating paired, ordered data [20]. This allows the calculation of the pattern of changes for patients as a group and as individuals, a pattern displayed by frequency distributions of every pair of assessment in a cross tabulation. The pairs of data that do not change between the two assessments are referred to as the proportion of unchanged assessments (PA) and expressed in percentage and number. The measurement for a systematic shift (i.e., the group is shifting homogenously towards a lower or higher rate of disturbance on the second measurement) is referred to as the relative position (RP). In the cross tabulation, a lower rate of disturbance can be visualized as a greater proportion of paired assessments on the right side of the diagonal. The RP value calculates the difference between the probabilities of an increased or decreased level of disturbance between assessments. Possible values of RP range between -1 and 1 . A large negative RP value indicates a high probability of a shift towards a lower level of disturbance on the second assessment. For example, if the RP value is -0.16 , there is a $16 \%$ greater probability of improvements rather than deteriorations at the second assessment. The uncertainty of this statement is calculated by a $95 \%$ confidence interval (CI).

The individual difference from the systematic pattern of changes is mentioned as the relative rank variance (RV). It manifests if the individual changes are part of the homogenous group change or an individual divergence. The RV value could be up to 1 . An RV value approaching 1, with $95 \%$ CI that does not cover the zero value, indicates that the individual variations must be taken into account when interpreting the results. Missing data are excluded pairwise [21].

\section{Global score of recovery}

The global score of recovery (GSR) was calculated for each individual patient and assessment displaying the level of recovery. The number of items in each questionnaire answered 
with none was counted, leaving an indicator sum ranging from 0 to 19 depending on the number of none responses from each individual patient. The criterion for fully recovered was all items answered with none - that is, an indicator sum of 19. Further, an indicator sum of 15-18 corresponds to almost fully recovered, 8-14 to partly recovered, 7 to slightly recovered and less than 7 to not at all recovered. The GSR was calculated only for questionnaires with no missing data.

\section{Demographics}

Demographic variables were calculated and described by frequency distributions in number, percentages, mean, median and standard deviation (SD). The distribution of normality was calculated using the Kolmogorov-Smirnov test. Significant differences between the three groups were calculated using a one-way ANOVA and the Kruskal-Wallis test when appropriate. For significant differences detected, independentsamples $T$ test and the Mann-Whitney $U$ test were used to further evaluate the differences [22]. A $p$ value $<0.05$ was considered significant. Calculations were made using the Statistical Package for the Social Sciences (SPSS version 21, IBM, New York, USA).

\section{Results}

Of the 225 patients invited to participate in this study, 49 patients declined (recruitment rate $78 \%$ ). A total of 176 patients gave their written consent; of those, 119 patients completed the questionnaire on all three occasions (Fig. 1). There were 57 patients lost at follow-up, of which 48 patients did not return their questionnaires ( 30 men and 18 women, mean age 73.2). One patient was withdrawn from ERAS owing to complications during surgery (APR), four patients were still hospitalized 1 month after surgery, thus missing the 1-month assessments (three rectal resections and one APR), two patients died during hospitalization (both rectal resections), and two patients were moved to a palliative unit and did not receive any questionnaires (both rectal resections).

The three groups of patients differed significantly in age, preoperative treatment, duration of surgery, blood loss, occurrence of ostomy, day of first defecation and length of stay (LoS), as displayed in Table 1. Patients who underwent colonic resections were significantly older than those who had rectal resections but not older than APR patients. Furthermore, patients who had colonic resections underwent significantly less preoperative adjuvant treatment and experienced shorter duration of surgery, less blood loss, shorter time before first defecation and shorter LoS than both APR patients and rectalresection patients. Differences between APR patients and rectal-resection patients were only significant regarding the duration of the surgery; APR patients experienced the longest procedures.

At discharge, a majority of APR patients were considered partly recovered (59.3\%), a distribution that remained 1 month after surgery $(57.1 \%)$. Further, $4.0 \%$ reached a level of almost fully recovered at discharge, increasing to $9.5 \%$ after 1 month and to $27.3 \%$ after 6 months. One and 6 months after discharge, 4.8 and $9.1 \%$, respectively, were considered fully recovered. The patients who were not at all recovered decreased from $37.0 \%$ at discharge to $18.2 \%$ after 6 months (Fig. 2). However, as for the proportions of changes in recovery, no significant improvements could be seen in any item between the day of discharge and 1 month after surgery (Table 2). Instead, significantly higher levels of problems were reported in the items fatigue (RP 0.23), muscle weakness (RP 0.30 ) and feeling down (RP 0.25) 1 month after surgery, without individual variations. When looking at the cross tabulation for the item with the greatest deterioration, muscle weakness, it can be seen that 13 patients (PA $48 \%$ ) reported no change, and in total, five patients deteriorated from experiencing mild muscle weakness at discharge to experiencing moderate $(n=4)$ or severe $(n=1)$ weakness 1 month postoperatively (Table 3(a)). For several items, individual variations imply that change in recovery was heterogenic. Between 1 and 6 months after surgery, significant improvements were reported in the responses to 10 of 19 items, with only a few individual variations.

On the day of discharge, $4.9 \%$ of patients who had undergone rectal resections reached a level of almost fully recovered; the percentage increased after 1 month (11.1\%) and again after 6 months (15.8\%). After 1 month, $2.8 \%$ were considered fully recovered, and after 6 months $5.3 \%$. After 6 months, there was a reduction in patients who were not at all recovered $(31.6 \%)$ relative to the percentage 1 month after surgery (33.3\%) (Fig. 2). Patients recovering from rectal resection showed significant improvements in four of 17 items between the day of discharge and 1 month after surgery (Table 2). The greatest improvements were reported regarding appetite change ( $\mathrm{RP}-0.31)$; however, there were some individual variations (RV 0.40), meaning that change in this item was common for the group with additional individual variations. Patients reported significantly higher levels of problem 1 month after surgery regarding feeling down (RP 0.18 ), with negligible individual variations (RV 0.06). In 16 items, individual variations were negligible, meaning that the group of patients recovering from rectal resection could be considered homogenous. Proportions of changes between 1 month after surgery and 6 months after surgery indicated significant improvements in 7 of the 19 items, with no individual variations (Table 4). However, the item gastrointestinal function distinguished, as it manifest significant deterioration towards a higher level of problems 6 months after surgery (RP 0.26), with individual variations (RV 0.25 ). Cross tabulation shows 
Table 1 Demographics

\begin{tabular}{|c|c|c|c|c|}
\hline & $\begin{array}{l}\text { Abdominoperineal } \\
\text { resection (APR) }(n=27)\end{array}$ & $\begin{array}{l}\text { Rectal resection } \\
(\mathrm{RR})(n=44)\end{array}$ & $\begin{array}{l}\text { Colonic resection } \\
(\mathrm{CR})(n=48)\end{array}$ & $p$ value \\
\hline Age, mean (SD) & $67.5(10.1)$ & $64.4(11.4)^{\mathrm{b} * * *}$ & $71.9(10.1)$ & 0.003 \\
\hline Sex, $n(\%)$ & & & & 0.180 \\
\hline Male & $13(48.1)$ & $25(56.8)$ & $18(37.5)$ & \\
\hline Female & $14(51.9)$ & $19(42.2)$ & $30(62.5)$ & \\
\hline ASA classification, md & 2.00 & 2.00 & 2.00 & 0.291 \\
\hline Type of cancer & $\begin{array}{l}\text { Sigmoid } 1(3.7) \\
\text { Rectum } 25(92.6) \\
\text { Colon and rectum } 1(3.7)\end{array}$ & $\begin{array}{l}\text { Colon } 1(2.3) \\
\text { Sigmoid } 2(4.5) \\
\text { Rectum } 37(84.1) \\
\text { Colon and rectum } 1(2.3) \\
\text { Recto-sigmoid } 3(6.8)\end{array}$ & $\begin{array}{l}\text { Colon } 20(41.7) \\
\text { Sigmoid } 16(33.3) \\
\text { Caecal } 10(20.8) \\
\text { Recto-sigmoid } 2(4.2)\end{array}$ & \\
\hline Preoperative treatment, $n(\%)$ & $14(51.8)^{\mathrm{a} * * *}$ & $14(31.8)^{\mathrm{b} * * *}$ & $1(2.1)$ & $<0.001$ \\
\hline Length of surgery, minutes, mean (SD) & $367(89.2)^{\mathrm{a} * *, c_{* *}}$ & $295(100.4)^{\mathrm{b} * * *}$ & $220(96.1)$ & $<0.001$ \\
\hline Blood loss, milliliters, mean (SD) & $527.9(390.1)^{\mathrm{a} * *}$ & $651.2(388.0)^{\mathrm{b} * * *}$ & $319.4(316.3)$ & $<0.001$ \\
\hline Ostomy, $n(\%)$ & $27(100.0)^{\mathrm{a} * * *}$ & $38(86.4)^{\mathrm{b} * * *}$ & $5(10.4)$ & $<0.001$ \\
\hline Mobilization, postoperative day, mean (SD) & $1.1(0.42)$ & $1.02(0.56)$ & $0.92(0.40)$ & 0.257 \\
\hline Oral intake, postoperative day, mean (SD) & $0.93(0.96)$ & $0.52(0.59)$ & $0.67(0.98)$ & 0.107 \\
\hline Defecation, postoperative day, mean (SD) & $3.37(2.44)^{\mathrm{a} *}$ & $3.1(2.68)^{\mathrm{b} * *}$ & $4.88(2.59)$ & $<0.001$ \\
\hline Length of stay, days, mean (SD) & $10.6(3.9)^{\mathrm{a}_{*}}$ & $11.0(4.5)^{\mathrm{b} *}$ & $9.0(4.7)$ & 0.005 \\
\hline Postoperative treatment, $n(\%)$ & $10(37.0)$ & 17 (38.6) & $17(35.4)$ & 0.986 \\
\hline
\end{tabular}

$S D$ standard deviation, $A S A$ American Society of Anesthesiologists

${ }^{*} p<0.05 ;{ }^{* *} p<0.01 ; * * * p<0.001$

${ }^{\text {a }}$ Significant difference between APR and CR

${ }^{\mathrm{b}}$ Significant difference between RR and CR

${ }^{\mathrm{c}}$ Significant difference between APR and RR

that 19 patients reported the level of disturbance as none 1 month after surgery, but after 6 months 13 of those patients reported mild $(n=8)$, moderate $(n=3)$ or severe $(n=2)$ levels of disturbance (Table 3(b)). On the other hand, four patients reported moderate and two patients reported severe levels of disturbance 1 month after surgery, but this improved to a mild
Fig. 2 Individual global score of recovery on day of discharge and 1 and 6 months after surgery

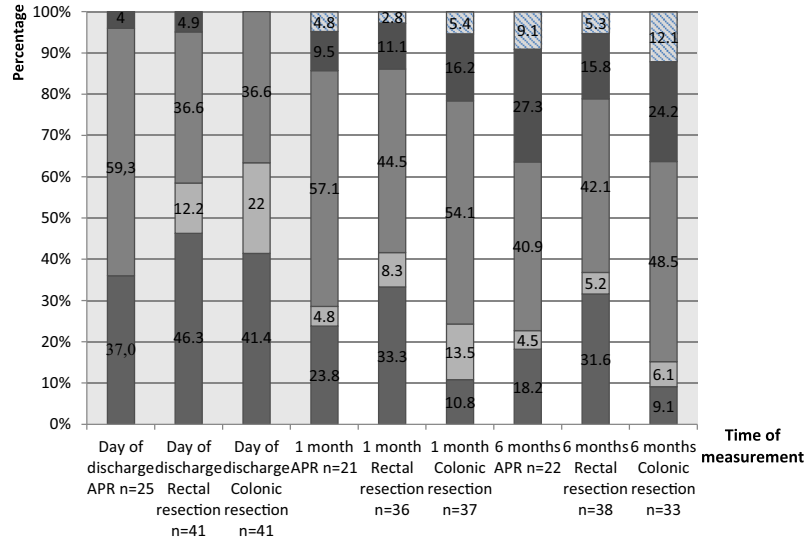

$\square$ Not at all recovered $\square$ Slightly recovered $\square$ Partly recovered $\square$ Almost fully recovered $\$$ Fully recovered 


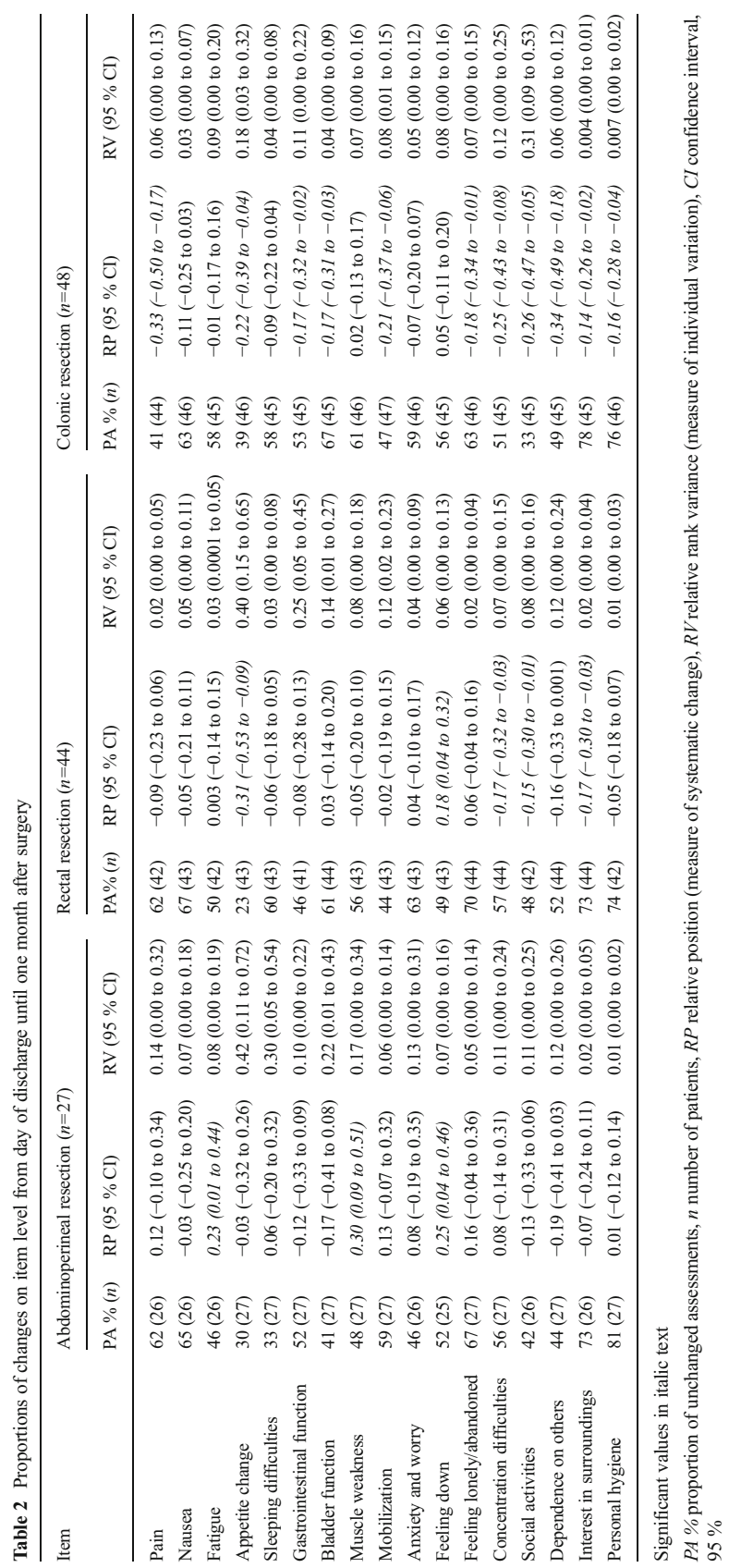


Table 3 Frequency distribution of paired assessments. X-axis displays the first assessment, $\mathrm{y}$-axis displays the second assessment. The diagonal from lower left corner to upper right corner indicates unchanged assessments. A shift towards the left side of the diagonal indicates a higher level of disturbance on the second assessment.

\begin{tabular}{|c|c|c|c|c|c|}
\hline & None & Mild & Moderate & Severe & Total \\
\hline \multicolumn{6}{|c|}{ a. Abdominoperineal resection. Item, muscle weakness } \\
\hline Severe & & 1 & & & 1 \\
\hline Moderate & 3 & 4 & 2 & & 9 \\
\hline Mild & 3 & 6 & 3 & & 12 \\
\hline None & 5 & & & & 5 \\
\hline Total & 11 & 11 & 5 & 0 & 27 \\
\hline \multicolumn{6}{|c|}{ b. Rectal resection. Item, gastrointestinal function } \\
\hline Severe & 2 & & 1 & & 3 \\
\hline Moderate & 3 & 4 & 1 & & 8 \\
\hline Mild & 8 & 7 & 4 & 2 & 21 \\
\hline None & 6 & 2 & & & 8 \\
\hline Total & 19 & 13 & 6 & 2 & 40 \\
\hline \multicolumn{6}{|c|}{ c. Colonic resection. Item, pain } \\
\hline Severe & & & 1 & & 1 \\
\hline Moderate & & 2 & 1 & & 3 \\
\hline Mild & 2 & 8 & 4 & & 14 \\
\hline None & 9 & 16 & 1 & & 26 \\
\hline Total & 11 & 26 & 7 & 0 & 44 \\
\hline
\end{tabular}

level at 6 months - a phenomenon indicating the individuality of this item.

The GSR showed that no patient in the colonic resection group had fully recovered or almost fully recovered on day of discharge. Instead, $41.4 \%$ were not at all recovered. After 1 month, 5.4 and $16.2 \%$ had reached the levels of fully recovered and almost fully recovered, respectively. The majority of patients $(54.1 \%)$ were considered partly recovered. Further improvements were seen at 6 months: $12.1 \%$ were considered fully recovered, and $24.2 \%$ were almost fully recovered (Fig. 2). The proportion of changes in recovery from the day of discharge to 1 month after surgery showed significant improvements in 11 of 17 items on a group level (variance RP -0.17 to -0.34 ), with negligible individual variations except for the item social activities (RV 0.31) (Table 2). This shows that the pattern for recovery in this group and period was homogenous and moving towards lower levels of disturbance.

The greatest improvements were reported for dependence on others $(\mathrm{RP}-0.34)$ and pain $(\mathrm{RP}-0.33)$. For the item pain, the percentage of agreement (PA) showed that $41 \%(n=18)$ reported no changes between the two assessments, and $48 \%$ $(n=21)$ assessed their level of pain as lower 1 month after surgery. However, the cross tabulation demonstrates that most patients $(n=26)$ reported pain as mild at discharge (Table 3(c)). The proportion of changes in recovery from 1 to 6 months after surgery shows that patients significantly improved regarding 2 of the 19 items: appetite change and dependence on others (RP -0.35 and RP -0.18 , respectively) (Table 4). Individual variations were countable only in reestablishing everyday life, implying that the group was homogenous except for this item.

\section{Discussion}

In the study, it became apparent that the three groups of patients with colorectal cancer differed in their recovery processes. Most patients recovering from APR were considered partly recovered at discharge, according to the GSR; however, 1 month after surgery, deterioration was seen in pain, fatigue, weakness, immobilization and a feeling of sadness. Those items are probably naturally correlated to each other. Persistent pain after APR may be caused by several factors, such as wound-healing problems and tumour recurrence. The excision can also induce phantom-rectum syndrome (PRS) [23, 24]. The prevalence of PRS has been reported for up to $68 \%$ of APR patients, ranging from non-painful sensations, such as feelings of an existing rectum with faeces or the need to pass flatus, to painful sensations. But 6 months after surgery, the APR group of patients had recovered considerably. This implies that health-care professionals should pay attention to the symptoms mentioned above in patients recovering from APR, at least during the first month after surgery and probably for some time after that.

For patients who had undergone rectal resection, the item gastrointestinal function was characterized by deterioration at 6 months, with individual variations. It is a well-known fact that surgical procedures with low rectal or anal end-to-end anastomosis can induce considerable problems in terms of bowel dysfunction. Low-anterior resection syndrome (LARS), which entails problems with clustering, urgency, frequent bowel movements and incontinence of both faeces and flatus, has been reported to affect up to $90 \%$ of patients $[25,26]$. Emmertsen and Laurberg [27] demonstrated a high rate of such bowel symptoms 3 and 12 months after colorectal surgery. At 12 months, the prevalence of symptoms had decreased. Gastrointestinal symptoms can also appear after stoma reversal, and this has been described as the principle matter of concern for patients [28, 29]. The deterioration in gastrointestinal function reported in the present study after 6 months could be a sign of LARS, whether patients had an end-to-end anastomosis or a stoma that had been reversed. Insecurity owing to disturbed gastrointestinal function could affect other items, such as social activities, and even though no significant deteriorations were reported regarding other items, it could well be that the affected items were answered with responses other than none, thereby resulting in a low indicator sum in the GSR. 


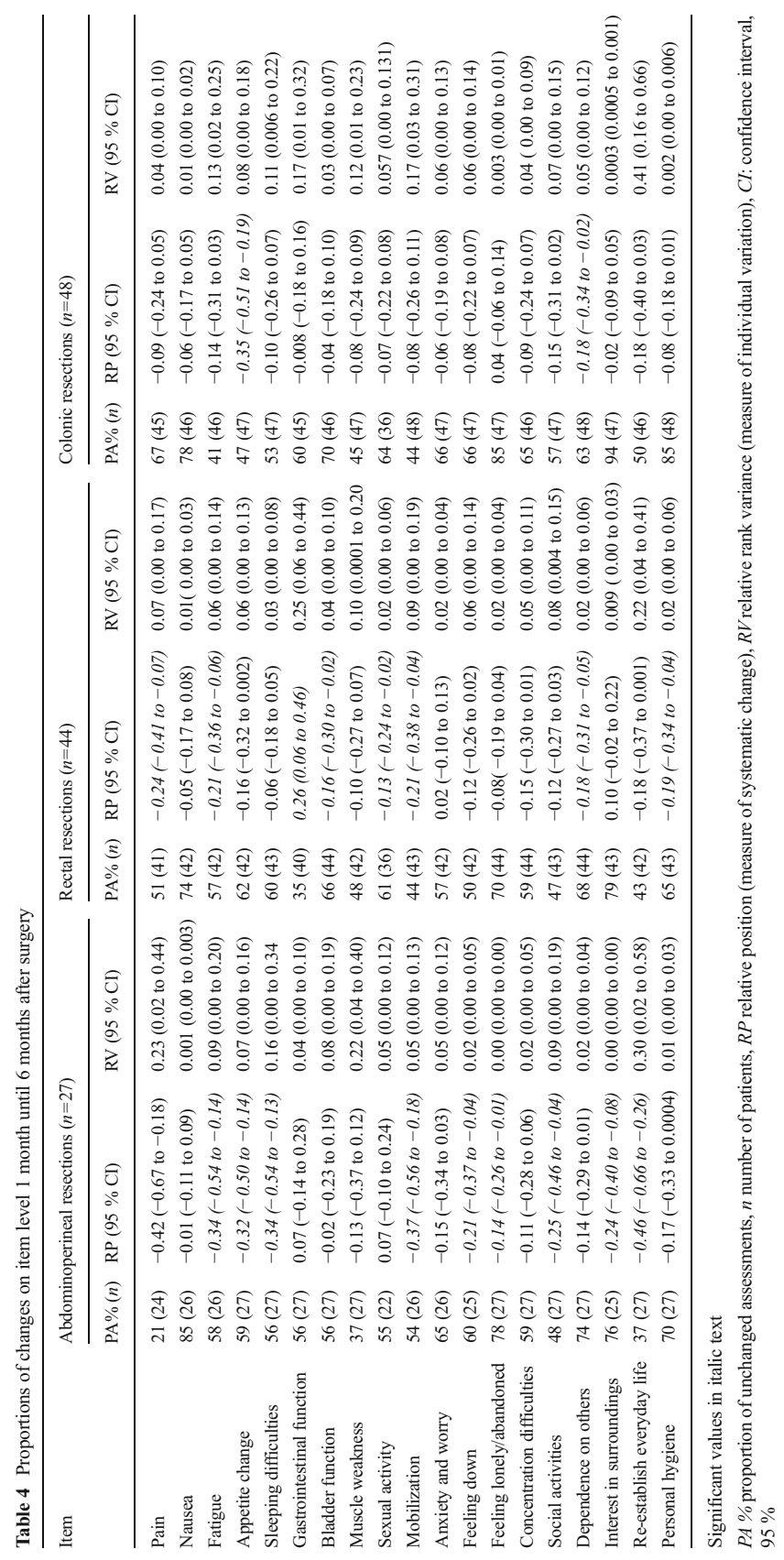


Patients in the colonic resection group were discharge after a mean of 9 days. When discharged, a majority reported themselves to be not at all recovered, according to the GSR. There was, however, rapid improvement in reported recovery within the first month - again, as seen in the GSR. The proportions of changes also indicated that the patients generally improved significantly in most items. In the study by Wennström et al. [17], patients recovering from sigmoid resection or from a right hemicolectomy reported minor problems with pain 1 week postoperatively. The first and second weeks, problems were also reported with nausea, vomiting, defecation and fatigue. Patients in the present study were discharged within this time frame, and their level of recovery at discharge corresponds with the results of Wennström et al. Further, the improvements in recovery after 1 month were comparable to those reported in the study by Wennström et al.: after 5 weeks, patients reported only fatigue to be a problem. In the present study, the colon-resection group exhibited a homogenous pattern of recovery from the day of discharge to 1 month after surgery. Only the item social activities showed individual but not negligible variations. There could be several explanations for this individuality, and it is not possible to say whether the variation resulted from the surgery or from the recovery process or whether individual diversity existed even before the surgery. Proportions of changes in recovery from 1 month after surgery to 6 months after surgery showed further improvements, with individual variations accounted for only in the item re-establishing everyday life. Thus, it can be demonstrated that patients recovering after a colorectal resection experience a rather quickly progressing recovery.

The process of recovery after a colorectal surgical intervention is a long-term procedure which does not depend only on the type of surgery, preoperative habitus, comorbidities, age or perioperative strategy. A great many colorectal surgical patients are also recovering from a life-threatening disease. To our knowledge, the interventions within the ERAS concept are concentrated to the period before and during surgery and hospitalization. However, patients who are discharged early go through the greatest part of their recovery at home, on their own. As the present study has shown, patients with a need for prolonged support from specialist health-care professionals can be identified, and with this knowledge, it is possible to provide individualized postoperative support. Predischarge information preparing the patients for the recovery period at home, coupled with sufficient support after discharge, may render even troublesome postoperative symptoms easier to handle and prevent.

\section{Methodological considerations}

To describe patient-reported postoperative recovery, the PRP questionnaire was used. There are other instruments for assessing postoperative recovery in different respects; however, they are designed to evaluate recovery after anaesthesia, early postoperative phases, recovery during hospitalization, or recovery at home after ambulatory surgery [30,31]. The PRP questionnaire is a validated instrument which assesses selfreported, postoperative symptoms [2,32]. Using the statistical method used for evaluating the pattern of change in recovery, it is possible to show changes that are individual or common within a group. This opportunity could be of great value for evaluating a treatment or, as in the present study, for gaining more detailed knowledge about the changes in a specific recovery process.

This study has some limitations. When reporting the proportions of changes, focus is on items that exhibit change. However, we do not know the exact baseline values unless we also study the cross tabulations. For example, a great significant improvement could falsely be interpreted as indicating that the group of patients reported a high level of disturbance on the first assessment. Conversely, some items may be neglected because significant changes are absent. If that is the case, the absence of change could be interpreted as indicating that there is no problem, even though the patients reported high levels of problems on both the first and the second assessment. Furthermore, the GSR is a hard-lined scale, as the criteria for the different levels of recovery are based on the number of items answered with none. To indicate full recovery, a patient must answer all the items with none. This means, for instance, that a patient who responded to 11 of 17 items with mild and to the other six items with none is considered not at all recovered even though the patient actually feels quite well. As patients today are not meant to be hospitalized until they are fully recovered, it should not be possible to have obtained full recovery according to the GSR at discharge. If the GSR indicates that a patient is fully recovered when leaving hospital, it could be argued that he or she should have been discharged earlier.

\section{Conclusion}

In conclusion, this study shows that patients recovering from different types of colorectal surgical interventions differ in their patterns of recovery and that postoperative recovery is a process that reaches far beyond discharge. This suggests that there is a need to individualize follow-up routines for patients and to identify patients with problems in order to provide sufficient support. Further research focusing on the postoperative recovery process and factors affecting postoperative recovery is needed. This knowledge can be used to better prepare patients for discharge and to develop strategies for supporting patients throughout the recovery process. 
Acknowledgments The authors would like to thank Doctor Renée Allvin, Örebro University Hospital, and Professor Bengt Jeppsson, Skane University Hospital, for valuable advice and support.

\section{References}

1. Lassen K, Soap M, Nygren J, Cox BW, Hendry PO, Spies C, Dejong $\mathrm{CHC}$ (2011) Consensus review of optimal perioperative care in colorectal surgery. Arch Surg 144:961-969

2. Allvin R, Berg K, Idvall E, Nilsson U (2007) Postoperative recovery: a concept analysis. J Adv Nurs 57:552-558

3. Kehlet H (2008) Fast-track colorectal surgery. Lancet 371:791-793

4. American Society of Anesthesiologists http:/www.asahq.org/ clinical/physicalstatus.htm [2013-11-22]

5. Hendry PO, Hausel J, Nygren J, Lassen K, Dejong CH, Ljungqvist O, Enhanced Recovery After Surgery Study Group (2009) Determinants of outcome after colorectal resection within an enhanced recovery programme. Br J Surg 96:197-205. doi:10.1002/ bjs. 6445

6. Smith JJ, Lee J, Burke C, Contractor KB, Dawson PM (2002) Major colorectal cancer resection should not be denied to the elderly. Eur J Surg Oncol 28:661-666

7. Schwenk W, Neudecker J, Raue W, Haase O, Muller JM (2006) "Fast track" rehabilitation after rectal cancer resection. Int $\mathrm{J}$ Color Dis 21(6):547-553

8. Fearon KC, Luff R (2003) The nutritional management of surgical patients: enhanced recovery after surgery. Proc Nutr Soc 62:807-811

9. Wilmore DW, Kehlet H (2001) Management of patients in fast track surgery. BMJ 322:473-476

10. Basse L, Raskov HH, Hjort Jakobsen D, Sonne E, Billesbolle P, Hendel $\mathrm{H}$ et al (2002) Accelerated postoperative recovery program after colonic resection improves physical performance, pulmonary function and body composition. Br J Surg 89:446-453

11. Aasa A, Hovbäck M, Berterö CM (2013) The importance of preoperative information for patient participation in colorectal surgery care. J Clin Nurs 22:1604-1612

12. Taylor C, Burch J (2011) Feedback on an enhanced recovery programme for colorectal surgery. Br J Nurs 20:286-290

13. Lithner M, Johansson J, Andersson E, Jakobsson U, Palmquist I, Klefsgard R (2012) Perceived information after surgery for colorectal cancer - an explorative study. Color Dis 14:1340-1350

14. Norlyk A, Harder I (2011) Recovering at home: participating in a fast-track colon cancer surgery programme. Nurs Inq 18:165-173

15. Blazeby JM, Soulsby M, Winstone K, King PM, Bulley S, Kennady RH (2009) A qualitative evaluation of patients' experiences of an enhanced recovery programme for colorectal cancer. Color Dis 12: e236-e242
16. Burch J (2012) Enhanced recovery and nurse-led telephone followup post surgery. Br J Nurs 21:24-29

17. Wennström B, Warrén Stomberg M, Modin M, Skullman S (2010) Patient symptoms after colonic surgery in the era of enhanced recovery - a long-term follow-up. J Clin Nurs 19:666-672

18. Allvin R, Ehnfors M, Rawal N, Svensson E, Idvall E (2009) Development of a questionnaire to measure patient-reported postoperative recovery: content validity and intra-patient reliability. J Eval Clin Pract 15:411-419

19. Allvin R, Svensson E, Rawal N, Ehnfors M, Kling AM, Idvall E (2011) The Postoperative Recovery Profile (PRP) - a multidimensional questionnaire for evaluation of recovery profiles. J Eval Clin Pract 17:236-243

20. Avdic A, Svensson E. Svenssons method 1.1 ed. Örebro 2010 Interactive software supporting Svenssons method. Accessed from http://www.oru.se/hh/Elisabeth-Svensson/Svenssons metod 201305-08

21. Svensson E (1998) Ordinal invariant measures for individual and group changes in ordered categorical data. Stat Med 17:2923-2936

22. Field A (2013) Discovering statistics using IBM SPSS statistics. Sage Publications Ltd, London

23. Fingren J, Lindholm E, Carlsson E (2013) Perceptions of phantom rectum syndrome and health-related quality of life in patients following abdominoperineal resection for rectal cancer. J Wound Ostomy Cont Nurs 40:280-286

24. Ovesen P, Kroner K, Ornsholt J, Bach K (1991) Phantom-related phenomena after rectal amputation: prevalence and clinical characteristics. Pain 44:289-291

25. Desnoo L, Faithfull S (2006) A qualitative study of anterior resection syndrome: the experiences of cancer survivors who have undergone resection surgery. Eur J Cancer Care 15:244-251

26. Karanjia N, Schache D, Heald R (1992) Function of the distal rectum after low anterior resection for carcinoma. Br J Surg 79:114-116

27. Emmertsen KJ, Laurberg S (2013) Impact of bowel dysfunction on quality of life after sphincter-preserving resection for rectal cancer. $\mathrm{Br}$ J Surg 100:1377-1387

28. Siassi M, Hohenberger W, Losel F, Weiss M (2008) Quality of life and patient's expectations after closure of a temporary stoma. Int $\mathrm{J}$ Colorectal Dis 23:1207-1212

29. O'Leary DP, Fide CJ, Foy C, Lucarotti ME (2001) Quality of life after low anterior resection with total mesorectal excision and temporary loop ileostomy for rectal carcinoma. Br J Surg 88:1216-1220

30. Kleinbeck SV (2000) Self-reported at-home postoperative recovery. Res Nurs Health 23:461-472

31. Myles PS, Weitkamp B, Jones K, Melick J, Hensen S (2000) Validity and reliability of a postoperative quality of recovery score: the QoR40. Br J Anaesth 84:11-15

32. Allvin R, Ehnfors M, Rawal N, Idvall E (2008) Experiences of the postoperative recovery process: an interview study. Open Nurs J 2:17 
II 



\title{
ORIGINAL RESEARCH: EMPIRICAL RESEARCH - QUANTITATIVE
}

\section{General health and state anxiety in patients recovering from colorectal cancer surgery}

\author{
Jenny Jakobsson, Ewa Idvall \& Christine Wann-Hansson
}

Accepted for publication 10 September 2015

\author{
Correspondence to J. Jakobsson: \\ e-mail: jenny.jakobsson@mah.se \\ Jenny Jakobsson RN \\ $\mathrm{PhD}$ Student \\ Department of Care Science, Malmö \\ University, Sweden and \\ Department of Surgery, Skane University \\ Hospital, Malmö, Sweden

\section{Ewa Idvall RN} \\ Professor \\ Department of Care Science, Malmö \\ University, Sweden and \\ Department of Intensive Care and \\ Perioperative Medicine, Skane University \\ Hospital, Malmö, Sweden \\ Christine Wann-Hansson RN \\ Associate Professor \\ Department of Care Science, Malmö \\ University, Sweden
}

JAKOBSSON J., IDVALL E. \& WANN-HANSSON C. (2016) General health and state anxiety in patients recovering from colorectal cancer surgery. Journal of Advanced Nursing 72(2), 328-338. doi: 10.1111/jan.12841

\begin{abstract}
Aim. To describe and compare general health and state anxiety before surgery and up to 6 months after surgery in patients with colorectal cancer undergoing elective rectal resection, abdominoperineal resection or colonic resection in an enhanced recovery context.

Background. Little is known about patient-reported health and anxiety after colorectal cancer surgery in an enhanced recovery context.

Design. A prospective cohort study.

Methods. Data were collected from October 2011-February 2013. The questionnaires - EuroQol 5-Dimensions 3-Levels and State-Trait Anxiety Inventory - were answered before surgery, at discharge and 1 and 6 months after surgery. Data were analysed using inferential statistics to describe differences between groups of patients (Kruskal-Wallis test) and between assessments within groups (Friedman's ANOVA).

Results. Patients $(N=105)$, divided into three groups based on surgical procedure, showed a high health index and a low state anxiety in all assessments without differences between the groups. Patients considered for abdominoperineal resection rated their pre-operative health as significantly higher than patients after rectal and colonic resections did. Within groups, patients recovering from abdominoperineal resection and rectal resection deteriorated significantly in health index 1 month after surgery. However, after 6 months they had improved again. After colonic resection, patients improved significantly in self-rated health and anxiety 1 month after surgery with no further discernible improvement after 6 months.

Conclusion. The study showed that patients generally had a high level of health and a low level of anxiety throughout the study period. Only a few differences occurred between assessments within groups.
\end{abstract}

Keywords: colorectal cancer, EQ-5D-3L, ERAS, general health, nursing practice, STAI, state anxiety, surgery 
Why is this research needed?

- Short hospital stays for patients undergoing colorectal surgery induce a need for knowledge about the postoperative period outside of the hospital.

- To gain an holistic understanding of the postoperative recovery period for patients with colorectal cancer, it is necessary not only to focus on surgical outcomes - such as physiological symptoms - but also on general health and state anxiety.

What are the key findings?

- After different types of colorectal cancer surgery, patients did not differ in general health or state anxiety before surgery or during the first 6 months after surgery.

- There was a change in both general health and state anxiety during the patients' surgical journey. General health temporarily deteriorated 1 month after surgery for patients undergoing abdominoperineal resection and rectal resection. Patients undergoing colonic resection had the lowest health and highest state anxiety before surgery, but they improved significantly during the first month postoperatively.

How should the findings be used to influence policy/ practice/research/education?

- Knowledge of general health and state anxiety for patients undergoing and recovering from different types of colorectal cancer surgery procedures is important to guide healthcare professionals to provide for appropriate individual information and support.

- Healthcare professionals should not only pay attention to signs of physical complications during the patients' recovery process after colorectal surgery but also adopt a holistic approach with the attention on perceived health and/or anxiety.

\section{Introduction}

Colorectal cancer is the third most common cancer in the world. In 2012, some 746000 men and 614000 women worldwide were diagnosed with the disease (Ferlay et al. 2014). Curative surgery is the first choice of treatment and improvements in early detection, surgical techniques and perioperative care allow surgery even for older patients and those with comorbidities (Delaney et al. 2001, Pawa et al. 2012). Colorectal cancer can cause not only several physical symptoms but also psychological distress, such as anxiety.
Such consequences all have a negative impact on health (Davis 2009, Marvetano et al. 2013).

In recent decades, enhanced recovery after surgery (ERAS) has become a common perioperative strategy. It was developed based on the identification of factors that negatively affect postoperative recovery. Interventions such as preoperative information and patient education, together with minimal invasive surgical techniques, early postoperative feeding and intense mobilization - were gathered into a concept aimed at increasing patients' opportunities for accelerated postoperative recovery (Lassen et al. 2009). The ERAS concept has been widely evaluated, showing benefits that include reduced postoperative complications and length of hospital stay (LoS) compared with conventional strategies (Spanjersberg et al. 2011). However, there is still little knowledge about how patients perceive their health and state of anxiety when recovering after colorectal cancer surgery in an ERAS context.

\section{Background}

There is a growing interest in patient reported outcomes and quality of life (QoL) is a commonly used outcome measure after surgery for colorectal cancer. Quality of life has been referred to as a multidimensional measure covering aspects of physical, functional, emotional and social wellbeing (Cella 1994). Health- related quality of life (HRQoL) represents aspects in QoL that directly relate to a person's health (Fayers \& Hays 2005). However, the two concepts are commonly used without any distinction. In this study, our focus is health, which consequently affects the patient's HRQoL. The concept of health has been widely discussed resulting in different theories. According to Tengland (2007), two dimensions constitute health-ability and wellbeing. Ability refers to as abilities or dispositions that people typically develop. For example, the ability to perform activities of daily living. Well-being is a subjective experience of some kind of feeling in the form of a sensation, mood or emotion. To be health-related, the well-being must have an immediate cause in the person, therefore, Tengland only count sensations and moods as health-related. The two dimensions influence each other and an increase or decrease in either of the two dimensions cause an increase or decrease in health. A patient recovering from colorectal cancer surgery is most likely experiencing some postoperative symptoms affecting their subjective health-related wellbeing and/or their ability to fully live their ordinary life. Based on the two-dimensional theory of health, it could therefore be assumed that the health of a patient recovering 
from colorectal cancer surgery is affected in various degrees during the postoperative recovery period.

Several studies have investigated HRQoL in patients with colorectal cancer undergoing surgery. It has been shown that the patients may suffer from a reduced HRQoL and that they report both physical and psychological problems (Arndt et al. 2004, Wilson et al. 2006, Tsunoda et al. 2007). The location of the tumour has been shown to influence HRQoL. A tumour on the right side of the colon can cause anaemia, weight loss or deterioration of one's general condition. Predominant symptoms for tumours on the left side of the colon or in sigmoid colon are problems with defecation and blood or mucus in the stool. A more distal tumour causes more distinct problems; therefore, defecation problems typically accompany rectal tumours (Debas 2004). Furthermore, colorectal surgery can have diverse side effects - such as incontinence, diarrhoea or sexual dysfunction, mostly occurring in patients after rectal surgery - and some of these side effects have also proved to be persistent (Wilson et al. 2006, Di Fabio et al. 2008, Caravati-Jouvenceaux et al. 2011). However, studies on longtime survivors (up to 15 years) have pointed out that the HRQoL in these patients, in general, was comparable to that of the norm population, despite both physical and psychological symptoms (Jansen et al. 2010).

Some studies have evaluated HRQoL in patients undergoing colorectal surgery according to the ERAS concept. King et al. (2006) showed that patients undergoing colorectal surgery according to ERAS did not differ in HRQoL from patients receiving conventional colorectal surgical hospital care. Scarpa et al. (2013) studied the benefits of minimally invasive surgery, that is, laparoscopic surgery, comparing older ( $>70$ years) and younger $(<70$ years) patients undergoing either laparoscopic colectomy or an open colectomy. Before surgery, there was no statistically significant difference in HRQoL between groups. One month after laparoscopic colectomy, HRQoL had deteriorated significantly in older patients with respect to younger ones. There was no statistically significant difference between older patients undergoing laparoscopic or open surgery.

An additional factor that may negatively affect health is anxiety (Ramos et al. 2008, Davis 2009). The reasons for anxiety in relation to surgical procedures have been described as fear of surgery itself, complications after surgery, postoperative pain and physical disability (Yilmaz et al. 2011). The waiting period before surgery has been reported by patients as frustrating and filled with anxiety (Moene et al. 2005). Furthermore, anxiety has been demonstrated to have a negative impact on recovery and postoperative outcomes, such as pain and length of hospital stay
(Kiecolt-Glaser et al. 1998, Ramos et al. 2008). According to the ERAS concept, patients receive extensive information and education prior to surgery, mostly from the colorectal nurse specialist. This is supposed to prepare and encourage the patients to participate actively in their recovery. Studies have demonstrated that preoperative information eases fear prior to surgery and patients have indicated that the information delivered according to ERAS made their upcoming hospital stay less frightening (Aasa et al. 2013, Shahmansouri et al. 2014). During the patient's hospital stay, ward nurses should prepare patients individually for the recovery period that takes place outside the hospital, that is, at home. The encounter with nurses has been experienced by patients as valuable and as a source of information (Moene et al. 2005). Hence, it is essential that the nurses have knowledge of patient-related postoperative outcomes to give patients correct and useful information. Postoperative outcomes can differ not only due to surgical procedure but it also depends on the patients' health status and feelings of anxiety before surgery and at discharge. It has been proposed that surgical patients are less likely to access a health facility after discharge if they have received information about issues such as wound care and pain management (Henderson \& Zernike 2001). Furthermore, during the recovery process when the patients are at home, it has been revealed that patients hesitate to initiate contact with healthcare professionals because they do not know if their problems are important enough to justify contact (Beech et al. 2011).

In summary, it is known that patients with colorectal cancer may suffer from deteriorated HRQoL and from anxiety owing to the disease, the surgery and postoperative symptoms. It is also known that the tumour's location causes different postoperative outcomes and long-term symptoms related to the surgical procedure (Wilson et al. 2006, Di Fabio et al. 2008, Jansen et al. 2010, CaravatiJouvenceaux et al. 2011, Jakobsson et al. 2014). The ERAS concept induces an accelerated physiological recovery and fewer complications (Basse et al. 2002, Kehlet \& Wilmore 2002, Varadhan et al. 2010, Ren et al. 2012). However, health and anxiety in patients undergoing different colorectal surgical procedures according to ERAS have not been clearly described. Neither has the question been studied from a longitudinal perspective. The concept of ERAS is frequently implemented for patients undergoing different types of colorectal cancer surgery all over the world. But since patients treated according to ERAS are surrounded by professionals only during their short hospital stay, they have to go through main part of their recovery on their own. Therefore, there is a need to further evaluate 
patient-related outcomes such as health and anxiety so as to enable nurses, among others in the multidisciplinary team, to provide adequate individual information and support throughout the patients' surgical journey (Neville et al. 2014, Feldman et al. 2015).

\section{The study}

\section{Aim}

The aim of this study was to describe and compare general health and state anxiety before surgery and up to 6 months after surgery in patients with colorectal cancer undergoing elective rectal resection, abdominoperineal resection or colonic resection in an enhanced recovery context.

\section{Design}

A prospective cohort study design was used.

\section{Participants}

A total of 225 patients at a university hospital in southern Sweden were eligible for participation in the study. In all, 176 patients agreed to participate (Figure 1). Patients were considered for inclusion if they had been diagnosed with colorectal cancer, would undergo elective surgery on the colon or rectum with the intention to follow the ERAS concept and had the ability to understand and complete questionnaires in Swedish.

\section{Procedure}

Patients were consecutively enrolled to the study. Written information was sent to the patients by mail prior to the preoperative informational visit at the surgical outpatient clinic. During the visit, additional oral information about the study was given by the colorectal nurse specialist and written informed consent was obtained. If the patients chose to participate, they received the first questionnaire to measure preoperative values of health and anxiety. The questionnaire contained the EuroQol 5-Dimensions 3-levels (EQ-5D-3L) and the State-Trait Anxiety Inventory (STAI) along with a prepaid mailing envelope to return the questionnaire before surgery. No reminders were distributed due to the short time between the visit at the surgical outpatient clinic and surgery. Patients who did not return the questionnaire were excluded. To capture feelings of anxiety related to discharge, patients received the STAI on the day of discharge from hospital and were asked to return the

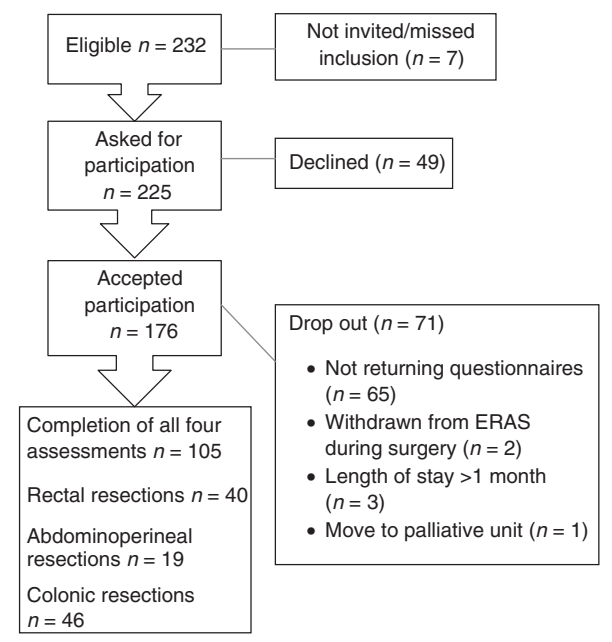

Figure 1 Data collection process.

completed questionnaire before leaving. Non-responders received no reminders. To observe changes in health and anxiety over time, the patients received the EQ-5D-3L and the STAI at 1 month and 6 months after surgery. The questionnaire was distributed by mail together with a prepaid envelope for return. Non-responders received two reminders.

\section{Data collection}

Data were collected from October 2011-February 2013. Demographical variables - namely age, gender, American Society of Anaesthesiologists (ASA) classification, surgical procedure, length of hospital stay and pre- and postoperative treatment - were collected from each patient's medical records.

General health and state anxiety was measured using two instruments: the EQ-5D-3L and the STAI. The instruments were used with permission from the EuroQol Executive Office and Mind Garden Inc.

\section{General bealth}

The EQ-5D-3L is a generic instrument designed for selfcompletion and it provides a descriptive health profile and an index value for health status (The EuroQol group, 1990). The first part includes five items, referred to as dimensions, about mobility, self-care, usual activities, pain/ discomfort and anxiety/depression. Each dimension has 
three response levels scored as 1-3: 'no problems' (1); 'some problems' (2); and 'extreme problems' (3). Based on scores from the five dimensions, a health status is achieved and defined by a five-digit number (Brooks 1996). An EQ index value can then be derived from the five-digit number. The index can range from -0.59 (indicating worst health) to 1 (indicating best health). The second part is the EQ Visual Analog Scale (EQ VAS), where patients indicate their selfrated state of health on a vertical analogue scale ranging from the worst imaginable (VAS 0) to the best imaginable health (VAS 100).

\section{State anxiety}

The STAI is intended for self-reported measures of state and trait anxiety (Spielberger 1983). In this study, the stateanxiety form was used. State anxiety has been described by Spielberger (1983) as an emotional state existing at a given moment in time and at a particular level of intensity. It is characterized by subjective feelings of tension, apprehension, nervousness and worry. The state-anxiety form consists of 20 items expressed as statements that indicate how respondents feel 'right now, at this moment'; responses are: (1) 'not at all'; (2) 'somewhat'; (3) 'moderately so' and (4) 'very much so'. The answers are transformed into weighted scores of 1-4, where 4 indicates the presence of a high level of anxiety. However, 10 items are phrased so that a high score reflects absence of anxiety. In those 10 items, the weighted scores are reversed. Scores derived from the stateanxiety form can vary from a minimum of 20 (absence of anxiety)-a maximum of 80 (high level of anxiety).

\section{Ethical considerations}

Research Ethics Committee approval was obtained from the Regional Ethics Board, Lund, Sweden (Dnr 2011/451). Patients who were asked to participate in the study received verbal and written information before written consent was obtained. Patients were informed of their right to withdraw from the study at any time. Personal information about the patients was kept confidential.

\section{Data analysis}

Prior to analysis, patients were divided into three groups based on surgical procedure: rectal resection $(n=40)$, abdominoperineal resection (APR) $(n=19)$ and colonic resection $(n=46)$. Demographical variables for the three groups of patients were calculated and described by frequency distributions in number, percentage, mean, median and standard deviation (SD). The distribution of normality was calculated using the Kolmogorov-Smirnov test. Statistically significant differences between groups regarding demographical variables were calculated using one-way ANOVA, Chi-square or the Kruskal-Wallis test when appropriate. If significance occurred, an independent-samples $t$-test or the Mann-Whitney $U$-test was used for pairwise comparisons.

To derive an index value from the EQ-5D-3L questionnaire, the time trade-off (TTO) valuation technique was used. Since there is no value sets available for the Swedish population, the British value sets was used (Dolan 1997).

Values of EQ index, EQ VAS and state anxiety were calculated and described by means and standard deviations (SD). Statistically significant differences between groups and assessments were calculated using the Kruskal-Wallis test owing to a general skewed distribution and presence of small groups. Hence, statistical differences between assessments within groups were calculated using Friedman's ANOVA.

The level of significance was set at $P \leq 0.05$. To reduce the risk of Type I error due to multiple tests, each significant value was adjusted using Bonferroni's method (Altman 1999).

To obtain scores from the STAI, the weighted scores for all 20 statements were added together. In cases where there were blank answers, the expected raw score was used by calculating the average of the statements answered and then multiplying it by 20 (Spielberger 1983). Cases with more than three blank answers were excluded from the analysis.

Calculations were made using the Statistical Package for the Social Sciences (SPSS version 21; IBM, New York, NY, USA).

\section{Validity and reliability/rigour}

To ensure the accuracy of data, this study was based on well-established instruments developed and validated in Swedish. The EQ-5D-3L is an instrument originally developed and validated in five languages, among them Swedish (The EuroQol Group 1990). Because it is non-disease specific, it has been frequently used both in general settings and in patient samples, such as patients with colorectal cancer.

The STAI questionnaire is a validated, well-recognized instrument that has been adapted to over 30 languages and has been extensively used in different settings throughout the years (Spielberger et al. 1970, Spielberger 1983).

\section{Results}

Of the $176(78.2 \%)$ patients who agreed to participate, 105 $(59.6 \%)$ patients - 52 men $(49.5 \%)$ and 53 women 
$(50.5 \%)$ with a mean age of 68.5 years - answered the questionnaires on all four occasions (Figure 1). There were 71 patients lost for follow-up. Of those, 65 did not return the questionnaires. Furthermore, two patients were withdrawn from care according to ERAS during or immediately after surgery (surgical intervention unknown). Three patients were hospitalized for more than 1 month, consequently missing the 1-month assessment (two after rectal resection and one after APR) and one patient was transferred to a palliative-care unit (rectal resection). There were no significant differences between the patients who completed the study and those who were lost for follow-up regarding either age $(P=0.55)$ or gender $(P=0.099)$.

\section{Patient characteristics}

No significant differences appeared between patients undergoing rectal resection or APR in terms of the demographical variables (Table 1). Patients undergoing colonic resections were significantly older and had a shorter mean LoS than patients both after rectal resection and APR. Furthermore, both patients undergoing rectal resection and APR underwent pre-operative treatment, mainly radiotherapy, significantly more frequently than those patients undergoing colonic resection did.

\section{EQ index}

Before surgery, the three groups of patients all reached a high level of health as measured by the EQ index, without any statistically significant differences between groups (Table 2). The 1-month and 6-month assessment still showed no significant differences between the groups.

Within groups, patients recovering from rectal resection and APR had deteriorated significantly in health from before surgery to 1 month after surgery. From 1-6 months after surgery, the EQ index significantly improved for both groups. Among patients recovering from colonic resection, there were no statistically significant differences in EQ index across the three assessments.

\section{EQ VAS}

Between groups, patients rated their preoperative health status differently to a significant degree (Table 2). Patients considered for APR reported significantly higher EQ VAS scores than did patients set to undergo colonic resection and rectal resection. However, at the 1-month and 6-month assessments, no significant differences appeared between the groups of patients.

Table 1 Demographics and differences between groups of patients.

\begin{tabular}{|c|c|c|c|c|}
\hline & $\begin{array}{l}\text { Rectal resection } \\
\text { (RR) } \\
n=40\end{array}$ & $\begin{array}{l}\text { Abdominoperineal } \\
\text { resection (APR) } \\
n=19\end{array}$ & $\begin{array}{l}\text { Colonic resection } \\
\text { (CR) } n=46\end{array}$ & $P$ value* \\
\hline Age, mean (SD) & $65.5(11.2) 0.004^{\text {th }}$ & $65 \cdot 5(10 \cdot 1)^{\text {料 }} 0.014$ & $72.2(9.6)$ & $0.015^{\dagger, \pi}$ \\
\hline \multicolumn{5}{|l|}{ Gender $n(\%)$} \\
\hline Male & $23(57 \cdot 5)$ & $11(57.9)$ & $18(39.1)$ & $0 \cdot 170^{\ddagger}$ \\
\hline Female & $17(42 \cdot 5)$ & $8(42 \cdot 1)$ & $28(60.9)$ & \\
\hline $\begin{array}{l}\text { Pre-operative } \\
\text { treatment, } n(\%)\end{array}$ & $14(35 \cdot 0)<0.001^{\dagger 4}$ & $8(42 \cdot 1)^{\text {t木 }}<0.001$ & $1(2 \cdot 2)$ & $<0 \cdot 001^{\ddagger}$ \\
\hline ASA classification, md & 2 & 2 & 2 & $0.359^{\S}$ \\
\hline $\begin{array}{l}\text { Length of hospital stay, } \\
\text { days, mean (SD) }\end{array}$ & $11.3(4.6) 0.001^{+\dagger}$ & $10 \cdot 1(3.8)^{\text {椋 }} 0.037$ & $8.9(4.8)$ & $0.009^{\S, * * *}$ \\
\hline $\begin{array}{l}\text { Postoperative treatment } \\
\text { (chemotherapy), } n(\%)\end{array}$ & $16(41 \cdot 0)$ & $8(42 \cdot 1)$ & $17(38.6)$ & $0.959^{\ddagger}$ \\
\hline
\end{tabular}

"Level of significance was set at $P<0 \cdot 05$. Statistically significant values were adjusted using Bonferroni's method.

†One-way ANOVA.

The chi-square.

§The Kruskal-Wallis test.

Independent-samples $t$-test.

**Mann-Whitney $U$-test.

${ }^{\dagger}$ Statistically significant difference between RR and CR.

${ }^{*}$ Statistically significant difference between APR and CR.

SD, standard deviation; ASA, American Society of Anesthesiologists. 
Table 2 Means and standard deviations (SD) for EQ VAS, EQ index and state anxiety (STAI questionnaire) and differences between groups of patients and between assessments within the groups of patients.

\begin{tabular}{|c|c|c|c|c|}
\hline & $\begin{array}{l}\text { Rectal resection } \\
n=40\end{array}$ & $\begin{array}{l}\text { APR } \\
n=19\end{array}$ & $\begin{array}{l}\text { Colonic resection } \\
n=46\end{array}$ & $\begin{array}{l}P \text { value between } \\
\text { groups" }{ }^{\dagger}\end{array}$ \\
\hline \multicolumn{5}{|c|}{ Preoperative mean (SD) } \\
\hline EQ VAS & $54 \cdot 8(30 \cdot 6)$ & $77 \cdot 1(9 \cdot 4)$ & $54 \cdot 5(25 \cdot 2)$ & $\begin{array}{r}0.0090 .014^{8} \\
<0.001^{\pi}\end{array}$ \\
\hline $\mathrm{EQ}$ index & $0.83(0.13)$ & $0.86(0.12)$ & $0 \cdot 81(0 \cdot 12)$ & 0.348 \\
\hline State anxiety & $43.4(14.5)$ & $39.3(11.7)$ & $41 \cdot 1(13 \cdot 8)$ & 0.600 \\
\hline \multicolumn{5}{|c|}{ Day of discharge mean (SD) } \\
\hline State anxiety & $39 \cdot 9(14 \cdot 1)$ & $32.7(9.4)$ & $37 \cdot 3(11.5)$ & $0 \cdot 231$ \\
\hline \multicolumn{5}{|c|}{ One month postoperative mean (SD) } \\
\hline EQ VAS & $64.8(21.8)$ & $69.1(17.0)$ & $72 \cdot 2(20 \cdot 7)$ & 0.222 \\
\hline $\mathrm{EQ}$ index & $0.77(0.13)$ & $0.75(0.13)$ & $0.83(0.14)$ & 0.063 \\
\hline State anxiety & $42 \cdot 5(13 \cdot 1)$ & $36 \cdot 7(12.4)$ & $36 \cdot 1(14.5)$ & 0.086 \\
\hline \multicolumn{5}{|c|}{ Six months postoperative mean (SD) } \\
\hline EQ VAS & $68.9(21.7)$ & $78 \cdot 8(16 \cdot 1)$ & $74.4(21 \cdot 0)$ & $0 \cdot 163$ \\
\hline $\mathrm{EQ}$ index & $0.81(0.14)$ & $0.83(0.11)$ & $0.86(0.15)$ & 0.330 \\
\hline State anxiety & $40 \cdot 0(13 \cdot 1)$ & $35 \cdot 0(13 \cdot 1)$ & $33.8(13.6)$ & $0 \cdot 129$ \\
\hline \multicolumn{5}{|c|}{$P$ value within group*, } \\
\hline EQ VAS & 0.074 & 0.052 & $<0.001<0.001^{* *}$ & \\
\hline \multirow[t]{2}{*}{ EQ index } & $0.0160 .003^{* * *}$ & $0.0400 .012^{* *}$ & $0 \cdot 330$ & \\
\hline & $0.034^{+\dagger}$ & $0.012^{\dagger \dagger}$ & & \\
\hline State anxiety & $0 \cdot 128$ & 0.231 & $0.004 \quad 0.014^{* * *}$ & \\
\hline
\end{tabular}

"Level of significance was set at $P<0.05$. Statistically significant values were adjusted using Bonferroni's method.

${ }^{\dagger}$ Kruskal-Wallis test.

${ }^{\dagger}$ Friedman's ANOva. Mann-Whitney U-test was used for pairwise comparisons.

${ }^{\S}$ Statistically significant difference between rectal resection and APR.

"Statistically significant difference between APR and colonic resection.

* Statistically significant difference within group between preoperative and day of discharge.

${ }^{\dagger}$ Statistically significant difference within group between 1 month and 6 months after surgery.

No significant differences were seen in the groups over time except for the patients recovering from colonic resection, who rated their health as significantly higher on the 1-month assessment compared with before surgery.

\section{State anxiety}

As Table 2 shows, no statistically significant differences could be seen in state anxiety between the three groups of patients in any assessment. However, within groups, patients undergoing colonic resection reported a significantly lower level of anxiety on the day of discharge compared with before surgery.

\section{Discussion}

The results of this study show that patients undergoing rectal resection, APR and colonic resection all had high levels of health as measured by EQ index and EQ VAS. Surprisingly, patients undergoing APR rated their preoperative health by EQ VAS as significantly higher than the other two groups did. Patients who are considered for a surgical intervention such as APR have a tumour located in the lower third of the rectum. This usually induces more problems with faecal incontinence and defecation than for patients with a more approximate tumour. In addition, patients considered for APR did not differ in preoperative treatment, such as radiotherapy, from patients considered for a rectal resection. Eventual side effects from the radiotherapy should be comparable for the both groups of patients. There is no apparent reason that can explain this finding and no previous study has reported similar results. However, the group is small and this outcome must, therefore, be interpreted with care.

There was a statistically significant but contemporary deterioration in EQ index at the 1-month assessment among patients recovering from rectal resection and APR. Similar results were obtained in the study by King et al. (2006), where patients - both cared for and not cared for according to ERAS, with no statistically significant difference between groups - had deteriorated in most aspects of HRQoL 2 weeks after surgery but then recovered after 
3 months. The patients in the study by Tsunoda et al. (2007) also showed deterioration in HRQoL 1 month after surgery compared with before surgery and the scores returned to preoperative levels or better after 4 months. However, both these studies were conducted on colorectal cancer patients in general, without considering the type of surgical intervention; further, the care setting in Tsunoda et al. (2007) was not according to ERAS.

A previous study by Wilson et al. (2006) used the EQ$5 \mathrm{D}-3 \mathrm{~L}$ in patients with colorectal cancer 6 weeks after rectal resection or colonic resection. The patients were not cared for according to ERAS. Univariate analysis indicated that patients recovering from rectal resection had a significantly lower EQ index than patients after colonic resection did. These results are very similar to the findings of our study about EQ index 1 month after surgery in patients recovering from rectal and colonic resection. However, owing to correction for multiple comparisons, the difference in this study became non-significant. The EQ-5D-3L has also been used to measure health in a Swedish norm population (Burström et al. 2001), showing an EQ index comparable to general health for patients in this study, except for patients 1 month after rectal resection and APR.

The patients in this study exhibited a low level of anxiety throughout the entire study period. Reference values for the Swedish norm population were presented in a study by Forsberg and Björvell (1993) showing a mean state anxiety lower than the values in present study; this indicates that the patients were not unaffected despite their low levels of anxiety. Few studies have been performed on state anxiety among colorectal cancer patients and to our knowledge there is no study of patients cared for according to ERAS. A study by Elkins et al. (2004) reported preoperative state anxiety measured with the STAI in patients undergoing general elective colorectal surgery. It showed a mean state anxiety comparable to the preoperative values in this study. Although there was a statistically significant difference in anxiety level for patients only in the colonic resection group in our study, the highest scores for all patients - that is, the highest levels of anxiety - were reported in the pre-operative assessment. This may reflect a natural response to the approaching surgery, as earlier described by Yilmaz et al. (2011). It is still not clear whether the low anxiety in this study is a result of ERAS, given its similarity to results in studies of patients that are not cared for according to ERAS.

\section{Limitations}

In this study, the patients were studied as three groups of patients. This was based on previous research by Jakobsson et al. (2014), which showed differences between types of surgical procedures in terms of length of surgery, blood loss and length of hospital stay, but also a variety in recovery. When analysing and presenting results from a joint group of patients undergoing colorectal cancer surgery, there is a risk that the result may not reflect the variations in health and anxiety that occur after different types of surgical procedures. However, the groups in this study were not large, nor were they equal in size, leading to difficulties in generalizing the results. The descriptive design and nature of data lead to difficulties in calculating an effect size, thereby no former power calculation was conducted. Hence, it could be that the sub-sample sizes were too small to detect statistically significant differences, thereby leading to a type II statistical error affecting the validity of the study (Argyrous 2011).

There were some dropouts throughout the study period; those patients did not differ from patients who completed the study about gender or age. Of the 71 patients not completing the study, 65 did not return questionnaires for unknown reasons. It could be that they did not have the energy to answer the questionnaires owing to complications or adverse side effects of surgery or additional treatment; if this is so, it could have led to a false-positive result in our study. On the other hand, the results of this study show similarities with those of other studies, indicating trustworthiness.

General health was measured on three occasions - before surgery, 1 month and 6 months after surgery - whereas state anxiety was measured also on the day of discharge. We chose not to measure general health on the day of discharge because it was assumed that patients would have had a shorter LoS and that general health could not be affected in that short a time. However, results showed a statistically significant deterioration in EQ index between the assessment before surgery and the 1-month follow-up for two groups of patients, so it would have been valuable to have additional information about health status on the day of discharge.

The majority of instruments measuring health or HRQoL contain a great amount of questions. This could lead to the risk of patients not answering and returning the questionnaires. Therefore, the decision to use the EQ-5D-3L was based on the need for a short, easy-to-use instrument to combine with the STAI questionnaire. However, the EQ5D-3L consists of five dimensions and only three levels of responses, making it less sensitive to small changes in health state. As respondents can choose only 'no, some or severe' problems, a person could improve or decline in some dimension but not enough to reach another level of problem (Herdman et al. 2011). It could be that the results in this study, which indicate a high level of health with little changes between measurements, are a consequence of the 
low sensitivity of the scale. It could, therefore, lead to reduced validity. Furthermore, there is always a potential risk in longitudinal studies for history bias when things other than the surgical procedure affect the patients' lives, thereby threatening the study's internal validity (Polit \& Beck 2013). With a generic instrument such as the EQ-5D$3 \mathrm{~L}$, this effect could be difficult to detect. The advantage of using a generic, non-disease-specific instrument is that the results can be compared with those from other groups of patients recovering from various types of surgery. Since ERAS is implemented in areas others than colorectal cancer surgery, it may be valuable to use an instrument that allows for comparisons between surgical procedures and with norm populations.

\section{Conclusion}

All three groups of patients reported a high level of health and a low level of anxiety both preoperatively and up to 6 months after surgery. The only difference between the three groups of patients appeared in the preoperative assessment, where patients undergoing APR rated their health as measured by EQ VAS significantly higher than those in the two other groups did.

Only a few differences arose in the patient groups between the different assessments. Patients recovering from rectal resection and APR had deteriorated contemporary in health at the 1-month assessment as measured by EQ index. Furthermore, patients undergoing colonic resection rated their health with EQ VAS significantly higher at the 1-month assessment than they had before surgery. Those patients also reported a significantly lower level of anxiety at the day of discharge than before surgery.

Most of the extensive information and education in the ERAS concept is provided before surgery. The way ERAS is currently presented, patient information and education about the postoperative period after discharge are not clearly described. In that concern, it would be beneficial to further develop the ERAS concept. It is important that nurses have a holistic approach in the contact with the patients and not only observe and treat complications. Attention should also be directed towards signs of perceived ill health and/or anxiety to individually support the patients throughout their recovery period.

\section{Funding}

This study was conducted with a grant from the Academy of Care Science at Skane University Hospital.

\section{Conflict of interest}

No conflict of interest has been declared by any of the authors.

\section{Author contributions}

All authors have agreed on the final version and meet at least one of the following criteria [recommended by the ICMJE (http://www.icmje.org/recommendations/)]:

- substantial contributions to conception and design, acquisition of data, or analysis and interpretation of data;

- drafting the article or revising it critically for important intellectual content.

\section{References}

Aasa A., Hovbäck M. \& Berterö C.M. (2013) The importance of preoperative information for patient participation in colorectal surgery care. Journal of Clinical Nursing 22, 1604-1612. doi:10.1111/jocn.12110.

Altman D.G. (1999) Practical Statistics for Medical Research. Chapman \& Hall, London.

Argyrous G. (2011) Statistics for research With a guide to SPSS. Sage Publications Ltd., London, Great Britain.

Arndt V., Merx H., Stegmaier C., Ziegler H. \& Brenner H. (2004) Quality of life in patients with colorectal cancer 1 year after diagnosis compared to the general population: a populationbased study. Journal of Clinical Oncology 22(23), 4829-4836. doi:10.1200/JCO.2004.02.018.

Basse L., Raskov H.H., Hjort Jakobsen D., Sonne E., Billesbolle P. \& Hendel H.W. (2002) Accelerated postoperative programme after colonic resection improves physical performance, pulmonary function and body composition. British Journal of Surgery 89(4), 446-453. doi:10.1046/j.0007-1323.2001.02044.x.

Beech N., Arber A. \& Faithfull S. (2011) Restoring a sense of wellness following colorectal cancer: a grounded theory. Journal of Advanced Nursing 68(5), 1134-1144. doi:10.1111/j.13652648.2011.05820.x.

Brooks R. (1996) EuroQol: the current state of play. Health Policy 37(1), 53-72. doi:10.1016/0168-8510(96)00822-6.

Burström K., Johannesson M. \& Diderichsen F. (2001) Swedish population health-related quality of life results using the EQ-5D. Quality of Life Research 10(7), 621-635. doi:10.1023/ A:1013171831202.

Caravati-Jouvenceaux A., Launoy G., Klein D., Henry-Amar M., Abeilard E., Danzon A., Pozet A., Velten M. \& Mercier M. (2011) Health-related quality of life among long-term survivors of colorectal cancer: a population-based study. The Oncologist 16(11), 1626-1636. doi:10.1634/theoncologist.2011-0036.

Cella D.F. (1994) Quality of life: concepts and definition. Journal of Pain and Symptom Management 9(3), 186-192. doi:10.1016/ 0885-3924(94)90129-5. 
Davis M.C. (2009) Building emotional resilience to promote health. American Journal of Lifestyle Medicine 3(suppl 1), 60S-63S. doi:10.1177/1559827609335152.

Debas H.T. (2004) Gastrointestinal Surgery: Pathophysiology and Management. Springer-Verlag, New York Inc., New York, NY.

Delaney C.P., Fazio V.W., Senagore A.J., Robinson B., Halverson A.L. \& Remzi F.H. (2001) 'Fast track' postoperative management protocol for patients with high co-morbidity undergoing complex abdominal and pelvic colorectal surgery. British Journal of Surgery 88(11), 1533-1538. doi:10.1046/ j.0007-1323.2001.01905.x.

Di Fabio F., Koller M., Nascimbeni R., Talarico C. \& Salerni B. (2008) Long-term outcome after colorectal cancer resection. Patients' self-reported quality of life, sexual dysfunction and surgeons' awareness of patients' needs. Tumori 94(1), 30-35.

Dolan P. (1997) Modeling valuations for EuroQol health states. Medical care 35(11), 1095-1108.

Elkins G., Staniunas R., Hasan Rajab M., Marcus J. \& Snyder T. (2004) Use of a numeric visual analog anxiety scale among patients undergoing colorectal surgery. Clinical Nursing Research 13(3), 237-244. doi:10.1177/1054773803262222.

Fayers P. \& Hays R., eds. (2005) Assessing Quality of Life in Clinical Trials: Analysis and Interpretation, 2nd edn. Oxford University Press, New York. ISBN 0-19-852769-1.

Feldman L.S., Lee L. \& Fiore J. Jr (2015) What outcomes are important in the assessment of Enhanced recovery After Surgery (ERAS) pathways? Canadian Journal of Anesthesia 62, 120-130. doi:10.1007/s12630-014-0263-1.

Ferlay J., Soerjomataram I., Dikshit R., Eser S., Mathers C., Rebelo M., Parkin D.M., Forman D. \& Bray M. (2014) Cancer incidence and mortality worldwide: sources, methods and major patterns in GLOBOCAN 2012. International Journal of Cancer 136(5), 359-386. doi: 10.1002/ijc.29210.

Forsberg C. \& Björvell H. (1993) Swedish population norms for the GHRI, HI and STAI-state. Quality of Life Research 2(5), 349-356. doi:10.1007/BF00449430.

Henderson A. \& Zernike W. (2001) A study of the impact of discharge information for surgical patients. Journal of Advanced Nursing 35(3), 435-441. doi:10.1046/j.1365-2648.2001. 01857.x.

Herdman M., Gudex C., Lloyd A., Janssen M.F., Kind P., Parkin D., Bonsel G. \& Badia X. (2011) Development and preliminary testing of the new five-level version of EQ-5D (EQ-5D-5L). Quality of Life Research 20(10), 1727-1736. doi:10.1007/ s11136-011-9903-x.

Jakobsson J., Idvall E. \& Wann-Hansson C. (2014) Patientreported recovery after enhanced colorectal cancer surgery: a longitudinal six-month follow-up study. International Journal of Colorectal Disease 29(8), 989-998. doi:10.1007/s00384-0141939-2.

Jansen L., Koch L., Brenner H. \& Arndt V. (2010) Quality of life among long-term ( $>5$ years) colorectal cancer survivors systematic review. European Journal of Cancer 46(16), 2879 2888. doi:10.1016/j.ejca.2010.06.010.

Kehlet H. \& Wilmore D.W. (2002) Multimodal strategies to improve surgical outcome. The American Journal of Surgery 183 (6), 630-641. doi:10.1016/S0002-9610(02)00866-8.
Kiecolt-Glaser J.K., Page G.G., Marucha P.T., MacCallum R.C. \& Glaser R. (1998) Psychological influences on surgical recovery. Perspectives from psychoneuroimmunology. American Psychologist 53, 1209-1218. doi:10.1037/0003-066X.53.11. 1209.

King P.M., Blazeby J.M., Ewings P., Longman R.J., Kipling R.M., Franks P.J., Sheffield J.P., Evans L.B., Soulsby M., Bulley S.H. \& Kennedy R.H. (2006) The influence of an Enhanced Recovery Programme on clinical outcomes, costs and quality of life after surgery for colorectal cancer. Colorectal Disease 8(6), 506-513. doi:10.1111/j.1463-1318.2006.00963.x.

Lassen K., Soop M., Nygren J., Cox P.B., Hendry P.O., Spies C., von Meyenfeldt M.F., Fearon K.C., Revhaug A., Norderval S., Ljungqvist O., Lobo D.N., Dejong C.H. \& Enhanced Recovery After Surgery (ERAS) Group (2009) Consensus review of optimal perioperative care in colorectal surgery: Enhanced Recovery After Surgery (ERAS) Group recommendations. Archives of Surgery 144(10), 961-969. doi:10.1001/archsurg.2009.170.

Marvetano S., Forjaz M.J., Grosso G., Mistretta A., Giorgianni G., Platania A., Gangi S., Basile F. \& Biondi A. (2013) Health related quality of life in colorectal cancer patients: state of the art. BMC Surgery 13(suppl 2), S15. doi:10.1186/1471-2482-13-S2-S15.

Moene M., Bergbom I. \& Skott C. (2005) Patients' existential situation prior to colorectal surgery. Journal of Advanced Nursing 54(2), 199-207. doi:10.1111/j.1365-2648.2006.03800.x.

Neville A., Lee L., Antonescu I., Mayo N.E., Vassiliou M.C., Fried G.M. \& Feldman L.S. (2014) Systematic review of outcomes used to evaluate enhanced recovery after surgery. British Journal of Surgery 101, 159-170. doi:10.1002/bjs.9324.

Pawa N., Cathcart P.L., Arulampalam T.H.A., Tutton M.G. \& Motson R.W. (2012) Enhanced recovery program following colorectal resection in the elderly patient. World Journal of Surgery 36(2), 415-423. doi:10.1007/s00268-011-1328-8.

Polit D.F. \& Beck C.T. (2013) Essentials of Nursing Research. Appraising Evidence for Nursing Practice, 8th edn. Lippincott Williams \& Wilkins, Philadelphia, PA.

Ramos M.I., Cardoso M.J., Vaz F., Torres M.D., Garcia F., Blanco G. \& González E.M. (2008) Influence on the grade of anxiety and level of cortisol on post-surgical recovery. Actas Espanolas de Psiquiatria 36(3), 133-137.

Ren L., Zhu D., Wei Y., Pan X., Liang L., Xu J., Zhong Y., Xue Z., Jin L., Zhan S., Niu W., Qin X., Wu Z. \& Wu Z. (2012) Enhance Recovery After Surgery (ERAS) program attenuates stress and accelerates recovery in patients after radical resection for colorectal cancer: a prospective randomized controlled trial. World Journal of Surgery 36(2), 407-414. doi:10.1007/s00268012-1613-1.

Scarpa M., Di Cristofaro L., Cortinovis M., Pinto E., Massa M., Alfieri R., Cagol M., Saadeh L., Costa A., Castoro C., Bassi N. \& Ruffolo C. (2013) Minimally invasive surgery for colorectal cancer: quality of life and satisfaction with care in elderly patients. Surgical Endoscopy 27(8), 2911-2920. doi:10.1007/ s00464-013-2854-2.

Shahmansouri N., Janghorbani M., Omran A.S., Karimi A.A., Noorbala A.A., Arjmandi A. \& Nikfam S. (2014) Effects of a psychoeducation intervention on fear and anxiety about surgery: Randomized trial in patients undergoing coronary artery bypass 
grafting. Psychology, Health o Medicine 19(4), 375-383. doi:10.1080/13548506.2013.841966.

Spanjersberg W.R., Reurings J., Keus F. \& van Laarhoven C.J.H.M. (2011) Fast track surgery versus conventional recovery strategies for colorectal surgery. Cochrane Database of Systematic Reviews 2, CD007635. doi: 10.1002/ 14651858.CD007635.pub2.

Spielberger C.D. (1983) State-Trait Anxiety Inventory for Adults Mind Garden Inc, Manual, Instrument and Scoring Guide.

Spielberger C.D., Gorsuch R.L. \& Lushene R.E. (1970) STAI Manual for the State-trate Anxiety Inventory. Consulting Psychologist Press, Palo Alto, CA.

Tengland P.A. (2007) A two-dimensional theory of health. Theoretical Medicine and Bioethics 28, 257-284. doi:10.1007/ s11017-007-9043-z.

The EuroQol Group (1990) EuroQol- a new facility for the measurement of health-related quality of life. Health Policy 16 (3), 199-208. doi:10.1016/0168-8510(90)90421-9.
Tsunoda A., Nakao K., Hiratsuka K., Tsunoda Y. \& Kusano M. (2007) Prospective analysis of quality of life in the first year after colorectal cancer surgery. Acta Oncologica 46(1), 77-82. doi:10.1080/02841860600847053.

Varadhan K.K., Neal K.R., Dejong C.H., Fearon K.C., Ljungqvist O. \& Lobo D.N. (2010) The enhanced recovery after surgery (ERAS) pathway for patients undergoing major elective open colorectal surgery: a meta-analysis of randomized controlled trials. Clinical Nutrition 29(4), 434-440. doi:10.1016/ j.clnu.2010.01.004.

Wilson T.R., Alexander D.J., Kind P. \& Phil M. (2006) Measurement of health-related quality of life in the early followup of colon and rectal cancer. Diseases of the Colon and Rectum 49(11), 1692-1702. doi:10.1007/s10350-006-0709-9.

Yilmaz M., Sezer H., Gürler H. \& Bekar M. (2011) Predictors of preoperative anxiety in surgical patients. Journal of Clinical Nursing 21(7-8), 956-964. doi:10.1111/j.1365-2702. 2011.03799.x.

The Journal of Advanced Nursing (JAN) is an international, peer-reviewed, scientific journal. JAN contributes to the advancement of evidence-based nursing, midwifery and health care by disseminating high quality research and scholarship of contemporary relevance and with potential to advance knowledge for practice, education, management or policy. JAN publishes research reviews, original research reports and methodological and theoretical papers.

For further information, please visit JAN on the Wiley Online Library website: www.wileyonlinelibrary.com/journal/jan

$\underline{\text { Reasons to publish your work in JAN: }}$

- High-impact forum: the world's most cited nursing journal, with an Impact Factor of 1.527 - ranked 14/101 in the 2012 ISI Journal Citation Reports (C) (Nursing (Social Science)).

- Most read nursing journal in the world: over 3 million articles downloaded online per year and accessible in over 10,000 libraries worldwide (including over 3,500 in developing countries with free or low cost access).

- Fast and easy online submission: online submission at http://mc.manuscriptcentral.com/jan.

- Positive publishing experience: rapid double-blind peer review with constructive feedback.

- Rapid online publication in five weeks: average time from final manuscript arriving in production to online publication.

- Online Open: the option to pay to make your article freely and openly accessible to non-subscribers upon publication on Wiley Online Library, as well as the option to deposit the article in your own or your funding agency's preferred archive (e.g. PubMed). 



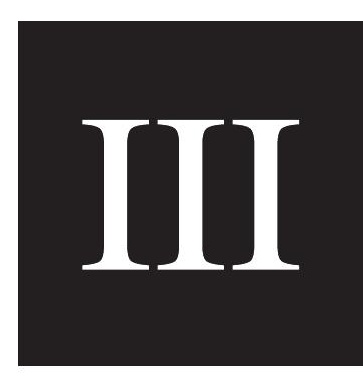





\section{The lived experience of recovery during the first six months after colorectal cancer}

surgery.

Authors: Jenny Jakobsson, RN, PhD student. Faculty of Health and Science, Department of Care Science, Malmö University and the Department of Surgery, Skåne University Hospital, Malmö, Sweden.

Ewa Idvall, PhD, RN, Professor. Faculty of Health and Science, Department of Care Science, Malmö University, Malmö, Sweden.

Christine Kumlien, PhD, RN, Professor. Faculty of Health and Science, Department of Care Science, Malmö University and the Department of Vascular Diseases, Skåne University hospital, Malmö, Sweden.

The authors would like to acknowledge the participants for sharing their experiences.

The authors declare no conflicts of interest

Correspondence: Jenny Jakobsson, RN, PhD-student, Malmö University, Faculty of Health and Society, S-205 06 Malmö, Sweden

E-mail: jenny.jakobsson@mah.se 


\begin{abstract}
Aims and objectives. The objective of this study was to describe the lived experience of recovery during the first six months after colorectal cancer surgery.
\end{abstract}

Background. Colorectal cancer is the third most common cancer diagnose worldwide. Early discharge poses demands on health care professionals to prepare patients for their return home and to provide appropriate support throughout the recovery process. This entails knowledge of what it is like to recover from colorectal cancer surgery.

Design. A qualitative phenomenological design was used to describe the structure of recovery after colorectal cancer surgery.

Methods. Ten patients recovering from colorectal cancer surgery were interviewed at one month and six months after surgery. The descriptive phenomenological method by Giorgi was used throughout the study.

Results. Postoperative recovery was described as a progressive process. This process was accompanied by experiences of physical powerlessness, difficulties with food intake, altered bowel function and dependence on others. The experiences were most intense at the beginning of the recovery but disappeared as time went by and normality in life returned.

Conclusion: While recovering from colorectal cancer surgery, patients experience obstacles that impede their ability to live life as normal. Six months after surgery, those experiences disappear or become adjusted to being part of normal life.

Relevance to clinical practice. Patients should be provided with information about expected postoperative recovery before discharge from hospital. The need for professional support appears to be most frequently needed in early recovery but should be considered on an individual basis. 


\section{What does this paper contribute to the wider global clinical community?}

- This paper highlight the postoperative recovery process during the first six months after colorectal cancer surgery. The findings are based on experiences described by patients.

- Knowledge of the postoperative recovery process after colorectal cancer surgery enables health care professionals to provide patients with information about the expected recovery process regarding the first six months after surgery.

- This paper provide knowledge that can guide practice when designing and justifying follow up routines.

Key words: colorectal cancer, surgery, postoperative recovery, lived experiences, nursing intervention, information, phenomenology, Giorgi. 


\section{INTRODUCTION}

To be diagnosed with cancer and subsequently go through and recover from surgery can be a major event in a person's life. The incidence of colorectal cancer is increasing worldwide, with 1.4 million new cases in 2012 alone, whereof $55 \%$ of the cases occurred in industrialized countries (Ferlay et al. 2014). In 2014, nearly 6500 men and women in Sweden were diagnosed with the disease (The National Board of Health and Welfare).

According to research, the initial diagnose can cause reactions of shock, fear, uncertainty and thoughts about survival and death (Worster \& Holmes 2008, Beech et al. 2012). For colorectal cancer, curative surgery is the first choice of treatment. Research relates that upon awakening after surgery, patients feel both relief and gratitude that the surgery is over, that they have survived and that the tumor has been removed (Worster \& Holmes 2009). Thereafter, the patients' focus changes from not only caring about overcoming surgery but also to being on the road to recovery (Norlyk \& Harder 2011).

Due to the high occurrence of colorectal cancer, health care professionals frequently meet patients undergoing or recovering from colorectal cancer surgery. Modern perioperative care, aiming to optimize recovery, commonly results in short hospital stays (Varadhan et al. 2010). Consequently, much of the postoperative recovery will take part outside of the hospital. This requires health care professionals to prepare the patients for their recovery period and also provide them with appropriate support during recovery. To do so, it is essential that health care professionals have knowledge of what it is like to recover from colorectal cancer surgery.

\section{BACKGROUND}

Taking place in hospital, early recovery has been characterized as coinciding with a variety of postoperative symptoms that cause vulnerability (Norlyk \& Harder 2011). For example, the presence of physical weakness and of tubes and drains, along with a fear of pulling out these 
drains or bursting the wound open have been experienced as aggravating mobilization (Worster \& Holmes 2009). Moreover, postoperative nausea and vomiting can make food intake troublesome (Norlyk \& Harder 2009).

During hospitalization, bodily reactions, especially bowel activity, call for great attention from the patients. Participants in the study by Worster and Holmes (2009) feared that the first bowel movement would be painful. Jonsson et al (2011) described how participants who had received a stoma experienced not only feelings of insecurity about how to manage the stoma but also feelings of disgust and a fear of stoma-related complications.

In recent decades, enhanced recovery after surgery (ERAS) has become a common strategy of perioperative care (Lassen et al. 2009). Through interventions such as preoperative patient information and education, early and intense mobilization together with early oral food intake, length of hospital stay has become shortened (Keane et al. 2012). Although being discharged from hospital has been described as a major milestone in recovery, it can also be associated with feelings of insecurity as the hospital represents a safe environment with professional surveillance (Worster \& Holmes 2009). Participants in a study by Taylor et al. (2010) stated that recovery and reconnection with the body could start in earnest after discharge from hospital. In the first few weeks following discharge, adequate food intake and the balance between activity and rest was considered the most essential matter; but as strength returned, the focus changed to the resumption of activities and daily routines. Wennström et al. (2010) reported that fatigue was the most prominent symptom one month after colonic resection, though there were also concerns about changes in bowel behavior. Participants in the study by Norlyk and Harder (2011) described how they paid great attention to bodily discomfort and unfamiliar sensations, which lead to feelings of insecurity. They contemplated, often together with family members, whether the symptoms were common after effects of surgery, and therefore ignorable, or whether they actually should be paid attention to. When recovery did 
not proceed as expected, participants in the study by Beech et al. (2012) doubted the validity of their concern due to their lack of experience or knowledge. A strategy of "wait and see" has been described in studies because participants hesitate to contact health care professionals as they believe their symptoms will eventually disappear or that they are not important enough to warrant contact (Beech et al. 2012, Krogsgaard et al. 2014). It has also been communicated that participants do not know what to expect when coming home from hospital, leading to anxiety and concerns (Beaver et al. 2010, Taylor et al. 2010).

Experiences of unfamiliar bodily reactions after surgery, along with the emotional impact of the cancer diagnose, can affect patients' ability to manage their lives. Lithner et al. (2015) inform that patients expressed a need for information about how to handle both the physical and emotional challenges after being discharged from hospital. Other research confirms that the pattern of recovery, as well as the time needed to reach the state of being fully recovered, depends on the individual (Jakobsson et al. 2014).

Only a few studies focus on recovery after colorectal cancer surgery from a long-term patient perspective. Further, available studies were designed to produce a theoretical understanding of postoperative recovery (Beech et al. 2012, Taylor et al. 2010), or they used interviews in addition to a quality of life questionnaire (Wennström et al. 2010). Undoubtedly, health care professionals have to acquire knowledge of the postoperative recovery process as a whole. Such knowledge enables the provision of appropriate information and support prior to discharge and during the patients' recovery period at home. However, this kind of knowledge should be based on core descriptions from patients to be clinically useful. Hence, the objective of this study was to describe the lived experience of recovery during the first six months after colorectal cancer surgery. 


\section{METHODS}

Since postoperative recovery was considered to be a subjective phenomenon, it is best described from the perspective of a person's lived experience. Therefore, the descriptive phenomenological method by Giorgi (Giorgi 2009) was used. By this method, the general structure of the phenomenon can be formulated based on the participants' descriptions.

According to the method, it is essential to assume the attitude of the phenomenological reduction throughout the whole research process, which means to set aside previous knowledge, premises and preconceptions to be able to describe the phenomena as it presents itself, without adding or subtracting anything (Giorgi 2009, 2012). The first author's (JJ) preconception was derived from clinical experiences as a registered nurse at a surgical clinic. At the time of data collection, the first author was not involved in the care of colorectal cancer patients. The encounter with the participants was performed only in the role as researcher. In order to assume the attitude of the phenomenological reduction, the researchers strived to bracket previous knowledge, experiences and preconceptions and maintain transparency with participants' descriptions without making own interpretations or explanations throughout the whole research process (Giorgi, 2012).

\section{Participants}

Participants were recruited at a surgical unit specializing in elective colorectal surgery at a university hospital in southern Sweden. A purposive sampling strategy was chosen. Patients were eligible for inclusion if they had the lived experience of recovering from colorectal cancer surgery, and were expected to be able to take part in an interview to describe their experience verbally (Giorgi 2009). Eligible patients were asked for participation by the first author during their hospital stay after surgery. Thirteen patients agreed to participate; however, three of them (one man and two women) withdrew from participation. The ten 
remaining participants (seven women and three men) varied in age, from 62 years to 80 years of age. All participants had recently been diagnosed with cancer in the colon or rectum and were undergoing open colorectal surgery as a part of the treatment. Participant characteristics are presented in Table 1.

\section{Data collection}

Data were collected from April 2012 to September 2013 through face-to-face interviews both one month and six months after surgery to capture the long-term perspective of postoperative recovery. One week prior to the interviews, participants were contacted by telephone to set the time and the place of the interview. During this conversation, the research question was repeated. According to Englander (2012), this gives the participants time to reflect on their experience, which can result in richer descriptions. As the phenomenon is the object of interest, the focus during interviews is a description of the phenomenon; therefore, the interviewer should ask for a description of the experience (Giorgi 2009, Englander 2012). The interviews began with the following question: Could you please describe how you have experienced your recovery after surgery from the time that you woke up from anesthesia until now? Following narratives from participants, additional questions such as what do you mean by... or could you tell me more about... were asked with the intention of obtaining clarification or a deeper description of the experiences (Kvale \& Brinkmann 2009).

For the one-month interview, two participants were interviewed at the hospital ward, because they were still hospitalized due to complications following surgery. Another two participants choose to be interviewed in a secluded room at the surgical outpatient clinic. The majority of the six-month interviews were conducted at the participants' residences, except for two that were conducted at the surgical outpatient clinic. All interviews were carried out by the first author (JJ), they lasted for 18-58 minutes and were digitally recorded and transcribed verbatim. 


\section{Ethical considerations}

Ethical approval was obtained from the Regional Ethics Board, Lund, Sweden (Dnr 2011/451). At the time for inclusion, all participants were given both oral and written information about the study and about their right to withdraw at any time. Written consent was collected before data collection. Throughout the study, confidentiality was respected.

\section{Data analysis}

Data were analyzed following the four steps described by Giorgi (2009) while maintaining the attitude of the phenomenological reduction. The four steps are as follows:

1. Read for sense of the whole.

2. Determination of meaning units.

3. Transformation of participant's natural attitude expressions into phenomenologically expressions.

4. Formulation of a general structure of the phenomena.

In the first step, all transcripts were read and re-read in order to get a holistic understanding. Next, transcripts were read again and the text was divided into meaning units. This was done by setting a mark in the text where one experienced a shift or a change in the meaning. This step is primarily practical as it allows one to create smaller text units that are easier to handle. In step three, keeping in mind the study's objective and the perspective of nursing science, each meaning unit was transformed into a description. During transformation, the technique of free imaginative variations was used, in which the description of the meaning is analytically tested by changing it until the most exact description of the meaning emerges. An example of the three first steps is visualized in Table 2. From these descriptions of all meaning units, constituents of the phenomena were identified. The constituents are interdependent parts that together constitute a general structure of the phenomena. If one 
constituent is removed, the structure will fall apart and the phenomena will dissolve or transform into something else. The general description of the structure of the phenomena is formulated in the last and fourth step, using free imaginative variations.

\section{FINDINGS}

In this study, participants described the structure of recovery after colorectal cancer surgery as a progressive process. During this process, participants experienced physical powerlessness, difficulties with food intake, altered bowel function and a dependence on others. These experiences were described as most intense at the beginning of the recovery process but fading away as time went by. Normality in life was thereby regained, even though adaption to persistent physical changes may have been required.

\section{Physical powerlessness}

In hospital after surgery, the participants were encouraged to move around as soon and much as possible. However, they experienced great physical powerlessness: taking even a few steps required a great deal of effort. Powerlessness was accompanied by sensations of dizziness and reduced body control, which initially induced a need for support from the nursing staff or physiotherapist in combination with different walking aids in order to dare to mobilize:

...I nearly fell, so I said, "I have to have something". Then they ran off to get one of those high walking frames, so I could get to the toilet. Then they walked with me... It was because I was afraid I would collapse. It kind of grows over you.,. the instability of the body. (ID05, 1 month after surgery)

In addition, having tubes or drains made it difficult, and sometimes painful, for participants to get out of bed. However, encouragement from ward staff and knowledge of the physical benefits of mobilization motivated them to resist the sense of powerlessness and get up, move around or sit in an armchair: 
I don't like pain you know. It's very difficult to deal with it. And they told me that I should get up and walk and all that, but it worked. I raised myself. And then I forced myself to get up. Every time I heard [name of physiotherapist] in the corridor, the physiotherapist, I thought oh, now I have to get up... Because I know that I have to get up and move around. I know that. I am not supposed to lie here. So, there was a little inducement to get up. (ID08, 1 month)

After discharge from hospital, the physical powerlessness continued to cause an urge to rest, which resulted in limitations both socially and in the daily living. The participants did not want to have guests as they felt they were being impolite when they needed to go to bed to rest. They also felt too weak to be able to perform any household activities or to go outside for a walk. For some participants, the powerlessness became frustrating and the inactivity sometimes boring because of their desire to have the strength to be more active:

Well, I actually was very tired. I didn't think it would feel like that, physically that is... You didn't have the strength to do anything and just felt like that everything was so hard... I think it took almost three months before you felt that you could do things without sitting every fifteen minutes. (ID07, 6 months)

Participants who had undergone abdominoperineal resection (APR) were instructed not to sit during the first weeks after surgery, thereby taking away the option of resting in a sitting position. This resulted in them resting lying down more than was actually required - a position that was considered less active than sitting.

Most participants experienced substantial powerlessness during the first month after surgery. However, at the one month interview they could now sense that they were regaining strength, a transformation they sometimes regarded as rapid. Physical powerlessness gradually decreased to be almost nonexistent six months after surgery. Nevertheless, the improvement was fragile and easily disturbed by health-reducing events such as complications, chemotherapy or even common health disorders like a cold or the season bound flu. All of these events could have participants feeling that their recovery was regressing. 


\section{Difficulties with food intake}

Participants were allowed to eat and drink immediately after surgery with the intention to manage by themselves without intravenous infusion. However, a loss of appetite was experienced, which, in combination with a rapid sensation of feeling full and changes in taste, made food intake difficult. Further, analgesics sometimes induced nausea. Encouraged by the ward staff and with own knowledge of the importance of food and drink intake, participants tried to compensate these difficulties by drinking as much as possible and choosing dietary supplements as beverages. Because it was more appealing, they also chose to eat ice cream, hard bread with marmalade or candy instead of hospital food:

It wasn't tasty. Not tasty at all. ... You just didn't feel hungry. ...It is like you have a lump here in the stomach saying 'stop'. And sometimes even a feeling of nausea. ...I drank, I did. And I got those dietary supplements, and I tried to eat a little of what I felt was eatable. ... I complemented with other things that perhaps weren't so nutritive. (ID 07, 1 month)

Difficulties with food intake lasted after discharge and sometimes more than one month after surgery. Even if their appetite did return, participants had the rapid sensation of feeling full for quite a while. The initial powerlessness could make food intake even more difficult for participants who had undergone APR because they had to eat standing for several weeks. Additionally, participants living alone had troubles shopping for groceries or standing long enough to be able to cook. Some participants had prepared and frozen meals before surgery and some had a daily goal to walk to the nearest store:

I mean, I haven't had much of an appetite. I still haven't much. It is rare that I eat a whole portion of food. I try to drink a lot, but my appetite hasn't, it has not yet returned. ...I eat because it is necessary. ... I don't want to skip any meal either, so I go out and sit down to eat. I start to eat and try to do as you should, chewing properly. But then it is like, no, I don't want any more; it doesn't appeal to me. I am not hungry. (ID02, 1 month) 
Weight loss after surgery was common, but it did not worry the participants because most of them wanted to lose weight. However, six months after surgery, participants felt that they were putting on undesired weight again.

\section{Altered bowel function}

One of the criteria for being discharged from hospital was the evacuation of feces, an event that participants often anticipated. Once home, they experienced concerns and insecurity about altered bowel function, which consequently affected their social contact. For example, because diarrhea induced a need to be close to a toilet, this limited their ability to leave home. Moreover, as the need for bowel emptying was most frequent before noon, participants had to plan activities based on their bowel movements:

When I need to, I can go six, seven times, but I don't feel it until the very last moment... And it is like, they want me to come and visit at work. Well, I don't dare because I don't dare to get on a bus. If it starts like that in the morning, then I have to stay home because I don't know when it settles so to speak. ... It is the only thing that, that worries me. (ID05, 1 month)

Diarrhea was sometimes replaced by constipation and the need to push. However, the participants were afraid to strain themselves because they were worried they might burst the intestinal anastomosis. Those with a stoma were quite insecure about having to deal with an unexpected appliance leakage in public. Over time, the bowel functions stabilized to normal, or close to normal, while the managing of the stoma became more familiar. Six months after surgery, both bowel emptying and the management of the stoma had become a part of the daily morning routine:

Now, I have got into the habit of going to the toilet before I shower, and at least twice. And it has become sort of a part of the morning routine, so you don't think about it so much. It goes on as normal here. (ID03, 6 months) 
This with the bag (stoma bag), and the like, when I was here (at hospital) and was about to change the bag, I thought “no, how will I manage this?" Now I can, I can do it in the dark, I believe. Now it works automatically. There is nothing strange about it, not at all. I feel that it works. (ID10, 6 months)

\section{Dependence on others}

During the postoperative recovery process, participants conveyed a dependence on others mainly due to their sense of physical powerlessness. Initially, there was a need for direct or indirect support from the ward staff to facilitate and motivate mobilization and food intake. When discharged, the participants needed support from family members or friends to manage practical matters concerning daily living. However, as physical power improved, their independence returned:

...My husband had to cook and everything like that, and it was like I was just up to eat... But thereafter, I felt like I started to help a little by doing the dishes, and suddenly one day I was peeling potatoes... Then yesterday I did the most by myself. (ID10, 1 month)

\section{DISCUSSION}

In this study, participants described recovery after colorectal cancer surgery as a progressive process, indicating that recovery takes time. Further, it was apparent that during the postoperative recovery they had a desire to leave the surgical experience behind and return to normal daily living. In the study by Allvin et al. (2008), the overall theme of postoperative recovery was 'A dynamic process in an endeavor to continue with everyday life' (Allvin et al. 2008 p.3). Everyday life was referred to as life as it was before surgery. However, everyday life after surgery and during the recovery process was not always comparable to life before surgery, making it difficult to set a point where a state of being recovered was achieved. The present study, using a phenomenological approach, describes postoperative recovery as a phenomenon constituted by a set of postoperative experiences. During recovery, those experiences emerged as obstacles to the notion of living a normal life compared to before 
surgery. As time elapsed, the experiences successively disappeared. Phenomenologically, this means that the phenomenon of postoperative recovery gradually resolves and, thereby, the patient becomes recovered. At the six months interview, it appears that most of the participants felt themselves to be recovered from surgery as they were living their lives much as they did before. Nevertheless, there was the possibility of having to overcome new obstacles due to the side effects of conditions such as undergoing chemotherapy. Such conditions, however, were correlated to the disease and not to the surgery itself.

The notion of feeling recovered and living a normal life is likely to be subjective and sometimes requires an adaption to physical changes such as having a stoma. In this study, stoma management was initially associated with insecurity, but eventually it became a habit and a part of normal life. Beaver et al. (2010) described how the participants in their study experienced daily life with a stoma, with it posing both practical problems and a potential loss of independence. Over time, the participants developed practical solutions to deal with life with a stoma. The majority of the participants in present study had retired from work before they were diagnosed with colorectal cancer. This can be considered as a factor facilitating the acceptance of persistent, physical changes since the retired participants had the possibility to adapt their morning routines according to their new situation.

The findings in this study describe mainly physical experiences. Participants were asked to describe how they experienced their recovery after surgery, which was the objective of the study. The phrasing of the question might have invited them to talk mostly about physical experiences but physical experiences are prominent during recovery as shown also in previous studies. Olsson et al. (2002) recounted how the participants in their study experienced that physical symptoms dominated their existence following surgery, though the symptoms were seen as a reminder of the disease and the disappearance of the symptoms was, consequently, experienced as a sign of recovery. It can also be that there are two dimensions 
of the experience of recovering from colorectal cancer surgery. On the one hand, the participants are dealing with having been diagnosed with cancer, which raise feelings of concern, uncertainty and thoughts about death (Moene et al. 2006, Shaha and Cox, 2003, Worster \& Holmes, 2008). On the other hand, the surgery itself is meant to be curative. In the study by Worster and Holmes (2009), participants described an urgent need right after surgery to be assured that the tumor had been removed. Another study by Shaha and Cox (2003) described how patients after the initial experiences of fear and anxiety adapted the cancer to be omnipresent in life, deciding to regain control over their life and return to a semblance of normality. To that knowledge, it can be that the participants perceive themselves as cured-if that be the case - once they are through with surgery. This enables them to leave their anxiety behind them and turn their focus to their healing body, as was described by participants in the study by Norlyk and Harder (2011).

This study identified the regression of the described postoperative experiences from being intense in early recovery to decreasing over time. As the participants were discharged home, they experienced a continued dependence on others as long as they were limited by physical powerlessness. Support was provided mainly from relatives or friends. In the study by Norlyk and Harder (2011), knowing that help from relatives was at hand was a factor that provided participants with the courage to leave hospital early after surgery. This implies a need to revise nurse-led follow-up routines to be more frequent when patients are at the initial stage of their recovery.

In this study, the experience of physical powerlessness was distinct. However, it also had a negative impact on the other experiences constituting recovery. In the study by Wennström et al. (2010), physical powerlessness, mentioned as fatigue, was the most dominant and troublesome symptom five weeks after colonic resection. During the first two weeks, the lack of functional ability disturbed the relationship with family and other social contacts for $40 \%$ 
of the participants. In the present study, participants recovering from abdominoperineal resection also described their struggle regarding balancing activity and rest, and the obstacles hindering social contacts due to the restrictions on sitting down. This has, to our knowledge, not been described earlier. In addition, this knowledge is valuable as it is an example that illustrates the need for individualized information prior to discharge.

In short, recovery after colorectal cancer surgery is complex; therefore, information and support is important not only before surgery but also as long as the patients require it. The result in this study bring knowledge of the postoperative recovery process which patients must be prepared for in order to avoid unnecessary anxiety and concern.

\section{Methodological considerations}

The descriptive phenomenological method by Giorgi (2009) was used in this study. In accordance with phenomenological philosophy, participants were chosen because of their experiences. According to Husserl (1983), a phenomenon- that refers to something given, whether it is an object, a condition or a feeling- is only understood by its presence to the consciousness of a person experiencing it. The consciousness of this person is the key to get access to a phenomenon and a tool for describing it (Englander 2007, Giorgi 2009). The number or gender of participants was therefore not a priority since transferability occurs with the general description of the structure of a phenomenon (Englander 2012).

The participants were interviewed twice to capture memories while they were vivid, which served to enhance dependability. Moreover, all data collection and analysis was carried out by the same researcher to minimize the risk of inconsistency. Giorgi (2009) suggested that two researchers most probably would produce different transformations of meaning units. However, it is anticipated that the structure of the phenomenon would still turn out to be the 
same. By the phenomenological reduction and the technique of free imaginative variations, raw data is constantly present throughout analysis, thus enhancing confirmability.

\section{CONCLUSIONS}

The findings in this study describe recovery after colorectal cancer surgery as a progressive, though sometimes not straightforward, process. During this process, it appears that the participants' lived experiences focus on physical experiences that negatively affect the possibility to live life as usual. In early recovery, the experiences are intense and pervasive; but as time goes by, they ease until they vanish or become a part of normal life. At that point, the phenomenon of postoperative recovery has resolved, since some or all of the constituents forming the phenomenon have disappeared. This means, phenomenologically speaking, that the patient has left the process of recovering.

\section{RELEVANCE TO CLINICAL PRACTICE}

During hospitalization, patients have constant access to information and support. Before discharge, nurses need to inform the patients about how they can expect their recovery to be when they are at home. Patients should receive individual information that they are going to experience discomfort that is considered normal after colorectal surgery and that this will diminish and eventually disappear within the first six months. Based on the findings in this study, discomfort such as physically powerlessness, difficulties in eating and concerns with bowel functioning should be emphasized. It should also be discussed that there probably would be a transient need for help solving practical matters, especially for those patients living alone. This question should preferably be discussed even before surgery, so that patients have time to prepare their home or arrange for help.

If, during hospitalization, a need for additional attention from health care professionals after discharge could be recognized, this information should be transmitted to the colorectal nurse 
specialist in the outpatient clinic. Based on that information, an individually formulated follow-up routine could be formulated.

\section{CONTRIBUTIONS}

JJ, EI, CWH designed the study. JJ performed data collection, analysis and preparation of manuscript. EI, CWH critically revised the manuscript. 


\section{REFERENCES}

Allvin R, Ehnfors M, Rawal N \& Idvall E (2008) Experiences of the postoperative recovery process: An interview study. The Open Nursing Journal 2, 1-7. Doi:

$10.2174 / 1874434600802010001$

Beaver K, Latif S, Williamson S, Procter D, Sheridan J, Heath J, Susnerwala S \& Luker K (2010) An exploratory study of the follow-up care needs of patients treated for colorectal cancer. Journal of Clinical Nursing 19, 3291-3300. Doi: 10.1111/j.1365-2702.2010.03407.x Beech N, Arber A, Faithfull S (2012) Restoring a sense of wellness following colorectal cancer: a grounded theory. Journal of Advanced Nursing 68(5), 1134-1144. Doi: $10.1111 /$ j.1365-2648.2011.05820.x

Englander M (2007) Persistent Psychological Meaning of Early Emotional Memories. Journal of Phenomenological Psychology 38, 181-216. Doi: 10.1163/156916207X234275

Englander M (2012) The interview: Data collection in Descriptive Phenomenological Human Scientific Research. Journal of Phenomenological Psychology 43, 13-35. Doi: $10.1163 / 156916212 X 632943$

Ferlay J, Soerjomataram I, Dikshit R, Eser S, Mathers C, Rebelo M, Parkin DM, Forman D \& Bray M (2014) Cancer incidence and mortality worldwide: Sources, methods and major patterns in GLOBOCAN 2012. International Journal of Cancer 136(5), E359-386. Doi: $10.1002 / \mathrm{ijc} .29210$

Giorgi A (2009) The Descriptive Phenomenological Method in Psychology: a modified Husserlian approach. Pittsburg, Pennsylvania: Duquenese University press. ISBN: 978-08207-0418-0 
Giorgi A (2012) The Descriptive Phenomenological Psychological Method. Journal of Phenomenological Psychology 43, 3-12. Doi: 10.1163/156916212X632934

Husserl E (1983) Ideas pertaining to a pure phenomenology and to a phenomenological philosophy. First book. (Transcription Kersten F.). The Hague: Martinus Nijhoff. (Original work published 1913). ISBN: 9789024728527

Jakobsson J, Idvall E, Wann-Hansson C (2014) Patient-reported recovery after enhanced colorectal cancer surgery: a longitudinal six-month follow-up study. International Journal of Colorectal Disease 29(8), 989-998. Doi: 10.1007/s00384-014-1939-2

Jonsson CA, Stenberg A, Frisman GH (2011) The lived experiences of the early postoperative period after colorectal cancer surgery. European Journal of Cancer Care 20, 248-256. Doi: 10.1111/j.1365-2354.2009.01168.x

Keane C, Savage S, McFarlane K, Seigne R, Robertson G, Eglinton T (2012) Enhanced recovery after surgery versus conventional care in colonic and rectal surgery. The ANZ Journal of Surgery 82, 697-703. Doi: 10.1111/j.1445-2197.2012.06139.x

Krogsgaard M, Dreyer P, Egerod I, Jarden M (2014) Post-discharge symptoms following fasttrack colonic cancer surgery: a phenomenological hermeneutic study. SpringerPlus 3: 276. Doi: $10.1186 / 2193-1801-3-276$

Kvale S, Brinkmann S (2009) Interviews. Learning the craft of qualitative research interviewing. Thousand Oaks, California: Sage Publications, Inc.

Lassen K, Soop M, Nygren J, Cox PB, Hendry PO, Spies C, von Meyenfeldt MF, Fearon KC, Revhaug A, Norderval S, Ljungqvist O, Lobo DN, Dejong CH, Enhanced Recovery After Surgery (ERAS) Group (2009) Consensus review of optimal perioperative care in colorectal 
surgery: Enhanced Recovery After Surgery (ERAS) Group recommendations. Archives of Surgery 144(10), 961-969. Doi: 10.1001/archsurg.2009.170

Lithner M, Klefsgard R, Johansson J, Andersson E (2015) The significance of information after discharge for colorectal cancer surgery- a qualitative study. BMC Nursing 14: 36.

Doi:10.1186/s12912-015-0086-6

Moene M, Bergbom I, Skott C (2006) Patient's existential situation prior to colorectal surgery. Journal of Advanced Nursing 54(2), 199-207.

Norlyk A, Harder I (2009) After colonic surgery: The lived experience of participating in a fast-track programme. International Journal of Qualitative Studies on Health and Well-being 4, 170-180. Doi: 10.1080/17482620903027726

Norlyk A, Harder I (2011) Recovering at home: participating in a fast-track colon cancer surgery programme. Nursing Inquiry 18(2), 165-173. Doi:10.1111/j.1440-1800.2011.00519.x Olsson U, Bergbom I, Bosaeus I (2002) Patient's experiences of the recovery period 3 months after gastrointestinal cancer surgery. European Journal of cancer care 11, 51-60.

Shaha M, Cox CL (2003) The omnipresence of cancer. European Journal of Oncology Nursing 7(3), 191-196. Doi: 10.1016/S1462-3889(03)00026-7

Taylor C, Richardson A, Cowley S (2010) Restoring embodied control following surgical treatment for colorectal cancer: A longitudinal qualitative study. International Journal of Nursing Studies 47, 946-956. Doi: 10.1016/j.ijnurstu.2009.12.008

The National Board of Health and Welfare.

http://www.socialstyrelsen.se/statistik/statistikdatabas/cancer. Retrieved in 170816

Varadhan KK, Neal KR, Dejong CHC, Fearon KCH, Ljungqvist O, Lobo DN (2010) The enhanced recovery after surgery (ERAS) pathway for patients undergoing major elective open 
colorectal surgery: A meta-analysis of randomized controlled trials. Clinical Nutrition 29, 434-440. Doi: 10.1016/j.clnu.2010.01.004

Wennström B, Warrén Stomberg M, Modin M, Skullman S (2010) Patient symptoms after colonic surgery in the era of enhanced recovery- a long-term follow-up. Journal of Clinical Nursing 19, 666-672. Doi:10.1111/j.1365-2702.2009.03099.x

Worster B, Holmes S (2008) The preoperative experience of patients undergoing surgery for colorectal cancer: A phenomenological study. European Journal of Oncology Nursing 12, 418-424. Doi: 10.1016/j.ejon.2008.05.007

Worster B, Holmes S (2009) A phenomenological study of the postoperative experiences of patients undergoing surgery for colorectal cancer. European Journal of Oncology Nursing 13, 315-322. Doi: 10.1016/j.ejon.2009.04.008 
Table 1. Characteristics of participants, $n=10$

\begin{tabular}{ll}
\hline Characteristics & \\
\hline Age, mean (SD) & $70,5(5,8)$ \\
Gender, n & 7 \\
Women & 3 \\
Men & \\
Civil status, $\mathbf{n}$ & 6 \\
Married & 1 \\
Living in relationship & 3 \\
Living alone & \\
Cancer site, $\mathbf{n}$ & 4 \\
Colon & 6 \\
Rectum & \\
Type of surgery, n & 3 \\
Abdominoperineal resection & 3 \\
Rectal resection & 4 \\
Colonic resection & 6 \\
Presence of stoma, $\mathbf{n}$ & \\
\hline
\end{tabular}

$\mathrm{n}=$ number, $\mathrm{SD}=$ standard deviation

Table 2. Example of step 1 to 3 following the descriptive phenomenological method by Giorgi (2009).

\begin{tabular}{|l|l|l|l|}
\hline Raw data & $\begin{array}{l}\text { Division into meaning } \\
\text { units }\end{array}$ & $\begin{array}{l}\text { Transformed meaning } \\
\text { units }\end{array}$ & $\begin{array}{l}\text { Constituent to } \\
\text { which the meaning } \\
\text { units contributed } \\
\text { to }\end{array}$ \\
\hline $\begin{array}{l}\text { And in the first } \\
\text { chews I felt the } \\
\text { taste. And it was } \\
\text { good. But then it } \\
\begin{array}{l}\text { was like it took } \\
\text { dead stop. And it } \\
\text { is still not as it } \\
\text { should be. }\end{array}\end{array}$ & $\begin{array}{l}\text { And in the first chews I } \\
\text { felt the taste. And it was } \\
\text { good. // But then it was } \\
\text { like it took dead stop. } \\
\text { And it is still not as it } \\
\text { should be. }\end{array}$ & $\begin{array}{l}\text { R experienced a } \\
\text { sensation of tasting } \\
\text { the food when taking } \\
\text { the first chews of the } \\
\text { food. R experienced } \\
\text { that the sensation of } \\
\text { the taste was good. } \\
\text { intake. }\end{array}$ \\
& & $\begin{array}{l}\text { While eating, R } \\
\text { experienced a sudden } \\
\text { bodily sensation of not } \\
\text { being able to eat more. } \\
\text { R is of the opinion } \\
\text { that the ability to eat } \\
\text { has not yet returned to } \\
\text { the way R believes } \\
\text { that it should be. }\end{array}$ & \\
\hline
\end{tabular}


IV 

Patient characteristics and surgery-related factors associated with patient-reported recovery at one and six months after colorectal cancer surgery

Authors: Jenny Jakobsson, RN, PhD student. Faculty of Health and Society, Department of Care Science, Malmö University and the Department of Surgery, Skåne University Hospital, Malmö, Sweden

Ewa Idvall, PhD, RN, Professor. Faculty of Health and Society, Department of Care Science, Malmö University, Malmö, Sweden

Christine Kumlien, PhD, RN, Professor. Faculty of Health and Society, Department of Care Science, Malmö University and the Department of Vascular Diseases, Skåne University hospital, Malmö, Sweden

Correspondence: Jenny Jakobsson, RN, PhD student, Malmö University, Faculty of Health and Society, S-205 06 Malmö, Sweden

Email: jenny.jakobsson@mah.se 


\begin{abstract}
Predictors for postoperative recovery after colorectal cancer surgery are usually investigated in relation to length of stay, readmission, or 30-day morbidity. This study describes patient characteristics and surgery-related factors associated with patient-reported recovery one and six months after surgery. In total, 153 consecutively included patients reported their level of recovery using the Postoperative Recovery Profile (PRP). Multiple logistic regression analysis was used to calculate associations with recovery, defined as good or poor, divided into five recovery dimensions: physical symptoms, physical functions, psychological, social, and activity, both at one and six months postoperatively. Better preoperative health predicted good recovery regarding three dimensions one month after surgery. Regarding all dimensions one month after surgery, poor recovery was predicted by a poor recovery on the day of discharge within corresponding dimensions. Higher age was associated with good recovery six months after surgery, while chemotherapy showed negative associations. Overall, a majority of factors had a negative impact on recovery, but without any obvious relation to one specific dimension or point in time. Those factors were high Body Mass Index, comorbidity, abdominoperineal resection, loop ileostomy, colostomy, and length of stay. This study illustrates the complexity of postoperative recovery and a need for individualised follow-up strategies.
\end{abstract}




\section{INTRODUCTION}

Cancer in the colon or rectum, known as colorectal cancer, is increasing worldwide. In 2012, the disease afflicted 1.4 million persons, 55\% of whom lived in industrialised countries (Ferlay et al. 2014). The first choice of treatment is surgery, which inevitably leads to a period of postoperative recovery. Previous studies have pointed out that recovery after colorectal cancer surgery varies depending on the tumour's location and the following surgical procedure (Caravati-Jouvenceaux et al. 2011; Knowles et al. 2013; Jakobsson et al. 2014). However, factors affecting postoperative recovery after colorectal cancer surgery need to be further described in order to identify patients with an increased need for support during their recovery trajectory.

Over the years, postoperative recovery has been investigated using various outcome measures. In a systematic review, Neville et al. (2014) reported that the most common outcome measures were biological or physiological as well as symptomatic or functional. A few studies reported postoperative outcomes in terms of general health perceptions or quality of life.

Length of stay (LoS) and the risk of morbidity within 30 days after colorectal surgery have been shown to be negatively affected by factors such as the patient's age being over 75 years (Hendry et al. 2009; Feroci et al. 2013), high comorbidity - as measured by the American Society of Anesthesiologists' (ASA) physical status classification system - (Hendry et al. 2009; Ahmed et al. 2010; Kahokehr et al. 2010; Feroci et al. 2014), male gender, and rectal surgery (Hendry et al. 2009). Additionally, the duration of surgery (Keller et al. 2013), the presence of an ileostomy (Smart et al. 2012; Feroci et al. 2013), and depression, have been shown to predict an increase in LoS (Balentine et al. 2011). Depression was reported to predict a six percent increase in LoS. Furthermore, preoperative neoadjuvant therapy, with either radiation therapy or chemotherapy, has been shown to predict a fourfold risk of readmission within 30 days after surgery (Francis et al. 2015).

In modern perioperative care, LoS, readmission rates, and 30-day morbidity have become important measures because of the need to justify sometimes expensive investments, for example, robotic surgery or enhanced recovery care settings which may require additional nursing staff (Jakobsen et al. 2006). Also, thanks to the knowledge gained from studies investigating factors predicting a prolonged LoS, readmission, or morbidity, it becomes possible to identify and prevent such adverse events. However, for a patient recovering from 
colorectal cancer surgery, recovery extends beyond discharge and 30 days after surgery. It has been suggested that patients' perceptions of outcomes do not always agree with those of the healthcare professionals (Avery et al. 2008). Consequently, objective outcomes, such as those previously presented, may not reflect postoperative recovery accurately. Therefore, it is important to also use patient-reported measures. Nevertheless, only a few studies take this approach and often with quality-of-life aspects as an outcome measure of surgery, although quality of life is not the same thing as postoperative recovery. Berg et al. (2012) explored the association between patient-reported postoperative recovery and health-related quality of life (HRQoL) in day-surgery patients undergoing various surgical interventions. It was discovered that postoperative recovery in addition to female gender was positively associated with HRQoL 30 days after surgery. Further, an ASA grade 2, which indicates mild systemic disease (ASA Physical Status Classification System), showed a negative association.

Efforts have also been made to investigate personality traits and the association of these with postoperative recovery. Trait anxiety refers to a personal tendency to perceive stressful situations, such as a cancer diagnosis, surgery, postoperative pain, or unfamiliar bodily reactions, as dangerous or threatening (Spielberg, 1983). Persons with high trait anxiety tend to respond to stressful situations with a more intense elevation of stress. It has been shown that stress has a negative impact on the wound healing process (Kiecolt-Glaser et al. 1995; Gouin et al. 2012) and induces increased levels of cortisol and adrenalin as well as postoperative pain (Munafò and Stevenson, 2001). It could be suggested that a higher trait anxiety also has a negative impact on recovery in general. Personality traits and their effect on patient-reported postoperative recovery were investigated by Nilsson et al. (2009), using the short Big Five scale in a day-surgery setting. Only minor significant correlations occurred, for example, the personality traits of extroversion and openness correlated with physical independence after surgery. In a study of patients undergoing open-heart surgery, Chunta (2009) showed that preoperative anxiety, expectations, and physical health status could explain the variation of postoperative physical health status.

After surgical interventions in connection with colorectal cancer, patients face a recovery period filled with unfamiliar bodily reactions, both physical and psychological (Taylor et al. 2010; Beech et al. 2011). Thus, knowledge of recovery, as experienced by the patients themselves and during an extended period of time, is scarce. In addition, few studies detail the factors associated with patient-reported postoperative recovery as an outcome. Therefore, the purpose of this study is to describe patient characteristics and surgery-related factors 
associated with patient-reported recovery at one and six months after colorectal cancer surgery.

\section{METHODS}

\section{Design}

This descriptive cohort study utilises data from a data collection in which patients undergoing colorectal cancer surgery were prospectively followed.

\section{Participants}

Patients were consecutively included at a university hospital in southern Sweden from October 2011 to February 2013. All patients considered for inclusion had a diagnosis of colorectal cancer and were planned for elective surgery on the colon or rectum. An additional criterion was the ability to understand and respond to questionnaires in Swedish. Approval for the study was obtained from the Regional Ethics Board, in Lund, Sweden (Reg.no. 2011/451).

\section{Data collection procedure}

All patients who met the inclusion criteria $(n=225)$ received written information about the study before their preoperative visit at the surgical outpatient clinic. At the visit, additional verbal information was provided by a colorectal nurse specialist, CNS. If the patients chose to participate, written informed consent was collected. Patients who chose to participate, $n=176$ $(80 \%)$, received the first questionnaire from the CNS containing the instruments EuroQol 5Dimension 3-levels (EQ-5D-3L) and the State-Trait Anxiety Inventory (STAI) in order to collect baseline values of preoperative general health and trait anxiety.

After surgery, postoperative recovery was measured using the Postoperative Recovery Profile (PRP) instrument (Allvin et al., 2009). Patients received the PRP from the ward staff on the day of discharge and were asked to complete and return it before leaving the hospital. One and six months after surgery, the PRP was distributed by mail along with a prepaid envelope for return. Contact details were retrieved from the patients' medical records. Nonresponders received reminders twice for the one- and six-month assessment.

\section{Measures}

Information about patient characteristics, namely, age, gender, household size, body mass index (BMI), and grade of ASA, was collected from the patients' medical records by the first author. In addition, measures of general health and trait anxiety were gathered through the use 
of questionnaires. Further, factors related to surgery, that is, preoperative neoadjuvant therapy, length of surgery, loss of blood during surgery, type of surgical intervention, presence of stoma, length of hospital stay, and postoperative adjuvant therapy, were collected from the medical records.

\section{General health}

As an indicator of the patients' preoperative general health, the EQ-5D-3L was used (The EuroQol group, 1990). The first part of this instrument includes five items concerning mobility, self-care, usual activities, pain/discomfort, and anxiety/depression. Answers are indicated on a three-level scale: (1) no problems, (2) some problems, or (3) extreme problems. The scores from the five items yield a five-digit number, a health status, from which an EQ index value can be derived (Brooks, 1996; Dolan, 1997). The index value is calculated using the time trade-off (TTO) valuation technique. The UK value set was used (Dolan, 1997) since no value set is available for the Swedish population.

In the second part of the instrument, patients rate their state of health on a visual analogue scale, the EQ VAS, ranging from 0 (worst imaginable health) to 10 (best imaginable health).

\section{Trait anxiety}

The STAI instrument measures state anxiety and trait anxiety (Spielberger, 1983) and consists of two separate forms concerning state and trait anxiety respectively. In the present study, the association between preoperative trait anxiety and postoperative recovery was to be described. Therefore, only the trait anxiety form was used. It includes 20 items formulated as statements indicating how patients generally feel. Responses are set on a four-point scale: (1) not at all, (2) somewhat, (3) moderately so, and (4) very much so. Each statement receives a weighted score of 1 to 4 , where 4 indicates a high level of anxiety for that statement. However, ten items are phrased so that a high score reflects the absence of anxiety. For those items, the weighted score is reversed. Weighted scores from the 20 STAI statements are added together to produce a raw score. Overall, raw scores of trait anxiety can vary from 20 (the absence of anxiety) to 80 (a high level of anxiety) (Spielberger, 1983).

\section{Postoperative recovery}

The Postoperative Recovery Profile, PRP, is a validated multi-item, multi-dimensional instrument used for self-assessment of postoperative recovery (Allvin et al. 2009). Nineteen items formulated as statements, such as 'Right now I feel a pain that is...', can be responded 
to on a four-point descriptive scale of none, mild, moderate, and severe. The items can be categorised into five dimensions: physical symptoms, physical functions, psychological, social, and activity (Table 1). The level of recovery for each dimension is defined by the most severe problem assessed among the items within the dimension. For example, the dimension physical symptoms consists of five items and if the responses for the items are none, mild, mild, moderate, and none, this means that the level of recovery in the dimension is defined as moderate (Allvin et al. 2012).

\section{Statistical analysis}

To describe patient characteristics and factors related to surgery, descriptive statistics were used to calculate frequencies, proportion, median, means, and standard deviations (SD) when appropriate.

\section{Predictive factors}

The selection of predictive factors was made from a clinical perspective. It was considered that it would be beneficial to describe factors that are easy for healthcare professionals to detect, before and during the hospital stay in connection with surgery. Factors related to patient characteristics were age (year), gender (male/female), household size (one-person household/ multi-person household), BMI, grade of ASA together with scores of EQ index, EQ VAS, and trait anxiety. Factors related to surgery were neoadjuvant therapy (none/radiation therapy), length of surgery (minutes), loss of blood during surgery (millilitres), type of surgical intervention (rectal resection/ colonic resection/ abdominoperineal resection, APR), presence of stoma (absence of stoma/ colostomy/ loop ileostomy), length of hospital stay (days), and postoperative adjuvant therapy (none/chemotherapy). In addition, it was assumed that the level of recovery in one assessment could predict the level of recovery in the following assessment. Therefore, the levels of recovery (none, mild, moderate, severe) for each PRP dimension on the day of discharge were included as potential predictors of recovery regarding the corresponding recovery dimension one month after surgery. In the same way, when predicting recovery six months after surgery, the levels of recovery from the assessments on the day of discharge, as well as one month after surgery, were used as predictor variables. 


\section{Outcome variables}

The five PRP dimensions (physical symptoms, physical functions, psychological, social, and activity) from the assessments one and six months after surgery were used one at a time as outcome variables in separate analyses. Because there are four levels of recovery within each PRP dimension (none, mild, moderate, severe), and the different levels were unequally represented, the level of recovery was dichotomised into good recovery (none/mild) or poor recovery (moderate/severe).

\section{Regression}

A multiple logistic regression analysis using the backward stepwise (Likelihood Ratio) method was performed to investigate the association between potential predictor variables and recovery regarding all five dimensions, both at one and six months after surgery (Field, 2013). Initially, all potential predictor variables were entered in the models. The variables were then excluded stepwise until all remaining variables had a $p$-value $\leq 0.2$.

All calculations were made using the Statistical Package for the Social Sciences (SPSS version 21; IBM, New York, NY, USA). The level of significance was set at $\mathrm{p}<0.05$ for all calculations.

\section{RESULT}

Of the 176 patients who agreed to participate in the present study, $23(13.1 \%)$ patients, with a mean age of 71.9 (SD 10.9), were lost for analysis (Figure 1). Of those, 17 did not return the questionnaires. Further, four patients were hospitalised for more than one month, one died, and one was moved to a palliative unit. Baseline characteristics for the patients who dropped out of the study, that is, characteristics regarding age, gender, and type of surgical intervention, are presented in Table 2.

As a result, data from 153 patients was available for analysis. Of those, 78 (51.0\%) were men and $75(49.0 \%)$ were women with a mean age of 69 years (SD 10.8). The mean BMI was 25.9 (SD 4.22) and the majority of the patients $(\mathrm{n}=78,51,0 \%)$ were graded as ASA 2. Most of the patients underwent a colonic resection $(n=62,40.5 \%)$ or a rectal resection $(n=60,39.2 \%)$. Further characteristics are presented in Table 2. 


\section{Associations with recovery}

Associations with recovery both one (Table 3) and six (Table 4) months after surgery are presented below and divided into each of the five recovery dimensions from the PRP instrument. The odds for a good recovery are represented by an odds ratio (OR) above 1 . In contrast, an OR below 1 represents low odds for a good recovery, that is, a poor recovery.

\section{Dimension physical symptoms}

A better preoperative health, as measured by EQ VAS (OR 1.282), was associated with higher odds for a good recovery regarding the dimension physical symptoms one month after surgery. Patients who were recovering from an APR (OR 0.103) had lower odds for a good recovery in this dimension one month after surgery than patients who recovered from rectal or colonic resection. In addition, a prolonged LoS (OR 0.829), as well as a poorer level of recovery regarding physical symptoms on the day of discharge (OR 0.186), predicted low odds for a good recovery.

Six months after surgery, it could be seen that patients with a poorer level of recovery in the dimension physical symptoms (OR 0.122) at the assessment one month after surgery, had low odds for a good recovery within the dimension also six months after surgery. Furthermore, patients who received postoperative treatment (OR 0.152) and had a higher preoperative grade of ASA (OR 0.406) as well as patients who did not receive a stoma (OR 0.243), had low odds for a good recovery. However, an increase in age was a factor with a positive impact (OR 1.099 ) on the recovery in the dimension physical symptoms six months after surgery.

\section{Dimension physical functions}

A longer duration of surgery (OR 0.995) lowered the odds for a good recovery regarding the dimension physical functions one month after surgery. Also, patients who showed a poorer level of recovery within the dimension (OR 0.433) on the day of discharge had low odds for a good recovery.

Six months after surgery, a higher age (OR 1.121) predicted a good recovery in the dimension physical functions. In contrast, a prolonged LoS (OR 0.763) and postoperative treatment (OR $0.195)$ lowered the odds for a good recovery. Patients with a poorer level of recovery within this dimension, both on the day of discharge (OR 0.223) and one month after surgery (OR 0.321 ), showed lower odds for a good recovery six months after surgery. 


\section{Dimension psychological}

Patients with a better preoperative health as measured by EQ VAS (OR 1.398), or a higher preoperative BMI (OR 1.144), had higher odds for a good recovery in the dimension psychological one month after surgery. Patients who underwent an APR procedure (OR 0.186) or had a prolonged LoS (OR 0.868) had low odds for a good recovery. A poorer level of recovery within the dimension psychological on the day of discharge was associated with low odds for a good recovery in the dimension both one month (OR 0.272) and six months (OR 0.078) after surgery.

Six months after surgery, the recovery in the dimension psychological was shown to be negatively affected by a prolonged length of stay (OR 0.791) and by postoperative treatment (OR 0.175 ), as well as by the presence of a colostomy (OR 0.123 ).

\section{Dimension social}

The dimension social on the day of discharge was negatively associated with recovery in the corresponding dimension one month after surgery (OR 0.150). Additionally, patients with a higher grade of ASA (OR 0.416), and those who underwent an APR procedure (OR 0.196), or received a loop ileostomy (OR 0.076) as a result of surgery, had lower odds for a good recovery.

Six months after surgery, recovery in the dimension social was negatively associated with the level of recovery in the corresponding dimension one month after surgery (OR 0.217).

\section{Dimension activity}

The odds for a good recovery in the dimension activity one month after surgery was positively associated with a higher preoperative health, as measured by EQ VAS (OR 1.286). Patients who, on the day of discharge, had a poorer level of recovery within this dimension (Or 0.390) had lower odds for a good recovery one month after surgery. The relation was the same for patients who received a colostomy (OR 0.158) or a loop ileostomy (OR 0.185).

Six months after surgery, good recovery within the activity dimension was associated with higher age (OR 1.063) and a better preoperative EQ VAS (OR 1.275). The odds for a good recovery at this point in time were low if the patient had a higher preoperative BMI (OR 0.857), a higher preoperative grade of ASA (OR 0.387), or a prolonged LoS (OR 0.857), or had received postoperative treatment (OR 0.231). 


\section{DISCUSSION}

Improvements in perioperative care have made it possible to provide surgery also for older patients (Pawa et al. 2012). Yet, being over 75 years has been described as a factor with a negative influence on LoS (Hendry et al. 2009; Feroci et al. 2013). In the present study, age was found to have a positive impact on the odds for a good recovery six months after surgery regarding the dimensions physical symptoms, physical functions, and activity. One explanation could be that older patients have had a slowly developing tumour at a site where it has been growing undetected for several years. Further, atypical or vague symptoms may increase the risk of not seeking advice due to a misinterpretation of symptoms (Oberoi et al. 2016). Older patients may also perceive the symptoms as being part of the normal ageing process (Withaker et al. 2015). As a result of the progression of an undetected tumour, the cancer can cause more general symptoms, such as anemia, weight loss, pain, or fatigue. Such symptoms lead to deteriorations in items within the dimensions physical symptoms, functions, and activity. After the removal of the tumour, it is possible that older patients in the present study perceived their recovery as better than those who were younger, as a result of the general symptom relief.

In this study, the presence of different types of stoma predicted low odds for a good recovery in various dimensions and assessments. In earlier research, Smart et al. (2012) reported that stoma formation yielded a 2.5 -fold risk of delayed discharge (defined as $\operatorname{LoS}>8$ days). Other studies have shown that patients with a stoma experienced impaired QoL (Sharma et al. 2007; Wilson et al. 2006). However, none of those studies specified the type of stoma. In the present study, it was shown that a loop ileostomy predicted low odds for a good recovery in both the social dimension and the activity dimension one month after surgery. In a study by Persson and Hellström (2002), patients experienced problems with the practical management of the stoma as well as a fear of leakage and odour, or worries that the stoma might be visible. Those problems probably impair both social contacts and the level of activity and can be applicable to the findings in this study regarding the negative impact of a loop ileostomy. In addition, besides the negative impact of a loop ileostomy shown in the present study, the presence of a colostomy predicted low odds for a good recovery in the dimension activity one month after surgery, as well as in the dimension psychological six months after surgery. The low odds for a good recovery in activity one month after surgery may be a result of the same circumstances as for the loop ileostomy, that is, fear of leakage, odours, and so on. If those worries remain, it may well be that patients begin to experience a reduction in QoL, as described in the study by 
Sharma et al. (2007). Thus, the low odds for a good recovery, in the dimension psychological six months after surgery in the present study, might be a reflection of a reduced QoL, caused by concerns related to the colostomy.

In the present study, APR procedures were shown to lower the odds for a good recovery in the dimensions physical symptoms, psychological, and social, one month after surgery. In a previous study by Jakobsson et al. (2014), patients after an APR procedure showed a significant deterioration in recovery one month after surgery regarding the PRP items fatigue, muscle weakness, and feeling down. The additional result from the present study emphasises that this group of patients are in a vulnerable position during at least the first month after surgery. Further, it is common that patients after an APR procedure suffer from painful, perineal wound healing problems. This might be seen in the present study, by the low odds for a good recovery in the physical symptoms dimension that includes the item pain. It can also be the case that the wound healing problems and the vulnerability are reflected by the low odds for a good recovery regarding the dimensions psychological and social.

Six months after surgery, chemotherapy was associated with low odds for a good recovery regarding four out of five dimensions - the dimensions physical symptoms, physical functions, psychological, and activity. It is well known that chemotherapy is a burdensome treatment. The result from the present study highlights the need to pay extra attention to patients receiving chemotherapy after surgery.

It is worth emphasising that recovery as an outcome was measured at one month and six months after surgery. Even if recovery at those points in time (especially one month after surgery) turned out to be poor for some patients, this does not automatically mean that those patients had recovered less well than expected. Instead, the reason could be that the patients had not yet recovered at a higher level due to the natural pattern of recovery after such colorectal surgical interventions. This is important information for patients, in order for them to have relevant expectations and avoid unnecessary concerns about a slow recovery.

\section{Limitations}

In this study, patient-reported postoperative recovery was used as an outcome measure. This approach was considered necessary when gathering knowledge with the potential to guide healthcare professionals in their encounter with patients undergoing and recovering from colorectal cancer surgery. 
Measuring postoperative recovery, both as a predictor variable and an outcome variable, a validated multi-item, multi-dimensional instrument, PRP (Allvin, 2009), was used. This allowed a versatile description of the recovery. As studies have shown that patients hesitate to get in contact with healthcare providers because they doubt the validity of their concerns (Beech et al. 2011), the selection of predictive factors was made from a clinical perspective. However, some of the factors (general health, trait anxiety, and postoperative recovery) were measured with multi-item instruments. In a clinical setting, multi-item instruments are not applicable as daily tools for measurements. Thus, an awareness of the risk of a poor recovery due to, for example, a poor general health or an APR procedure, can be helpful in the daily work of healthcare providers. Furthermore, the high number of selected, predictive factors could pose a risk of overfitting the final models, producing an unreliable result. To avoid this risk, a backwards selection was made, where variables were excluded stepwise until all variables fell below a p-value of 0.2 . It has been recommended in statistical literature (Altman, 1999) that the number of predictive variables in a model should not exceed $\mathrm{n} / 10$ variables. In this study, no model exceeded this number.

Despite the advantages of the PRP as a multi-item, multi-dimensional instrument, the procedure of defining the level of recovery for each dimension can be considered insensitive. The dimensional level of recovery equals the most severe problem among the items within the dimension, and this may lead to the risk that a patient is assigned a poorer level of recovery in a dimension than is actually true. In the analysis, this problem was somewhat compensated for by the dichotomisation of the outcome variable. Nevertheless, if a patient has one severe problem and no other problems, it could be questioned if the level of recovery is accurately reflected.

Even though the PRP instrument is validated (Allvin et al. 2009), it has only recently been developed, and therefore it has not yet been evaluated regarding its usability for different purposes. There is a need to further develop the instrument regarding the usability both in clinical settings, as an easy-to-use measure of postoperative recovery, and for scientific purposes.

\section{Conclusion and clinical implications}

In this study, the impact of patient characteristics and surgery-related factors on postoperative recovery was described. The study showed that recovery after colorectal cancer surgery can be predicted at a dimensional level by several factors. However, predictable factors are not 
clearly associated with one specific recovery dimension, which illustrates the complexity of postoperative recovery.

Factors regarding patient characteristics had an impact on recovery both one month and six months after surgery. A better preoperative health as well as a higher age were associated with a good postoperative recovery. In contrast, a higher preoperative BMI and a higher grade of preoperative ASA were associated with a poor postoperative recovery. Regarding factors related to surgery, an APR procedure, a prolonged LoS, the presence or absence of different types of stoma as well as postoperative chemotherapy, all had a negative impact on recovery. Those factors were associated with different recovery dimensions in different assessments. However, it was clear that patients who had a poor level of recovery at discharge were at risk of a poor recovery in the corresponding dimension also one month after surgery. This was the same for all five recovery dimensions. With regard to the associations between the recovery dimensions one month and six months after surgery, they were less consistent.

This means that patients who demonstrate a poor recovery in any dimension on the day of discharge are at risk of a continued poor recovery. Therefore, they may need a continuous and individualised follow-up after discharge.

The recommendation based on the results from this study are that extra attention should be paid to patients recovering from an APR procedure as well as patients who are undergoing chemotherapy treatment after surgery. Finally, it is of importance that patients receive information about the expected, natural pattern of recovery in order to avoid unnecessary feelings of concern.

To our knowledge, there are no studies, other than conducted in day-surgery settings, which describe predictors for postoperative recovery, as reported by patients as well as measured with an instrument developed for that purpose. This makes it difficult to validate the present findings by means of other studies. Therefore, the findings of this study should be regarded as a benchmark; further studies investigating other factors that have an impact on patientreported recovery after colorectal cancer surgery, for example, complications or factors related to the patients' life-style, are needed. 


\section{REFERENCES}

Ahmed, J., Lim, M., Khan, S., McNaught, C. \& MacFie, J. (2010) Predictors of length of stay in patients having elective colorectal surgery within an enhanced recovery protocol. International Journal of Surgery, 8, 628-632. doi: 10.1016/j.ijsu.2010.07.294

Allvin, R., Ehnfors, M., Rawal, N., Svensson, E. \& Idvall, E. (2009) Development of a questionnaire to measure patient-reported postoperative recovery: content validity and intrapatient reliability. Journal of Evaluation in Clinical Practice, 15, 411-419. doi: 10.1111/j.1365-2753.2008.01027.x

Allvin, R., Kling, AM., Idvall, E. \& Svensson, E. (2012) Patient Reported Outcome Measures (PROMs) after total hip- and knee replacement surgery evaluated by the Postoperative Recovery Profile questionnaire (PRP)- improving clinical quality and person-centeredness. The International Journal of Person Centered Medicine, 2(3), 368-376. doi: 10.5750/ijpcm.v2i3.250

Altman, D.G. (1999) Practical statistics for medical research. Chapman \& Hall, London. ASA Physical Status Classification System. Available at: http://www.asahq.org/resources/clinical-information/asa-physical-status-classification-system [last accessed 17.th May 2016]

Argyrous, G. (2011) Statistics for research. With a guide to SPSS. London: SAGE Publications Ltd.

Avery, K.N.L., Gujral, S. \& Blazeby, J.M. (2008) Patient-reported outcomes to evaluate surgery. Expert Review of Pharmacoeconomics \& Outcomes Research, 8(1), 43-50. doi: $10.1586 / 14737167.8 .1 .43$

Balentine, C.J., Hermosillo-Rodriguez, J., Robinson, C.N., Berger, D.H. \& Naik, A.D. (2011) Depression is associated with prolonged and complicated recovery following colorectal surgery. Journal of Gastrointestinal Surgery, 15, 1712-1717. doi: 10.1007/s11605-011-16405

Beech, N., Arber, A. \& Faithfull, S. (2012) Restoring a sense of wellness following colorectal cancer: a grounded theory. Journal of Advanced Nursing, 68(5), 1134-1144. doi:

$10.1111 / \mathrm{j} .1365-2648.2011 .05820 . \mathrm{x}$ 
Berg, K., Kjellgren, K., Unosson, M. \& Årestedt, K. (2012) Postoperative recovery and its association with health-related quality of life among day surgery patients. BMC Nursing, 11:24. doi: 10.1186/1472-6955-11-24

Birgisson, H., Pahlman, L., Gunnarsson, U. \& Glimelius, B., Swedish Rectal Cancer Trial Group (2005) Adverse effects of preoperative radiation therapy for rectal cancer: long-term follow-up of the Swedish Rectal Cancer Trial. Journal of Clinical Oncology, 34, 8697-8705. doi: 10.1200/JCO.2005.02.9017

Brooks, R. (1996) EuroQol: the current state of play. Health Policy, 37(1), 53-72. doi: $10.1016 / 0168-8510(96) 00822-6$

Caravati-Jouvenceaux, A., Launoy, G., Klein, D., Henry-Amar, M., Abeilard, E., Danzon, A., Pozet, A., Velten, M. \& Mercier, M. (2011) Health-related quality of life among long-term survivors of colorectal cancer: A population-based study. The Oncologist, 16, 1626-1636. doi: $10.1634 /$ theoncologist

Chunta, K.S. (2009) Expectations, anxiety, depression and physical health status as predictors of recovery in open-heart surgery patients. Journal of Cardiovascular Nursing, 24(6), 454464. doi: 10.1097/JCN.0b013e3181ac8a3c.

The EuroQol Group (1990). EuroQol - a new facility for the measurement of health-related quality of life. Health Policy, 16(3), 199-208. doi: 10.1016/0168-8510(90)90421-9

Dolan, P. (1997) Modeling valuations for EuroQol health states. Medical care, 35(11), 10951108 .

Ferlay, J., Soerjomataram, I., Dikshit, R., Eser, S., Mathers, C., Rebelo, M., Parkin, DM., Forman, D. \& Bray, M. (2014) Cancer incidence and mortality worldwide: Sources, methods and major patterns in GLOBOCAN 2012. International Journal of Cancer, 136(5), E359-386. doi: $10.1002 /$ ijc. 29210

Feroci, F., Lenzi, E., Baraghini, M., Garzi, A., Vannucchi, A., Cantafio, S. \& Scatizzi, M. (2013) Fast-track surgery in real life: how patient factors influence outcomes and compliance with an enhanced recovery clinical pathway after colorectal surgery. Surgical Laparoscopy, Endoscopy \& Percutaneous Techniques, 23(3), 259-265. doi:

10.1097/SLE.0b013e31828ba16f 
Field, A. (2013) Discovering statistics using IBM SPSS statistics. $4^{\text {th }}$ ed. London: SAGE Publications Ltd.

Francis, N.K., Mason, J., Salib, E., Allanby, L., Messenger, D., Allison, A.S., Smart, N.J. \& Ockrim, J.B. (2015) Factors predicting 30-day readmission after laparoscopic colorectal cancer surgery within an enhanced recovery programme. Colorectal Disease, 17, O148-O154. doi: $10.1111 /$ codi. 13002

Gouin, J-P. \& Kiekolt-Glaser, J.K. (2012) The impact of psychological stress on wound healing: Methods and Mechanisms. Critical Care Nursing Clinics of North America, 24(2), 201-2013. doi: 10.1016/j.ccell.2012.03.006

Hendry, P.O., Hausel, J., Nygren, J., Lassen, K., Dejong, C.H. \& Ljungqvist, O., Enhanced Recovery After Surgery Study Group. (2009) Determinants of outcome after colorectal resection within an enhanced recovery programme. British Journal of Surgery, 96, 197-205. doi: 10.1002/bjs.6445.

Ho, V.P., Lee, Y., Stein, S.L. \& Temple, L.K. (2011) Sexual function after treatment for rectal cancer: a review. Diseases of the Colon and rectum, 54(1), 113-125. doi:

10.1007/DCR.0b013e3181fb7b82

Jakobsen, D.H., Sonne, E. \& Kehlet, H. (2006) Nursing workload and fast-track colonic surgery. Journal of Advanced Perioperative Care, 2, 177-181

Jakobsson, J., Idvall, E. \& Wann-Hansson, C. (2014) Patient-reported recovery after enhanced colorectal cancer surgery: a longitudinal six-month follow-up study. International Journal of Colorectal Diseases, 29, 989-998. doi: 10.1007/s00384-014-1939-2

Kahokehr, A.A., Sammour, T., Sahakian, V., Zargar-Shoshtari, K. \& Hill, A.G. (2011) Influences on length of stay in an enhanced recovery programme after colonic surgery. Colorectal Disease, 13, 594-599. doi: 10.1111/j.1463-1318.2010.02228.x

Keller, D.S., Bankwitz, B., Woconish, D., Champagne, B.J., Reynolds Jr, H.L., Stein, S.L. \& Delaney, C.P. (2014) Predicting who will fail early discharge after laparoscopic colorectal surgery with an established enhanced recovery pathway. Surgical Endoscopy, 28, 74-79. doi: $10.1007 / \mathrm{s} 00464-013-3158-2$ 
Kiecolt-Glaser, J.K., Marucha, P.T., Malarkey, W.B., Mercado, A.M. \& Glaser, R. (1995)

Slowing of wound healing by psychological stress. The Lancet, 346, 1194-1196. doi:

10.1016/S0140-6736(95)92899-5

Knowles, G., Haigh, R., McLean, C., Phillips, H.A., Dunlop, M.G. \& Din, F.V.N (2013)

Long term effect of surgery and radiotherapy for colorectal cancer on defecatory function and quality of life. European Journal of Oncology Nursing, 17, 570-577. doi:

10.1016/j.ejon.2013.01.010

Komori, K., Kimura, K. \& Kinoshita, T. (2014) Complications associated with postoperative adjuvant radiation therapy for advanced rectal cancer. International Surgery, 2, 100-105. doi: 10.9738/INTSURG-D-13-00200.1

Konanz, J., Herrle, F., Weiss, C., Post, S. \& Kienle, P. (2013) Quality of life of patients after low anterior, intersphincteric, and abdominoperineal resection for rectal cancer-a matchedpair analysis. International Journal of Colorectal Diseases, 28, 679-688. doi: 10.1007/s00384-013-1683-z

Munafò, M.R. \& Stevenson, J. (2001) Anxiety and surgical recovery. Reinterpreting the literature. Journal of Psychosomatic Research, 51, 589-596. doi: 10.1016/S00223999(01)00258-6

Neville, A., Lee, L., Antonescu, I., Mayo, N.E., Vassiliou, M.C., Fried, G.M. \& Feldman, L.S. (2014) Systematic review of outcomes used to evaluate enhanced recovery after surgery. British Journal of Surgery, 101, 159-170. doi: 10.1002/bjs.9324

Nilsson, U., Berg, K., Unosson, M., Brudin, L. \& Idvall, E. (2009) Relation between personality and quality of postoperative recovery in day surgery patients. European Journal of Anaestesiology, 26, 671-675. doi: 10.1097/EJA.0b013e32832a9845

Oberoi, D.V., Jiwa, M., McManus, A., Hodder, R. \& De Nooijer, J. (2016) Help-seeking experiences of men diagnosed with colorectal cancer: a qualitative study. European Journal of cancer care, 25, 27-37. doi: 10.1111/ecc.12271

Pawa, N., Cathcart, P.L., Arulampalam, T.H.A., Tutton, M.G. \& Motson, R.W. (2012) Enhanced Recovery Program following Colorectal Resection in the Elderly Patient. World Journal of Surgery, 36, 415-423. doi: 10.1007/s00268 
Persson, E. \& Hellström, A.L. (2002) Experiences of Swedish men and women 6 to 12 weeks after ostomy surgery. Ostomy Care, 29(2), 103-108. doi: 10.1067/mjw.2002.122053

Smart, N.J., White, A.S., Allison, A.S., Ockrim, J.B., Kennedy, R.H. \& Francis, N.K. (2012) Deviation and failure of enhanced recovery after surgery following laparoscopic colorectal surgery: early prediction model. Colorectal Disease, 14, e727-734. doi: 10.1111/j.14631318.2012.03096.x

Spielberger, C.D., Gorsuch, R.L. \& Lushene, R.E. (1970) STAI manual for the state-trait anxiety inventory. Palo Alto: Consulting Psychologist Press.

Spielberger, C.D. (1983) State-Trait Anxiety Inventory for Adults. Manual, Instrument and Scoring Guide. Mind Garden, Inc.

Taylor, C., Richardson, A. \& Cowley, S. (2010) Restoring embodied control following surgical treatment for colorectal cancer: A longitudinal qualitative study. International Journal of Nursing Studies, 47, 946-956. doi: 10.1016/j.ijnurstu.2009.12.008

Whitaker, K.L., Macleod, U., Winstanley, K., Scott, S.E. \& Wardle, J. (2015) Help seeking for cancer 'alarm' symptoms: a qualitative interview study of primary care patients in the UK. British Journal of General Practice. E96-e105. doi: 10.3399/bjgp15X683533.

Wilson, T.R., Alexander, D.J., Kind, P. \& Phil, M. (2006) Measurement of health-related quality of life in the early follow-up of colon and rectal cancer. Diseases of the Colon and Rectum, 49, 1692-1702. doi: 10.1007/s10350-006-0709-9 
Figure 1. The flow of participants through the study

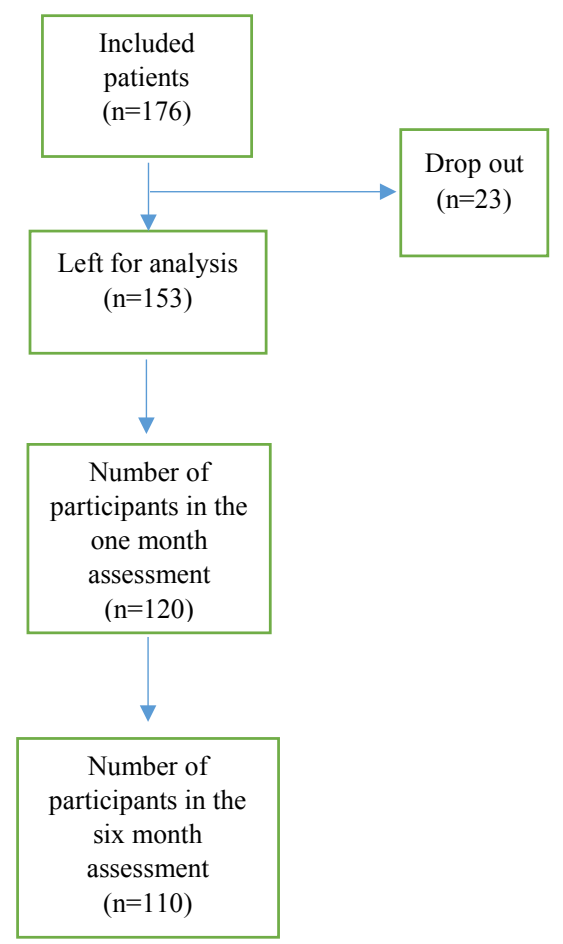


Table 1. Allocation of items for each PRP-dimension

\begin{tabular}{ll}
\hline Dimension & Item \\
\hline Physical symptoms & Pain \\
& Nausea \\
& Fatigue \\
Appetite change & Sleeping difficulties \\
& \\
Physical functions & Gastrointestinal function \\
& Bladder function \\
& Muscle weakness \\
& Sexual activity \\
Psychological & Mobilization \\
& Anxiety and worry \\
& Feeling down \\
& Feeling lonely/abandoned \\
& Difficulties in concentration \\
& Social activities \\
Activities & Dependence on others \\
& Interested in surroundings \\
& \\
& Re-establish everyday life \\
\end{tabular}

PRP, Postoperative Recovery Profile 
Table 2. Patient characteristics and factors related to surgery.

\begin{tabular}{|c|c|c|}
\hline Factors & $\begin{array}{l}\text { Patients who dropped } \\
\text { out from the study } \\
(n=23) *\end{array}$ & $\begin{array}{l}\text { Patients left for analysis } \\
(n=153)\end{array}$ \\
\hline \multicolumn{3}{|l|}{ Gender, n (\%) } \\
\hline Male & $17(73,9)$ & $78(51,0)$ \\
\hline Female & $6(26,1)$ & $75(49,0)$ \\
\hline Age, mean (SD) & $72(10,9)$ & $69(10,8)$ \\
\hline BMI, mean (SD) & - & $25,95(4,22)$ \\
\hline \multicolumn{3}{|l|}{ ASA, n (\%) } \\
\hline 1 & - & $38(24,8)$ \\
\hline 2 & - & $78(51,0)$ \\
\hline 3 & - & $35(22,9)$ \\
\hline Missing & - & $2(1,3)$ \\
\hline \multicolumn{3}{|l|}{ Household size } \\
\hline One-person household & - & $29(19,0)$ \\
\hline Multi-person household & - & $86(56,2)$ \\
\hline Missing & - & $38(24,8)$ \\
\hline EQ VAS, mean (SD) & - & $6,30(2,33)$ \\
\hline EQ index, mean (SD) & - & $0,76(0,24)$ \\
\hline Trait anxiety, mean (SD) & - & $34,63(10,04)$ \\
\hline \multicolumn{3}{|l|}{ Preoperative neoadjuvant therapy, $\mathrm{n}(\%)$} \\
\hline Yes [radiation therapy] & - & $35(22,9)$ \\
\hline No & - & $118(77,1)$ \\
\hline \multicolumn{3}{|l|}{ Type of surgery, n (\%) } \\
\hline Colonic resection & $10(43,5)$ & $62(40,5)$ \\
\hline Rectal resection & $8(34,8)$ & $60(39,2)$ \\
\hline APR & $5(21,7)$ & $31(20,3)$ \\
\hline Duration of surgery, minutes, mean (SD) & - & $277,11(120,34)$ \\
\hline Intraoperative bleeding, ml, mean (SD) & - & $489,44(430,33)$ \\
\hline \multicolumn{3}{|l|}{ Presence of stoma, $\mathrm{n}(\%)$} \\
\hline Absence of stoma & - & $57(37,3)$ \\
\hline Colostomy & - & $52(34,0)$ \\
\hline Loop-ileostomy & - & $38(24,8)$ \\
\hline Missing & - & $6(3,9)$ \\
\hline Length of stay, days, mean (SD) & - & $10,10(4,90)$ \\
\hline \multicolumn{3}{|l|}{ Postoperative treatment, $\mathrm{n}(\%)$} \\
\hline Yes [chemotherapy] & - & $51(33,3)$ \\
\hline No & - & $96(62,7)$ \\
\hline Missing & - & $6(3,9)$ \\
\hline
\end{tabular}

*Regarding patients who dropped out of the study, only information about age, gender and type of surgery was collected.

n, number; SD, standard deviation; BMI, Body Mass Index; ASA, American Society of Anesthesiologists physical status classification system; APR, abdominoperineal resection. 
Table 3. Final models showing patient characteristics and surgery related factors associated with recovery on a dimensional level of PRP one month after surgery.

\begin{tabular}{|c|c|c|c|c|}
\hline Dimension & Factor & OR & $95 \% \mathrm{CI}$ & P-value \\
\hline \multirow[t]{4}{*}{ Physical symptoms } & EQ VAS $\dagger$ & 1.282 & $1.013-1.623$ & $0.039 *$ \\
\hline & Length of stay & 0.829 & $0.737-0.933$ & $0.002 *$ \\
\hline & Abdominoperineal resection & 0.103 & $0.024-0.453$ & $0.003 *$ \\
\hline & Dimension physical symptoms ${ }^{1}$ & 0.186 & $0.080-0.436$ & $<0.001^{*}$ \\
\hline \multirow[t]{4}{*}{ Physical functions } & EQ VAS $\dagger$ & 1.208 & $0.968-1.508$ & 0.095 \\
\hline & Duration of surgery & 0.995 & $0.990-1.000$ & $0.031 *$ \\
\hline & Length of stay & 0.932 & $0.838-1.036$ & 0.189 \\
\hline & Dimension physical function ${ }^{1}$ & 0.433 & $0.223-0.843$ & $0.014^{*}$ \\
\hline \multirow[t]{6}{*}{ Psychological } & EQ VAS $\dagger$ & 1.398 & $1.045-1.872$ & $0.024 *$ \\
\hline & $\mathrm{BMI} \dagger$ & 1.144 & $1.005-1.303$ & $0.042 *$ \\
\hline & Length of stay & 0.868 & $0.761-0.990$ & $0.035^{*}$ \\
\hline & Abdominoperineal resection & 0.186 & $0.042-0.811$ & $0.025^{*}$ \\
\hline & Loopileostomy & 0.349 & $0.079-1.553$ & 0.167 \\
\hline & Dimension psychological ${ }^{1}$ & 0.272 & $0.128-0.578$ & $0.001 *$ \\
\hline \multirow[t]{4}{*}{ Social } & $\mathrm{ASA} \dagger$ & 0.416 & $0.173-0.999$ & $0.050 *$ \\
\hline & Abdominoperineal resection & 0.196 & $0.040-0.951$ & $0.043^{*}$ \\
\hline & Loopileostomy & 0.076 & $0.017-0.347$ & $0.001 *$ \\
\hline & Dimension social ${ }^{1}$ & 0.150 & $0.064-0.350$ & $<0.001^{*}$ \\
\hline \multirow[t]{5}{*}{ Activity } & EQ VAS $\dagger$ & 1.286 & $1.034-1.600$ & $0.024 *$ \\
\hline & Length of stay & 1.106 & $0.981-1.248$ & 0.099 \\
\hline & Colostomy & 0.158 & $0.043-0.573$ & $0.005^{*}$ \\
\hline & Loopileostomy & 0.185 & $0.048-0.716$ & $0.015^{*}$ \\
\hline & Dimension activity ${ }^{1}$ & 0.390 & $0.174-0.873$ & $0.022 *$ \\
\hline
\end{tabular}

OR, Odds ratio; CI, Confidence Interval; ASA, the American Society of Anesthesiologists physical status classification system; BMI, Body Mass Index; PRP, Postoperative Recovery Profile. Variables were included in the final models if $\mathrm{p} \leq 0.2$. Significance was set at $\mathrm{p} \leq 0.05$

${ }^{1}$ Day of discharge

*Significant association

$†$ Measured before surgery 
Table 4. Final models showing patient characteristics and surgery related factors associated with recovery on a dimensional level of PRP six months after surgery.

\begin{tabular}{|c|c|c|c|c|}
\hline Dimension & Factor & OR & $95 \% \mathrm{CI}$ & P-value \\
\hline \multirow[t]{6}{*}{ Physical symptoms } & Age† & 1.099 & $1.030-1.173$ & $0.004^{*}$ \\
\hline & $\mathrm{ASA} \dagger$ & 0.406 & $0.176-0.935$ & $0.034 *$ \\
\hline & Household size $\dagger$ & 0.272 & $0.065-1.132$ & 0.074 \\
\hline & Absence of stoma & 0.243 & $0.069-0.858$ & $0.028 *$ \\
\hline & Dimension physical symptoms ${ }^{2}$ & 0.122 & $0.047-0.320$ & $<0.001 *$ \\
\hline & Postoperative treatment ${ }^{3}$ & 0.152 & $0.044-0.527$ & $0.003 *$ \\
\hline \multirow[t]{8}{*}{ Physical functions } & Age† $\dagger$ & 1.121 & $1.036-1.214$ & $0.005^{*}$ \\
\hline & $\mathrm{ASA} \uparrow$ & 0.350 & $0.108-1.127$ & 0.079 \\
\hline & EQ index $\dagger$ & 0.006 & $0.000-0.570$ & $0.028 *$ \\
\hline & EQ VAS† & 1.492 & $0.965-2.308$ & 0.072 \\
\hline & Length of stay & 0.763 & $0.644-0.903$ & $0.002 *$ \\
\hline & Dimension physical functions ${ }^{1}$ & 0.223 & $0.084-0.589$ & $0.002 *$ \\
\hline & Dimension physical functions ${ }^{2}$ & 0.321 & $0.145-0.712$ & $0.005 *$ \\
\hline & Postoperative treatment ${ }^{3}$ & 0.195 & $0.044-0.861$ & $0.031 *$ \\
\hline \multirow[t]{6}{*}{ Psychological } & Trait anxiety $\dagger$ & 0.940 & $0.872-1.014$ & 0.108 \\
\hline & Gender $\dagger$ & 0.328 & $0.069-1.547$ & 0.159 \\
\hline & Length of stay & 0.791 & $0.664-0.942$ & $0.009 *$ \\
\hline & Colostomy & 0.123 & $0.020-0.776$ & $0.026^{*}$ \\
\hline & Dimension psychological $^{1}$ & 0.078 & $0.018-0.329$ & $0.001 *$ \\
\hline & Postoperative treatment ${ }^{3}$ & 0.175 & $0.034-0.895$ & $0.036^{*}$ \\
\hline \multirow[t]{4}{*}{ Social } & Household size $\dagger$ & 0.316 & $0.085-1.171$ & 0.085 \\
\hline & Absence of stoma & 0.288 & $0.076-1.086$ & 0.066 \\
\hline & Dimension social $^{2}$ & 0.217 & $0.092-0.511$ & $<0.001 *$ \\
\hline & Postoperative treatment ${ }^{3}$ & 0.438 & $0.139-1.376$ & 0.158 \\
\hline \multirow[t]{6}{*}{ Activity } & Age† & 1.063 & $1.005-1.125$ & $0.033 *$ \\
\hline & $\mathrm{BMI} \dagger$ & 0.857 & $0.749-0.981$ & $0.025^{*}$ \\
\hline & $\mathrm{ASA} \dagger$ & 0.387 & $0.156-0.962$ & $0.041^{*}$ \\
\hline & EQ VAS† & 1.275 & $1.027-1.584$ & $0.028 *$ \\
\hline & Length of stay & 0.857 & $0.758-0.968$ & $0.013^{*}$ \\
\hline & Postoperative treatment ${ }^{3}$ & 0.231 & $0.061-0.876$ & $0.031^{*}$ \\
\hline
\end{tabular}

OR, Odds Ratio; CI, Confidence Interval; ASA, the American Society of Anesthesiologists physical status classification system; BMI, Body Mass Index; PRP, Postoperative Recovery Profile. Variables were included in the final models if $\mathrm{p} \leq 0.2$. Significance was set at $\mathrm{p} \leq 0.05$

\footnotetext{
${ }^{1}$ Day of discharge

${ }^{2} 1$ month after surgery

${ }^{3}$ Chemotherapy

*Significant association

$\dagger$ Measured before surgery
} 


\section{Malmö University Health and Society Doctoral Dissertations}

Ross, M. W. Typing, doing and being. A study of men who have sex with men and sexuality on the Internet. 2006:1

Stoltz, P. Searching for meaning of support in nursing. A study on support in family care of frail aged persons with examples from palliative care at home. 2006:2

Gudmundsson, P. Detection of myocardial ischemia using real-time myocardial contrasts echocardiograpy. 2006:3

Holmberg, L. Communication in palliative home care, grief and bereavement. A mother's experiences. 2007:1

$\mathrm{Ny}, \mathrm{P}$. Swedish maternal health care in a multiethnic society - including the fathers. 2007:2

Schölin, T. Etnisk mångfald som organisationsidé. Chefs- och personalpraktiker i äldreomsorgen. 2008:1

Svensson, O. Interactions of mucins with biopolymers and drug delivery particles. 2008:2

Holst, M. Self-care behaviour and daily life experiences in patients with chronic heart failure. 2008:3

Bahtsevani, C. In search of evidence-based practices. Exploring factors influencing evidence-based practice and implementation of clinical practice guidelines. 2008:4

Andersson, L. Endocytosis by human dendritic cells. 2009:1

Svendsen, I. E. In vitro and in vivo studies of salivary films at solid/liquid interfaces. 2009:2

Persson, K. Oral health in an outpatient psychiatric population. Oral status, life satisfaction and support. 2009:3

Hellman, P. Human dendritic cells. A study of early events during pathogen recognition and antigen endocytosis. 2009:4

Baghir-Zada, R. Illegal aliens and health (care) wants. The cases of Sweden and the Netherlands. 2009:5

Stjernswärd, S. Designing online support for families living with depression. 2009:6 
Carlsson, A. Child injuries at home - prevention, precautions and intervention with focus on scalds. 2010:1

Carlson, E. Sjuksköterskan som handledare. Innehåll i och förutsättningar för sjuksköterskors handledande funktion i verksamhetsförlagd utbildning - en etnografisk studie. 2010:2

Sinkiewicz, G. Lactobacillus reuteri in health and disease. 2010:3

Tuvesson, H. Psychiatric nursing staff and the workplace. Perceptions of the ward atmosphere, psychosocial work environment, and stress. 2011:1

Ingvarsdotter, K. Mental ill health and diversity. Researching human suffering and resilience in a multicultural context. 2011:2

Hamit-Eminovski, J. Interactions of biopolymers and metal complexes at biological interfaces. 2011:3

Mellgren, C. What's neighbourhood got to do with it? The influence of neighbourhood context on crime and reactions to crime. 2011:4

Annersten Gershater, M. Prevention of foot ulcers in patients with diabetes mellitus. Nursing in outpatient settings. 2011:5

Pooremamali P. Culture, occupation and occupational therapy in a mental care context- the challenge of meeting the needs of Middle Eastern immigrants. 2012:1

Gustafsson A. Aspects on sepsis: treatment and markers. 2012:2

Lavant, E. Multiplex HLA-DR-DQ genotyping. For genetic epidemiology and clinical risk assessment. 2012:3

Wangel, A-M. Mental ill-health in childbearing women. Markers and risk factors. 2012:4

Scaramuzzino, R. Equal opportunities? - A cross-national comparison of immigrant organisations in Sweden and Italy. 2012:5

Ivert, A-K. Adolescent mental health and utilisation of psychiatric care

- The role of parental country of birth and neighbourhood of residence. 2013:1

Znamenskaya, Y. Effect of hydration on thermodynamic, rheological and structural properties of mucin. 2013:2 
Andersson, F. The female offender. Patterning of antisocial and criminal activity over the life-course. 2013:3

Lindroth, M. Utsatthet och sexuell hälsa - en studie om unga på statliga ungdomshem. 2013:4

Hulusjö, A. The multiplicities of prostitution experience - narratives about power and resistance. 2013:5

Falk, M. Direct electron transfer based biofuel cells. Operation in vitro and in vivo. 2014:1

Finnbogadóttir, H. Exposure to domestic violence during pregnancy. Impact on outcome, midwives' awareness, women's experience and prevalence in the south of Sweden. 2014:2

Fagerström, A. Effects of surfactant adjuvants on barrier properties of plant leaf cuticle. 2014:3

Lamberg, P. Design and characterization of direct electron transfer based biofuel cells including tests in cell cultures. 2014:4

Richert, T. Överdoser, försörjningsstrategier och riskhantering - livsvillkor för personer som injicerar narkotika. 2014:5

Örmon, K. Experiences of abuse during the life course. - Disclosure and the care provided among women in a general psychiatric context. 2014:6

Sjöblom, I. Planerade hemförlossningar i Norden - kvinnors och barnmorskors perspektiv. 2014:7

Albèr, C. Humectants and Skin - Effects of hydration from molecule to man. 2015:1

Kisch M., A. Allogeneic stem cell transplantation. - Patients' and sibling donors' perspectives. 2015:2

Weiber, I. Children in families where the mother has an intellectual or developmental disability - incidence, support and first person perspectives. 2015:3

Schlyter, M. Myocardial infarction, Personality factors, Coping strategies, Depression and Secondary prevention. 2016:1

Carlström, C. BDSM - Paradoxernas praktiker. 2016:2 
El-Schich, Z. Novel imaging technology and tools for biomarker detection in cancer. 2016:3

Boonsatean, W. Living with type 2 diabetes in Thai population: Experiences and socioeconomic characteristics. 2016:4

Vejzovic, V. Going through a colonoscopy and living with inflammatory bowel disease: Children's and parents' experiences and evaluation of the bowel cleansing quality prior to colonoscopy. 2016:5

Isma, G.E. Overweight and obesity in young children: Preventive work in child health care with focus on nurses' perceptions and parental risk factors. 2016:6

Brännvall, M. Frigörelse med förhinder - Om polisanmälan när kvinnor tar sig ur mäns våld i nära relationer. 2016:7

Pankratov, D. Self-charging biosupercapacitors. 2016:8

Guidi, P. Social work assessment of families with children at risk: Similarities and differences in Italian and Swedish public social services. 2016:9

Jakobsson, J. The process of recovery after colorectal cancer surgery: Patients' experiences and factors of influence. 2017:1

The publications are available on-line.

See www.mah.se/muep 

ISBN 978-9I-7IO4-756-4 (print)

ISBN 978-9I-7IO4-757-I (pdf)

ISSN I 653-5383

MALMÖ UNIVERSITY 20506 MALMÖ, SWEDEN WWW.MAH.SE 